Florida International University FIU Digital Commons

9-8-2011

\title{
Vacuum Brazing of Alumina Ceramic to Titanium Using Pure Gold as Filler Metal for Biomedical Implants
}

Mohammad S. Siddiqui

Florida International University, msidd005@fiu.edu

DOI: $10.25148 /$ etd.FI11120604

Follow this and additional works at: https://digitalcommons.fiu.edu/etd

\section{Recommended Citation}

Siddiqui, Mohammad S., "Vacuum Brazing of Alumina Ceramic to Titanium Using Pure Gold as Filler Metal for Biomedical Implants" (2011). FIU Electronic Theses and Dissertations. 497.

https://digitalcommons.fiu.edu/etd/497 


\section{FLORIDA INTERNATIONAL UNIVERSITY}

Miami, Florida

\section{VACUUM BRAZING OF ALUMINA CERAMIC TO TITANIUM FOR BIOMEDICAL IMPLANTS USING PURE GOLD AS THE FILLER METAL}

A dissertation submitted in the partial fulfillment of the requirement for the degree of DOCTOR OF PHILOSOPHY in

MATERIALS SCIENCE AND ENGINEERING

by

Mohammad S. Siddiqui

2011 
To: Dean Amir Mirmiran

College of Engineering and Computing

This dissertation, written by Mohammad Shadab Siddiqui, and entitled Vacuum Brazing of Alumina Ceramic to Titanium Using Pure Gold as Filler Metal for Biomedical Implants, having been approved in respect to style and intellectual content, is referred to you for judgment.

We have read this dissertation and recommend that it be approved.

Dr. Arvind Agarwal

Dr. Kuang-Hsi Wu

Dr. Norman D. H. Munroe

Anthony McGoron

Dr. W. Kinzy Jones, Major Professor

Date of Defense: September 8, 2011

The dissertation of Mohammad Shadab Siddiqui is approved.

Dean Amir Mirmiran

College of Engineering and Computing

Dean Lakshmi N. Reddi

University Graduate School

Florida International University, 2011 


\section{DEDICATION}

This dissertation is dedicated to my parents who have supported me through all the stages of my life. Their constant support and motivation is the source of strength to complete this dissertation. 


\section{ACKNOWLEDGMENTS}

I would like to extend my sincere gratitude to Dr. W. Kinzy Jones, my major advisor and the chair of my dissertation committee for his support, encouragement and guidance. His knowledge and perseverance has always been a motivation for working harder and towards achieving higher goals. I am thankful to him for his time and the effort which he dedicated, which helps a lot to complete this thesis and for the overall development of my career. I would like to thank him for giving me an opportunity to work on Boston Retinal Implant Project of which this thesis is a part.

I would like to thank my committee members Dr. Arvind Agarwal, Dr. Norman Munroe, Dr. Kuang Hsi Wu, and Dr. Anthony Mcgoron for serving on my dissertation committee. I would also like to thank Dr. Igor Tsukanov for his help in modeling and simulation. The valuable suggestions from my committee members and their help for different experiments were very critical in order to complete this work. Their constant support and motivation played a key role to provide a driving force for me to work harder.

I would like to thank Dr. Yanqing Liu, Jian Wang, Jenai Alexis, Richard Zicarelli, Andriy Duragen, Dr. Debrupa Lahiri, Neal Ricks, John Barchi, Ali Karbasi, Sadegh Behdad and other colleagues and friends in the MME department for their help and support time to time for experimental work. I would like to thank my friends Dr. Arshan Ahmad Khan, Dr. Shadab Anwar, Dr. Anup Keshari who were also Ph.D. students at FIU for their valuable discussions. 
I am thankful to Dr. Doug Shire the external collaborator of Boston retinal project and Bruce McKee who sputtered the requested thin films on alumina substrates for brazing as well as for scratch testing.

I would like to thank my family for their support and motivation throughout the course of this dissertation. Last but not the least I would like to thank the Almighty God. 
ABSTRACT OF THE DISSERTATION

VACUUM BRAZING OF ALUMINA CERAMIC TO TITANIUM FOR BIOMEDICAL IMPLANTS USING PURE GOLD AS THE FILLER METAL

\author{
by \\ Mohammad S. Siddiqui \\ Florida International University, 2011 \\ Miami, Florida \\ Professor W. Kinzy Jones, Major Professor
}

One of the many promising applications of metal/ceramic joining is in biomedical implantable devices. This work is focused on vacuum brazing of C.P titanium to $96 \%$ alumina ceramic using pure gold as the filler metal. A novel method of brazing is developed where resistance heating of C.P titanium is done inside a thermal evaporator using a Ta heating electrode. The design of electrode is optimized using Ansys resistive heating simulations. The materials chosen in this study are biocompatible and have prior history in implantable devices approved by FDA. This research is part of Boston Retinal implant project to make a biocompatible implantable device (www.bostonretina.org).

Pure gold braze has been used in the construction of single terminal feedthrough in low density hermetic packages utilizing a single platinum pin brazed to an alumina or sapphire ceramic donut ( brazed to a titanium case or ferrule for many years in implantable pacemakers. Pure gold (99.99\%) brazing of $96 \%$ alumina ceramic with CP titanium has been performed and evaluated in this dissertation. Brazing has been done by using electrical resistance heating. The $96 \%$ alumina ceramic disk was manufactured by high temperature cofired ceramic (HTCC) processing while the Ti ferrule and gold 
performs were purchased from outside. Hermetic joints having leak rate of the order of $1.6 \times 10^{-8} \mathrm{~atm}-\mathrm{cc} / \mathrm{sec}$ on a helium leak detector were measured.

Alumina ceramics made by HTCC processing were centreless grounded utilizing 800 grit diamond wheel to provide a smooth surface for sputtering of a thin film of $\mathrm{Nb}$. Since pure alumina demonstrates no adhesion or wetting to gold, an adhesion layer must be used on the alumina surface. Niobium $(\mathrm{Nb})$, Tantalum $(\mathrm{Ta})$ and Tungsten $(\mathrm{W})$ were chosen for evaluation since all are refractory (less dissolution into molten gold), all form stable oxides (necessary for adhesion to alumina) and all are readily thin film deposited as metals. Wetting studies are also performed to determine the wetting angle of pure gold to $\mathrm{Ti}, \mathrm{Ta}, \mathrm{Nb}$ and $\mathrm{W}$ substrates. Nano tribological scratch testing of thin film of $\mathrm{Nb}$ (which demonstrated the best wetting properties towards gold) on polished $96 \%$ alumina ceramic is performed to determine the adhesion strength of thin film to the substrate. The wetting studies also determined the thickness of the intermetallic compounds layers formed between $\mathrm{Ti}$ and gold, reaction microstructure and the dissolution of the metal into the molten gold. 


\section{TABLE OF CONTENTS}

CHAPTER

PAGE

1. INTRODUCTION 1

1.1 Challenges in vacuum brazing of C.P. Titanium to alumina ceramic

1.2 Focus of present research work

2

3

2. LITERATURE REVIEW 6

2.1 Metal/ceramic joining 6

2.1.1 Brazing

2.1.2 Adhesion, Wetting, Spreading, and Capillary Attraction

2.1.3 Challenges in Joining Ceramics

2.1.4 Other challenges in vacuum brazing of alumina Ceramic

2.2 Biocompatible, Hermetic Joining of Ceramics and Metals

2.2.1 Biocompatible active metal brazing

2.2.2 Noble Metal Brazing

2.3 Wetting and spreading of metals on different substrates

2.3.1 Contact Angle

2.3.2 Non reactive wetting

2.3.3 Reactive wetting

2.3.4 Au-Ti system

2.3.5 Au-Nb system

2.3.6 Au-W system

2.4 Nanoscratch testing

2.4.1 Constant load Nanoscratch testing

2.4.2 Ramping force Nanoscratch testing

2.5 Modulus mapping at the Au-Ti interface

2.6 Nanoindentation test

2.7 Four point flexural testing for mechanical properties of Alumina ASTM C 1161 Specification

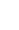

(6)

3. EXPERIMENTAL PROCEDURE AND RESULTS 30

3.1 Fabrication and flexural strength testing of $96 \%$ alumina $\begin{array}{ll}\text { high temperature cofired ceramic samples } & 30\end{array}$

3.1.1 Experiment Setup and fixtures used 33

$\begin{array}{lll}3.1 .2 & \text { Flexural Strength Values } & 35\end{array}$

3.2 Fabrication of Ceramic disk and its metallization by $\begin{array}{ll}\text { sputtering } & 35\end{array}$

$\begin{array}{ll}3.3 \text { Wetting Studies } & 38\end{array}$

$\begin{array}{lll}3.3 .1 & \text { Au-Ti system } & 40\end{array}$

$\begin{array}{ll}\text { 3.3.2 Au-Nb System } & 43\end{array}$

$\begin{array}{lll}3.3 .3 & \text { Au-W system } & 45\end{array}$ 
3.3.4 Au-Ta system

3.4 Scratch testing of sputtered thin $\mathrm{Nb}$ film over alumina substrate

3.5 Braze Development 50

3.6 EDX Analysis of the brazed samples for Au-Ti interface 56

3.7 Au-Nb sputtered alumina, interface 58

3.8 New Design of Ti ferrule for brazing 58

3.9 EDX analysis of the wetting studies samples for molten gold on Ti substrate at $1075 \pm 10^{\circ} \mathrm{C}$ for 287 seconds $\quad 59$

3.10 Modulus Mapping at the Au-Ti interface $\quad 62$

$\begin{array}{ll}3.11 \text { Quasistatic Nanoindentation } & 66\end{array}$

$\begin{array}{ll}3.12 \text { Leak Testing of Brazed Assembly } & 67\end{array}$

3.13 Mechanical Testing of brazed joint 68

$\begin{array}{ll}\text { 3.13.1 Analysis of Fractured Interface } & 70\end{array}$

3.13.2 Fracture Strength of brazed samples $\quad 72$

4. DISCUSSIONS AND CONCLUSIONS 73

5. SUGGESTIONS FOR FUTURE WORK 77

$\begin{array}{lll}5.1 & \text { Tensile testing of brazed sample } & 77\end{array}$

5.2 Three/four point flexural strength testing of the samples
with the vias at the center

5.3 Ti grain growth and determining the incubation period for the alpha to beta transformation

LIST OF REFERENCES

$\begin{array}{lr}\text { VITA } & 90\end{array}$ 


\section{LIST OF TABLES}

TABLE

PAGE

2.1: Conversion table for different units of vacuum

2.2: Coefficients of thermal expansion of materials of interest from room temperature to $100{ }^{\circ} \mathrm{C}$ (lowest value to highest value)

2.3: Comparison of hardness values from partial unloading experiments at indentation depths of $10 \%$ and $20 \%$ of the film thickness. Er corresponds to modulus value at $10 \%$ of the film thickness and $\mathrm{E}_{\mathrm{s}}$ corresponds to reduced modulus at $20 \%$ of film thickness

2.4: Fixture span as per ASTM C 1161

2.5: Sample size as per ASTM C 1161

2.6: Cross head speeds for different configurations

3.1: Composition of HTCC tape

3.2: Contact angle values of different sample for $\mathrm{Au}$ on $\mathrm{Ti}$

3.3 Contact angle values of different sample for $\mathrm{Au}$ on $\mathrm{Nb} \quad 44$

3.4: Wetting angle values of gold on tungsten metal at $1090 \pm 10^{\circ} \mathrm{C}$

3.5: Surface roughness measured by optical profilometery for samples 5A and 5D

3.6: Adhesion strengths for sample 5A

3.7: EDX analysis at the different points shown in figure 1 showing atomic percentages of $\mathrm{Au}$ and $\mathrm{Ti}$ at different point

3.8: Surface roughness measured by optical profilometery for samples 5A and 5D

3.9: Fracture Strength obtained for different samples 


\section{LIST OF FIGURES}

FIGURE

PAGE

1.1: Summary of work plan 1

1.2: Binary phase diagram of $\mathrm{Ti}$ and $\mathrm{Au} \quad 4$

2.1: Sessile drop configuration, top wetting and bottom non wetting condition 7

2.2: Film deposition by (a) PVD and (b) Sputtering 11

2.3: Wetting and dewetting 14

2.4: Sessile drop over a substrate 15

2.5: Molten drop of gold on alumina 15

2.6(a): Dissolutive wetting in Bi-Sn system without any formation of intermetallic compounds (IMCs)

2.6(b): Dissolutive wetting in Cu-Si system with the formation of Intermetallic compounds though not showing at this low magnification image

2.6(c): Dissolutive wetting in Au-Sn system with the formation of intermetallic compounds (IMCs) at the interface

2.7: Au-Nb binary phase

2.8: Au-W binary phase

2.9: Scratch made on Al surface using constant load testing mode by Berkovich tip

2.10: Scratch made on Al surface diagram using ramping load testing mode

2.11: Representative plot of Lateral force Vs time for a Nanoscratch test

2.12(a): Penetration depth versus load curve of nanoscratch test of Si/PEOX/ $\mathrm{SiCN} / \mathrm{SiOCH} / \mathrm{SiCN}$ film stack under a maximum applied load of $30 \mathrm{mN}$

2.12(b): SEM surface morphology along scratch track showing the beginning stage of Interface delamination.

2.13: Map of complex modulus. Dotted line corresponds to line-profile map

(b) which illustrates the difference in mechanical properties across the 
cross-section of the metal-oxide film and its substrate

2.14: Young's moduli E of Ti alloys, Error bar \pm SD 23

2.15: XRD analysis of the cast alloys 23

2.16: A typical curve showing loading and unloading during nano indentation 24

2.17: An AFM image of a Berkovich indentation on AlN thin films obtained at an indentation load of $50 \mathrm{mN}$. 26

2.18: The four point and thee point fixture configuration as per ASTM C $1161 \quad 28$

3.1: Thermo gravimetric analysis (TGA) curves for the tape FIAB-1 31

3.2: Firing cycle of green tape 31

3.3: Processing steps for the fabrication of samples 32

3.4: SEM micrograph of alumina sample showing alumina grains 33

3.5(a): Fixture used for cutting green laminated tape 34

3.5(b): Chamfered sample $\quad 34$

3.5(c): Fixture used for $\quad 34$

3.5(d): Setup used for chamfering the samples 34

3.5(e): Steel stub with the groove over which the samples were glued for chamfering 34

3.5(f): Endura tech machine used for mechanical testing of chamfered samples $\quad 34$

3.6: Flexural strength values of chamfered specimens tested as per ASTM C1161

3.7(a): Laser drilled ceramic disk after firing showing rough circumference 38

3.7(b): Centreless grounded disk 38

3.8: $\mathrm{Nb}$ Sputtered ceramic disk with kapton masking on one face 38

3.9: Two dimensional drawing of electrode used for wetting studies (All the dimensions are in inches) 
3.10: ANSYS simulation of electrode used for wetting studies

3.11: Graph showing the variation of contact angle with time at $1075 \pm 10^{\circ} \mathrm{C}$

3.12 (a): Ti-90 sec-1st sample (4C-1) 42

3.12(b): Magnified view of solidified drop center showing substrate dissolution

3.12(c): Magnified view of solidified drop end showing wetting angle

3.12(d): Sample Ti-90 secs. sample showing IMC formation

3.12(e): Sample Ti-300 secs. sample showing fracture at interface

3.12(f): Sample Ti-300 secs. sample showing void formation and fracture at the interface

3.13: Magnified view of the circle shown in figure 3.15 (b) showing a clearer image of void formation and fracture at interface at $2000 \mathrm{X}$

3.14: Graph showing variation of Ti substrate dissolution depth with time

3.15: Variation of wetting angle with time of gold on $\mathrm{Nb}$ at $1090 \pm 10{ }^{\circ} \mathrm{C}$

3.16(b): Drop end

3.17: Au-Nb interface for $\mathrm{Nb}-90$ secs. sample (3C-2) at $5000 \mathrm{X}$

3.18: Graph showing the variation of wetting angle of gold to Tungsten with time at a contact temperature of $1090 \pm 10^{\circ} \mathrm{C}$

3.19: Sample number W-90 seconds sample (1C2)

3.20: Au-Ta binary phase diagram

3.21: Sample number Ta-90 sec sample

3.22: Scratch test disk with $\mathrm{Nb}$ sputtering and some bare alumina regions 
3.24: Lateral force $(\mu \mathrm{N})$ vs. Lateral Displacement $(\mu \mathrm{m})$ plot for scratch 3

3.25: Thickness profile measured by SPM attached with the nanoindentor for sample $5 \mathrm{~A}$

3.26: JEOL model JEE-4X Thermal evaporator with the Ta electrode and parts to be brazed arranged before brazing

3.27(a): Top view of the Ti ferrule

3.27(b): $99.99 \%$ pure gold perform

3.27(c): Ta electrode used for brazing

3.28: (a)-Top view, (b)-Cross sectional view, (c)-bottom view of Ti ferrule shown in figure 3.27 (a)

3.29: Temperature measurement setup of the Ta electrode

3.30(a): Temperature vs. time plot

3.30(b): Voltage vs. time plot

3.30(c): Current vs. time plot

3.30(d): Power vs. time plot

3.31(a): Front side of the brazed assembly

3.31(b): Back side of the brazed assembly

3.32(a): Cross Sectioned brazed assembly

3.32(b): Au-Ti and Au-Nb sputtered alumina interfaces 55

3.33(a): BSC image showing Au-Ti interface at 5000X 56

3.33(b): FIB extracted sample of Au-Ti interface 56

3.34: (a) through (f) shows the Au-Ti interface at 50,000 magnification and 57 the points where the EDX data were collected 
3.36: Au-Nb sputtered alumina interface at $20000 \mathrm{X}$

3.37(a): Ti ferrule of new design, Bottom view

3.37(b): Ti ferrule of new design, side view

3.37 (c): Ti ferrule of new design, top view

3.37(d): Ti ferrule of new design top view

3.37(e): Ti ferrule of new design with the feedthrough disk

3.38: SEM image at 5000x where EDX point scan is performed 60

3.39: Line scan EDX analysis at the interface 61

3.40: Count rate variation along the length 61

3.41(a): Fractured gold drop $\quad 61$

3.41(b): Drop's Impression on Ti surface $\quad 61$

3.42: EDX at point 5 in figure $14 \quad 62$

3.43: Modulus Maps on Sample Ti-300 sec- $3^{\text {rd }}$ (4D3) on Gold away from the Interface

3.44: Modulus Maps on Sample Ti-300 sec-3rd (4D3) on Titanium away from the interface

3.45: Modulus Maps on Sample Ti-300 sec-3rd (4D3) at the Interface 65

3.46: Modulus Maps on Sample 4D3- Comparison 65

3.47(a): Varian 979 Helium leak detector $\quad 67$

3.47(b): Fixture mounted on the test port of Varian 979 Helium leak detector $\quad 67$

3.48: Raw materials used for making brazed joints $\quad 68$

3.49: Heated electrode showing the central hot zone 68

3.50: Brazed sample $\quad 68$

3.51: Lab View data for voltage Vs time 68 
3.53: Force Vs displacement data obtained from testing for one of the sample

3.54: Fracture Strength values obtained for different samples

3.56: Ti impression on the substrate and points of EDX data collection

3.57: Ti rod and the points of EDX data collection

3.58: Cross sectioned brazed sample

3.59: Au-Ti interface at $8000 \mathrm{X}$

5.1: Alumina tube with hole drilled for alumina thermocouple

5.2: Ta sheet wrapped around alumina tube

5.3: Micro furnace in operation and data collection

5.4: Brazed Sample

5.5(a): Voltage Vs. time curve

5.5(b): Current Vs. Time curve

5.5(c): Power Vs. time

5.5(d): Temperature Vs. time

5.6: Three point bend samples containing vias

5.7: Ansys simulation of Ti grain growth heating element

5.8: Temperature Vs. Time profile obtained the Ti heating element 


\section{LIST OF SYMBOLS}

\begin{tabular}{|c|c|}
\hline SYMBOL & : EXPANSION \\
\hline$\gamma_{\mathrm{sv}}$ & Surface tension at the solid-vapor interface \\
\hline$\gamma_{1 \mathrm{v}}$ & : Surface tension at the liquid-vapor interface \\
\hline$\gamma_{\mathrm{sl}}$ & : Surface tension at the solid-liquid interface \\
\hline $\mathrm{W}_{\mathrm{s}}$ & : Work of adhesion \\
\hline$\Delta \mathrm{G}_{\mathrm{R}}$ & : Free energy of reaction \\
\hline A & : Contact Area \\
\hline $\mathrm{P}_{\mathrm{c}}$ & : Critical load \\
\hline $\mathrm{d}_{\mathrm{c}}$ & : Scratch track with \\
\hline$\mu$ & : Measured friction coefficient of indenter sliding given by the \\
\hline & Nanoscratch tester \\
\hline$v_{\mathrm{f}}$ & : Poisson's ratio of $\mathrm{SiOCH} / \mathrm{SiCN}$ bilayer \\
\hline $\mathrm{E}_{\mathrm{f}}$ & :The average elastic modulus of the $\mathrm{SiOCH} / \mathrm{SiCN}$ bilayer \\
\hline $\mathrm{P}_{\max }$ & : Maximum load applied \\
\hline $\mathrm{A}_{\mathrm{c}}$ & : Area function, for Berkovich tip Ac is $=24.5 \mathrm{~h}_{\mathrm{c}}{ }^{2}$ \\
\hline $\mathrm{h}_{\mathrm{c}}$ & : Contact depth \\
\hline $\mathrm{h}_{\max }$ & : Maximum contact depth shown in Figure 1 \\
\hline $\mathrm{E}_{\mathrm{r}}$ & : Reduced modulus \\
\hline S & : Slope during unloading \\
\hline$v_{\mathrm{i}}$ & : Poisson's coefficient of the indenter \\
\hline$v$ & : Poisson's coefficient of the sample \\
\hline $\mathrm{E}_{\mathrm{i}}$ & : Young's modulus of indenter \\
\hline
\end{tabular}




$\begin{array}{ll}\mathrm{E} & : \text { Young's modulus of sample } \\ \mathrm{K}_{\mathrm{c}} & : \text { Fracture toughness } \\ \alpha & : \text { Empirical constant for a specific indenter } \\ \mathrm{H} & : \text { Hardness } \\ \mathrm{c} & : \text { Crack length } \\ \mathrm{P} & : \text { Applied load } \\ \mathrm{S} & : \text { Flexural Strength } \\ \mathrm{F} & : \text { Break force } \\ \mathrm{L} & : \text { Outer (support) span } \\ \mathrm{B} & : \text { Specimen width } \\ \varepsilon & : \text { Strain rate } \\ \text { d } & : \text { Specimen thickness } \\ \text { S } & : \text { Crosshead speed }\end{array}$

Nomenclature Used for samples in wetting studies X Y Z

$\mathrm{X} \quad$ : The sample metallization (1- W; 2- Ta; 3- Nb; 4-Ti)

Y : Time at braze temperature (A- 1 sec; B- 30 sec; C- 90 sec; D$300 \mathrm{sec})$

Z : Sample number for test X, Y

Example: 4D2 is a sample where $\mathrm{Ti}$ is the substrate and gold was kept molten over it for 30 seconds and this is the second sample of this type. 4D2 is also written as Ti-300sec- $2^{\text {nd }}$ sample. 


\section{INTRODUCTION}

The aim of the present work is to evaluate the process parameters of vacuum brazing alumina ceramic to titanium using pure gold as braze filler metal by characterizing the materials interactions. The present work can be divided into the following subtopics.

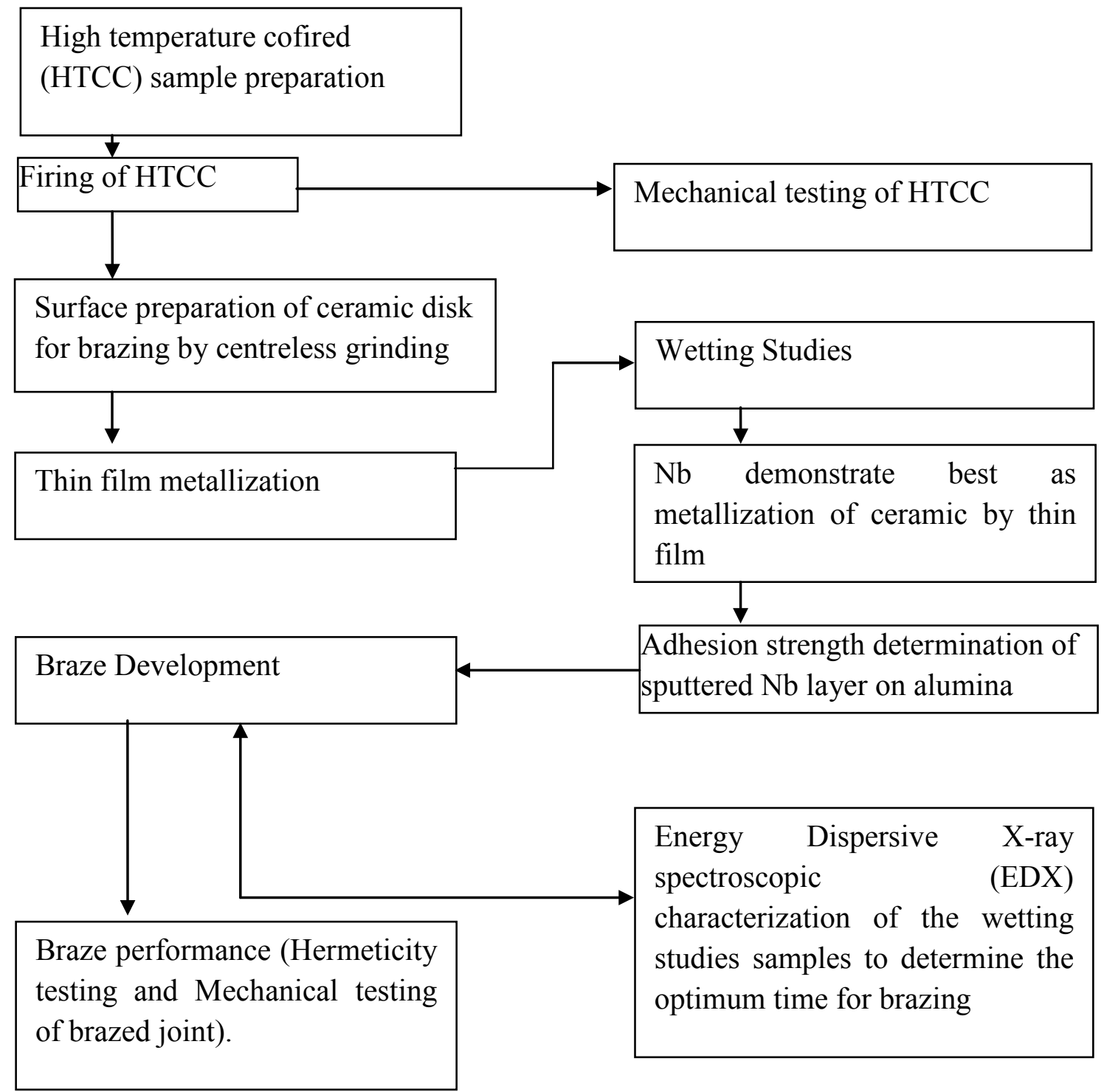

Figure 1.1: Summary of the work plan 


\subsection{CHALLENGES IN VACUUM BRAZING OF C.P. TITANIUM TO}

ALUMINA CERAMIC

Joining of ceramics is more difficult than joining metal to a metal as ceramics are not wetted by the filler metals used for brazing. This non wetting tendency of ceramics requires surface modification to improve the wetting of the ceramic to the braze filler metal. This work is focused on joining alumina $\left(\mathrm{Al}_{2} \mathrm{O}_{3}\right)$ ceramic to Ti metal using pure gold as the filler metal. Use of pure gold is desired as it releases thermal stresses (by plastically deforming the pure gold braze) when the joint assembly is cooled down from the brazing temperature to room temperature as it is biocompatible. The disadvantages associated with using pure gold are, the high melting point of gold which is above the allotropic transformation of $\mathrm{Ti}$ and that titanium and gold react and forms a series of intermetallic compounds (IMCs) some which are brittle and could be detrimental to the performance of the joint assembly. The formation of these intermetallic compounds can be avoided or minimized by understanding the reaction and growth kinetics of the intermetallic with temperature and time which will then improve the joint strength. This has been achieved by heating the parts to be brazed resistively. Rapid electrical pulses are used to heat the part rather than using slow heating in a furnace providing sufficient time for the intermetallic compounds (IMCs) to form and grow. Ta electrodes are used as heating elements, a thermal evaporator (JEOL JEE-4X) is used for the vacuum environment and a high current digital power supply is used for the current source in the resistive heating process to braze the parts.

The challenges that have to be overcome during brazing of ceramics to metals are (i) poor wetting tendency of ceramic by liquid braze alloy (ii) coefficient of thermal expansion 
mismatch between ceramic and metal leading to stress build up at the interface and (iii) interactions between the braze and the metals. These three factors are discussed in details in sections 2 and 3 of this dissertation.

\subsection{FOCUS OF PRESENT WORK}

Present research has been done in collaboration with Boston Retinal Project, a collaborative effort between Harvard Medical School, the Massachusetts Ear and Eye Institute, MIT and Cornell, with primary funding from the Veterans Administration (VA). This project is an effort made to develop an implantable retina device to restore sight FIU's role is to develop a high density feedthrough which is manufactured from technology with a proven history in implantable electrical stimulators The Boston Retinal Project had a 18 I/O feedthrough and FIU's Electronic Packaging Laboratory demonstrated the capability to fabricate a $331 \mathrm{I} / \mathrm{O}$ device, greatly increasing visual accuaty. A ceramic disk with $331 \mathrm{I} / \mathrm{Os}$ is brazed to a titanium ferrule using pure gold as filler metal. Brazing of Ti has to be performed in high vacuum Ti being very reactive metal to air, nitrogen or hydrogen. In the present work brazing is performed in vacuum of the order of $5 \times 10^{-4}$ Pascal inside a thermal evaporator. The alumina ceramic is metallized in the region where the braze joint is to be made of prior to brazing by sputtering a thin film of a refractory metal that wets well to gold (initial work used 500 $\mathrm{nm}$ thickness of $\mathrm{Nb}$ metal). Pure gold metal preforms of $99.99 \%$ purity are used a braze filler metal. Hermetic joints having leak rate of the order of $1.6 \times 10^{-8} \mathrm{~atm}-\mathrm{cc} / \mathrm{sec}$ on helium leak detector were demonstrated. The advantage of doing resistance brazing in the present work is that brazing could be performed at a faster ramp rates and the whole process done in less than a minute. This is significant as Ti reacts with gold resulting in 4 
intermetallic compounds reaction between gold and $\mathrm{Ti}$ as can be seen from the binary phase diagram in figure $1.2[1]$.

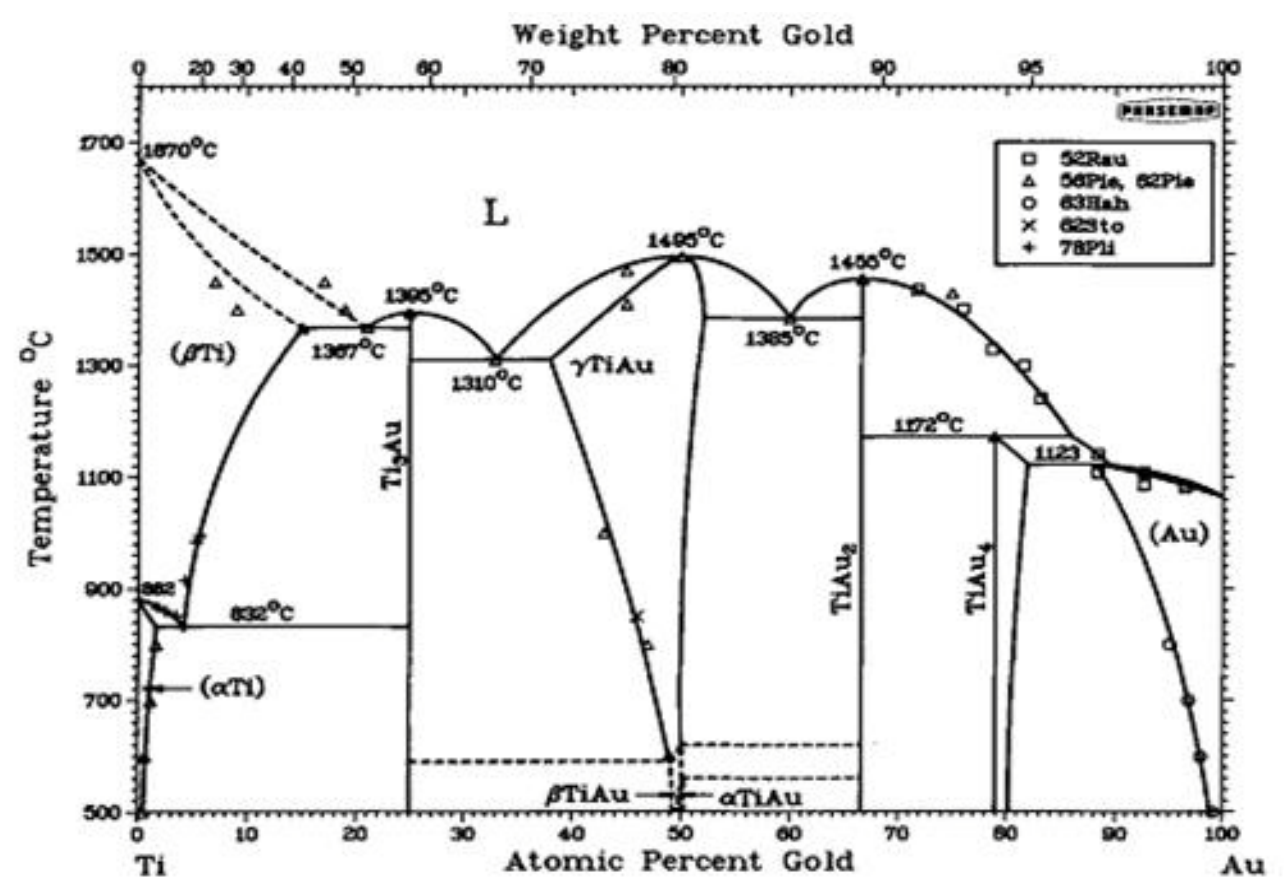

Figure 1.2: Binary phase diagram of Ti and $\mathrm{Au}[1]$

Two of these intermetallic compounds might be brittle because they exhibit no solid solubility. The use of pulsed resistive heating restricts the time for molten gold to interact with Ti and hence the growth of these intermetallic phases is decreased. The problem of formation of intermetallic compounds could not be avoided entirely but is reduced considerably. The formation of IMCs was observed when the samples were analyzed using scanning electron microscopy (SEM) and scanning transmission electron microscopy (STEM). Wetting studies performed for gold on Ti surface shows reactive wetting and dissolution of substrate material. Another advantage of utilizing a rapid heating process is that $\mathrm{Ti}$ undergoes an allotropic transformation from alpha to beta phase at $883{ }^{\circ} \mathrm{C}$ and the grain growth kinetics in the beta phase is an order of magnitude faster 
than in the alpha phase [2-3]. This causes large grain size in the end product leading to softer Ti metal, which is detrimental to the performance of the device.

Wetting studies were also performed with gold on different metals to determine the best thin film for metalizing the ceramic. A lower wetting angle in both cases is desired as the lower wetting angle helps spreading and capillary rise of molten gold between the metals to be joined. Scratch testing was also performed to analyze the adhesion strength of the thin films to the alumina ceramic and three point bending was performed to evaluate the strength of the fired alumina. 


\section{LITERATURE REVIEW}

\subsection{Metal/ceramic joining}

Metal to ceramic joining has been an area under investigation for last few decades because of its enormous scope in different fields like the aerospace industry or biomedical implants industry. A range of techniques are utilized for metal-ceramic joining depending upon the application and the base metal to be bonded. Ceramics and metals can be joined together by mechanical, direct or indirect processes [4-7]. Direct methods include brazing and indirect methods include diffusion bonding. Brazing would be discussed in detail in section 2.1.1.

Joining ceramic to metal via brazing technique is utilized where joints might get exposed to temperature as high as $500{ }^{\circ} \mathrm{C}$. Structural ceramics as $\mathrm{Si}_{3} \mathrm{~N}_{4}, \mathrm{SiC}, \mathrm{Al}_{2} \mathrm{O}_{3}, \mathrm{AlN}$ and $\mathrm{ZrO}_{2}$, have been successfully brazed to a number of metals and alloys [8,9]. Research in this area has lead to development of new and improved filler alloys [8].

\subsubsection{Brazing}

Brazing is a joining technique which does not involve any melting or plastic state of the base metal [10]. In this process coalescence is produced by heating to a temperature higher than $450{ }^{\circ} \mathrm{C}$ (if the liquidus is below $450{ }^{\circ} \mathrm{C}$, the process is called soldering) and by using a filler metal that must have a liquidus temperature higher than $450{ }^{\circ} \mathrm{C}$ and below the solidus temperature of the base metal. The filler metal is distributed between the closely fitted surfaces of the joint by capillary attraction.

Brazing has four distinct characteristics: 
- The coalescence, or joining, is achieved by heating the assembly or the region of the parts to be joined to a temperature of $450{ }^{\circ} \mathrm{C}$ or above.

- Assembled parts and filler metal are heated to a temperature high enough to melt the filler metal but not the parts.

- The molten filler metal spreads into the joint and must wet the base-metal surfaces.

- The parts are cooled to freeze the filler metal, which is held in the joint by capillary attraction and anchors the part together.

\subsubsection{Adhesion, Wetting, Spreading, and Capillary Attraction}

The Young's equation for a molten drop resting

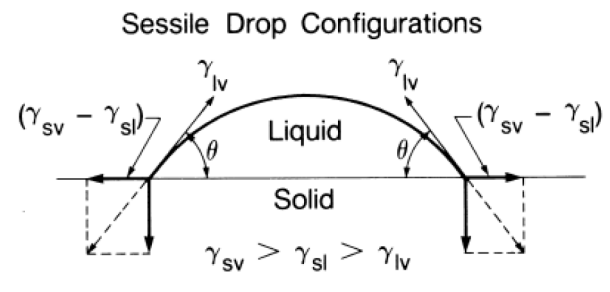

$\gamma_{\mathrm{sv}}-\gamma_{\mathrm{sl}}=\gamma_{\mathrm{IV}} \cos \theta$

Where, $\gamma_{\mathrm{sv}}=$ surface tension at the solid-vapor

$\gamma_{s v}-\left(\gamma_{s l}+\frac{-d G_{R}}{d A \cdot d t}\right) \rightarrow \gamma_{I V} \cos \theta$

interface; $\gamma_{\mathrm{lv}}=$ surface tension at the liquid-

vapor interface $\gamma_{\mathrm{sl}}=$ surface tension at the solid-

liquid Interface.

The derivation of Young's equation is made under the assumptions of spreading of non-reactive

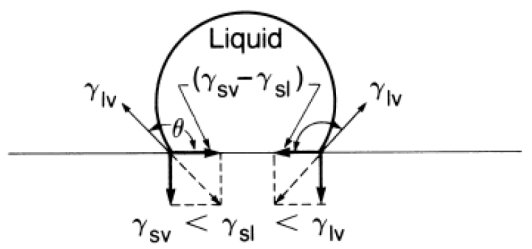

Figure 2.1: Sessile drop configuration, top wetting and bottom non wetting condition liquid on an ideal (physically and chemically inert, smooth, homogeneous and rigid) solid, a condition that is rarely met in practical situations. Nevertheless Young's equation is the most fundamental starting point for understanding of the complex field of wetting [11]. 
With a decrease in the contact angle the liquid drop surface area increases and hence the total liquid surface free energy increases. The total surface free energy of the solid decreases concurrently. The driving force for wetting is thus $\gamma_{\mathrm{sv}}-\gamma_{\mathrm{sl}}$.

When $\gamma_{\mathrm{sv}}<\gamma_{\mathrm{lv}}$ and $\gamma_{\mathrm{sv}}<\gamma_{\mathrm{sl}}<\gamma_{\mathrm{lv}}$ ( for non reactive wetting), a steady state condition results with $\theta>90$ degrees. In either wetting $\left(\gamma_{\mathrm{sv}}>\gamma_{\mathrm{lv}}\right)$ or nonwetting $\left(\gamma_{\mathrm{lv}}>\gamma_{\mathrm{sv}}\right)$, case, if the mating surfaces are not in intimate contact as in the case of an adsorbed carbonaceous matter, in this case $\gamma_{\mathrm{sl}}$ becomes larger that $\gamma_{\mathrm{sv}}$ and also $\gamma_{\mathrm{lv}}$ and hence a large obtuse contact angle forms which approaches towards 180 degrees. It is not favorable to use a nonwetting liquid as a braze filler metal as it lacks the capability of penetration of surface irregularities because of the lack of capillary behavior [10].

Young's equation can be modified to represent a work of adhesion $\mathrm{W}_{\mathrm{s}}$, by taking the case of 0 degrees contact angle yielding $\cos \theta$ value as 1 . The resisting force to the spreading of the drop then can be expressed as

$$
\mathrm{W}_{\mathrm{s}}=\gamma_{\mathrm{sv}}-\gamma_{\mathrm{sl}}-\gamma_{\mathrm{lv}} \ldots \ldots \ldots \ldots \ldots \ldots \ldots \ldots \ldots \ldots \ldots \ldots
$$

In order for spreading to occur $\mathrm{W}_{\mathrm{s}}$ should be positive.

If a reaction between the molten drop and the substrate occurs, then the free energy of the reaction $\Delta \mathrm{G}_{\mathrm{R}} / \mathrm{dAdt}$, contributes to the driving force for wetting, which normally always exceeds $\gamma_{\mathrm{lv}}$. This situation leads to spreading of drop.

Young's equation for the case of reactive wetting would be

$\gamma_{s v}-\left(\frac{\gamma_{\mathrm{sl}}+\mathrm{G}_{\mathrm{R}}}{\mathrm{dA}_{\mathrm{s}} \cdot \mathrm{dt}}\right) \geq \gamma_{\mathrm{sv}} \cos \theta$ 
The free energy required for the increase of the surface area of the drop as the perimeter expands provides the only resistance force for expansion of drop. Thermodynamically it can be proved that the driving force for wetting does not exceeds $\gamma_{\mathrm{lv}}$, which results in a steady state contact angle [10].

\subsubsection{Challenges in Joining Ceramics}

It is a well know fact that ceramics are poorly wetted by brazing alloys. This poor wettability of ceramics is due to the ionic and covalent bonding in their lattice due to which the electron movement is restricted [12]. There are two approaches to overcome the poor wetting characteristic of ceramic materials: Metallization of the ceramic or active metal brazing.

In the first approach a surface treatment is given to decrease the surface energy of ceramics and to alter the interfacial thermodynamics to provide a better wettable surface to brazing metal/alloy, this process is known as metallization of ceramics. There are several ways to metallize the ceramics as mentioned below.

i. Classical Mo-Mn process (not Biocompatible)

ii. Cofired W, Ni electroplating and Ag-Cu braze (not Biocompatible)

iii. The $\mathrm{TiH}_{2}$ process

iv. Mechanical metallization

v. Thin film deposition over ceramic by Physical vapor deposition (PVD)/Sputtering (Biocompatible)

Sputtering involves depositing a thin (less than a micron to few microns thick) coating of a reactive metal, such as titanium, $\mathrm{Nb}$ etc. onto the ceramic prior to brazing [13-15]. In Physical vapor deposition (PVD) a metal is vaporized, ionized and accelerated by a bias 
voltage. Sputtering is another PVD process. Both DC and AC power sources are used. In a DC discharge, the target acts as the cathode of the process and is connected to the negative pole of the high tension source. The ceramic substrate becomes the anode of the discharge and is either grounded or is under a floating potential $[16,17]$. As a discharge is generated between cathode and anode of a plasma reactor, Ar atoms are ionized and converts to $\mathrm{Ar}^{+}$after losing an electron. The positively charged Ar ions are accelerated towards the negatively biased target and because of momentum transfer eject the target atoms from the target. These ejected target atoms goes in all the direction in the sputtering chamber and some of them deposit over the ceramic substrate and form a thin film [16]. Sputtering technique is as old as 1877 but this technique has undergone phenomenal developments since then. Sputtering is a very versatile process and essentially adherent and dense films from virtually any material can be deposited [18].

Table 2.1: Table relating different units of vacuum

\begin{tabular}{|l|c|c|c|c|}
\hline & bar & Torr & Pa(Nm $\left.\mathbf{N m}^{-2}\right)$ & atm \\
\hline $1 \mathrm{mbar}=$ & $1 \times 10^{-3}$ & 0.75 & $10^{2}$ & $9.869 \times 10^{-4}$ \\
\hline $1 \mathrm{bar}=$ & 1 & $7.5 \times 10^{2}$ & $1 \times 10^{5}$ & 0.987 \\
\hline $1 \mathrm{torr}=$ & $1.333 \times 10^{-3}$ & 1 & $1.333 \times 10^{2}$ & $1.316 \times 10^{-1}$ \\
\hline $1 \mathrm{pa}\left(\mathrm{nm}^{-2}\right)=$ & $1 \times 10^{-5}$ & $7.5 \times 10^{-3}$ & 1 & $9.87 \times 10^{-6}$ \\
\hline $1 \mathrm{~atm}=$ & 1.013 & $7.6 \times 10^{2}$ & $1.013 \times 10^{5}$ & 1 \\
\hline $1 \mathrm{~mm} \mathrm{Hg}=$ & $1.333 \times 10^{-3}$ & 1 & $1.333 \times 10^{2}$ & $1.316 \times 10^{-3}$ \\
\hline
\end{tabular}

Sputtering chamber is pulled to a vacuum level of the order of $10^{-8}$ torr before the Ar is injected into the chamber. Sputtering is usually performed at an $\mathrm{Ar}$ gas pressure of $10^{-3}$ torr. Table 2.1 shows a table relating different units of vacuum.

The parameters that determine the sputtered thin film qualitatively and quantitatively are power level, sputtering gas, and sputtering pressure. An important feature of sputtering is that stoichiometric films can be formed. The ceramic substrate over which the film is 
deposited is cleaned in ultrasonic cleaner with organic solvents, successively in the order of Isopropanol, Methanol and Acetone. To avoid any residue left over from solvent cleaning the substrate can be cleaned using plasma ashing. A clean surface is an essential requirement for the thin film to adhere with the substrate, since the bonding is atomic in nature. Figure 2.2 (a) and 2.2 (b) shows the phenomenon of DC and RF sputtering respectively.

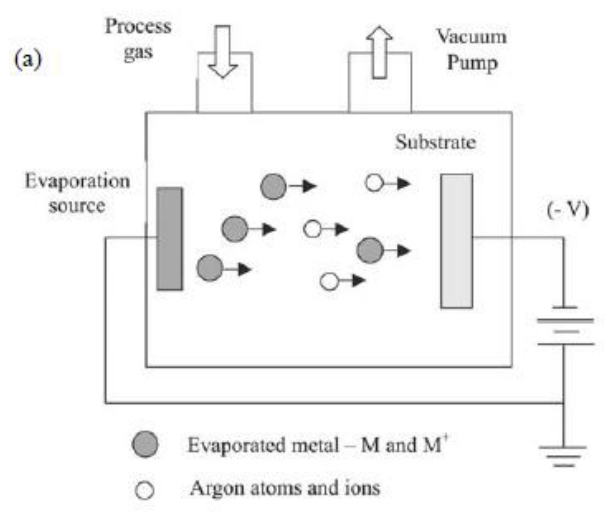

(b)

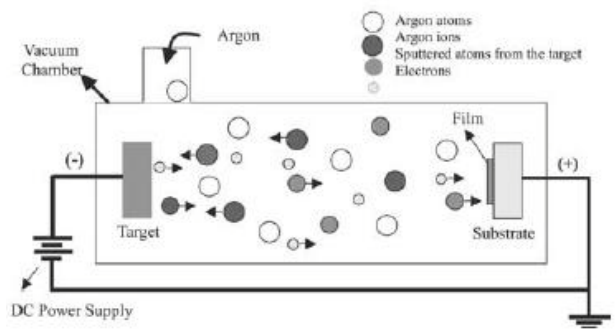

Figure 9: Film deposition by (a) PVD and (b) sputtering.

[Figura 9: Deposição de filme por (a) PVD e (b) sputtering.]

Figure 2.2: Film deposition by (a) DC and (b) RF sputtering

\subsubsection{Other challenges in vacuum brazing of alumina ceramic to metals}

In the previous section it has been discussed that joining ceramic to metal is not a simple process and one of the reason being the poor wettability of ceramic by filler metals used in brazing. Another challenge that has to overcome to join ceramic to metal is the difference in the coefficient of thermal expansion between metal and ceramic surfaces [25]. When the brazed joint is cooled down from the brazing temperature to the room 
temperature there are significant stress build up at the interface [26]. One way to release or to minimize the residual stresses is the use of a ductile filler metal or use of a ductile metal interlayer that undergoes plastic deformation to alleviate these stresses and to keep the brazed joint sound and leak proof [5, 27-29]. The quantification of residual stresses built up during metal to ceramic joint has been investigated by previous investigators like Abhijit Kar et al. [30]. They used x-ray diffraction (XRD) to measure the residual stresses in the brazed joint. Some researchers have used functionally graded materials to minimize the residual stresses [31].

The coefficient of thermal expansion of some of the materials of interest for the present work are mentioned below in table 2.2 .

Table 2.2: Coefficients of thermal expansion of materials of interest from room temperature to $100^{\circ} \mathrm{C}$ (lowest value to highest value)

\begin{tabular}{|l|l|}
\hline Element & Coefficient of thermal expansion $\left({\left.\mathrm{X} 10^{-6}\right) \mathrm{K}^{-1}}^{-1}\right.$ \\
\hline $96 \%$ alumina & 7 \\
\hline $\mathrm{Nb}$ & $7.2-7.3$ \\
\hline $\mathrm{Ti}$ & $8.4-8.6$ \\
\hline $\mathrm{Ta}$ & 6.5 \\
\hline $\mathrm{W}$ & $4.5-4.6$ \\
\hline $\mathrm{Au}$ & 14 \\
\hline
\end{tabular}

In the present work pure gold is used as braze filler metal which is very ductile and its used is expected to reduce the stress build up at the ceramic to metal interface. Pure gold brazing has been done in industry to braze Ti to alumina [32] although the details of the process are not made available and are held as trade secrets. 


\subsection{BIOCOMPATIBLE, HERMETIC JOINING OF CERAMICS AND}

METALS

\subsubsection{BIOCOMPATIBLE ACTIVE BRAZING}

Lasater patented a brazing technique using titanium-nickel braze filler alloy [37]. Jiang et. al showed in their work that strong hermetic, electrochemical corrosion resistant joint can be formed by brazing zirconia-to-Ti-6Al-4V using titanium nickel (TiNi)-clad braze filler material [38]. In such cases Ti from the base metal reacts with the Ni filler metal and form a eutectic alloy at the interface. At the interface $\mathrm{Ni}_{2} \mathrm{TiO}_{4}$ phase forms, which is responsible for the bond development. In this work the researchers also reported that the brazed joints have good biocompatibility and have been successfully used for second generation neuromuscular microstimulators developed at the Alfred Mann Foundation, Santa Clara, USA. Active brazing using TiNi-50® to form brazed joint between alumina and $\mathrm{Ti}-45 \% \mathrm{Nb}$ alloy for Cochlear implants and alumina to metal assembly brazed with a modified filler metal for artificial retinal project has also been used successfully.

\subsubsection{NOBLE METAL BRAZING}

Silver and platinum based filler alloy are more commonly used noble metals than copper and nickel and sometimes palladium and gold based noble metal alloys are also used for this technique. Such brazing is performed in air or even in oxygen rich environment to promote the formation of noble metal oxide at the interface which caused the bonding to occur. Correia et al investigated the In TZP, Ti joints using platinum, they reported that joints were failing at the interface [39]. Agathopoulos S et. Al in their study to joint tetragonal zirconia polycrystal (TZP), with Ti using 25 microns foil in between observed formation of intermetallic compounds of Au and Ti. They also observed that Ti diffused 
through the molten pool of gold and reacts with alumina forming undesirable oxides of Ti [40]. Silver was also tested to form TZP/Ti joints using $35 \mu \mathrm{m}$ foil of silver and the resulting joint had better strength than the joint using gold as filler metal. Also a thick zone of $\mathrm{Ti}_{3} \mathrm{O}_{2}$ forms at the interface having large holes causing non hermetic joints. When Zirconia was brazed to titanium and its alloys with palladium in an induction furnace, bonding formed at the interface but again the brazed joint contains pores, thus the hermeticity of such joints is a problem.

\subsection{WETTING AND SPREADING OF METALS ON DIFFERENT}

\section{SUBSTRATES}

One of the very important criteria for any metal to be used as a filler metal in the brazing process is that it should wet and spread readily on the mating surfaces. Wetting can be defined as the ability of the molten filler metal to adhere to the surface of a metal in the solid state and, when cooled below its solidus temperature, should make a strong bond with that metal [10]. Figure 2.3 shows examples of wetting and de-wetting [10].

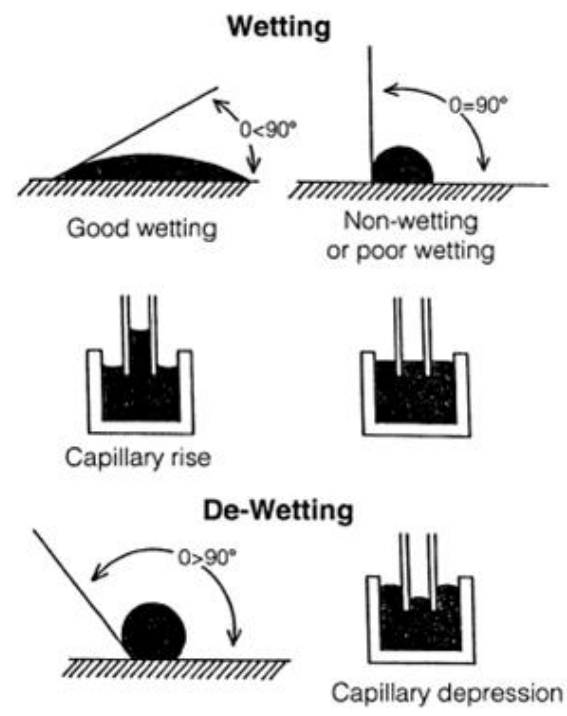

Figure 2.3: Wetting and dewetting 


\subsubsection{Contact angle}

When a metal melts on a substrate, it spreads to some extent on that substrate and then comes to rest making an angle shown in figure 2.4. The angle between the tangent drawn at the triple point between the three phases and the substrate surface is called as contact angle of that liquid with that substrate. Contact angle has been widely used for characterizing interfacial phenomenon, wetting dewetting of solid surfaces etc $[47,48]$.

This contact angle is the result of three surface tension forces acting at the triple point. The relation between these surface tension values and the contact angle is given by the Young's equation as shown in equation 1 in section 2.1.2.

Wetting can be classified in two categories namely

1. Non reactive wetting

2. Reactive wetting

\subsubsection{Non reactive wetting}

A liquid spreading on a substrate with no reaction/absorption of the liquid by substrate material is known as nonreactive or inert wetting [11]. Spreading of water or polymeric liquids on glass or metallic substrate is an example of nonreactive wetting. Wetting of alumina ceramic by pure gold or pure silver is an example of non reactive wetting.

$$
\gamma^{\mathrm{sv}}=\gamma^{\mathrm{s} 1}+\gamma^{\mathrm{lv}} \cos \theta
$$

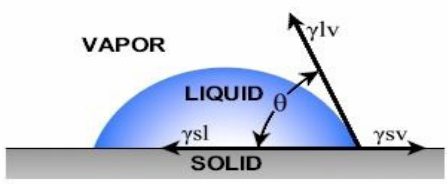

Figure 2.4: Sessile drop over a substrate

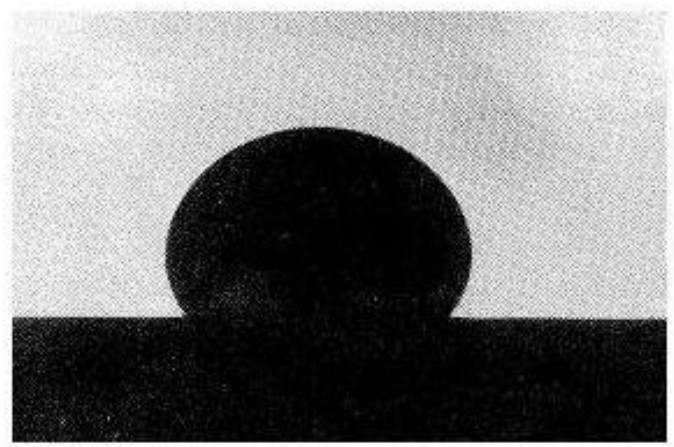

Figure 2.5: Molten drop of gold on alumina 
Figure 2.5 shows a molten drop of gold on alumina ceramic substrate forming an average wetting angle of 127 degrees [49].

\subsubsection{Reactive wetting}

In reactive wetting the wetting process is influenced by reaction between the spreading liquid and substrate material.

There may or may not be any formation Intermetallic compounds (IMCs) depending on the phase diagram of the two metals under study. Alteration of interface and possible formation of Intermetallic compounds are the two important features of reactive wetting that differentiate it from non-reactive wetting.

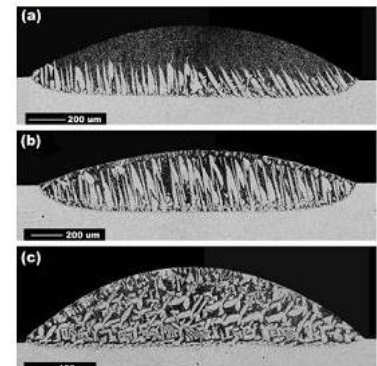

Figure 2.6(a):Dissolutive wetting in Bi-Sn system without any formation of intermetallic compounds (IMCs). Spreading of most of the non-metallic liquids on inert solids is generally nonreactive type. The whole process is spontaneous and almost completes within small duration of time. This phenomenon is governed by capillary/surface tension, gravity and viscous forces in the order given.

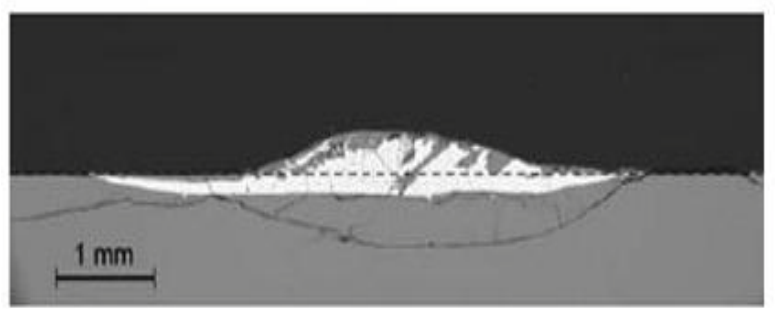

Figure 2.6 (b): Dissolutive wetting in $\mathrm{Cu}-\mathrm{Si}$ system with the formation of intermetallic though not showing at this low magnification image

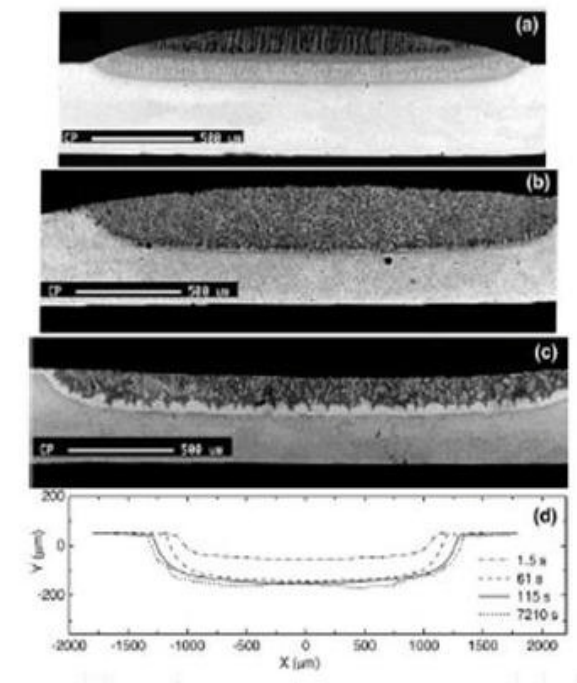

Figure 2.6 (c): Dissolutive wetting in $\mathrm{Au}-\mathrm{Sn}$ with IMC formation at interface. 
On the other hand, spreading of metallic liquids on solid substrates is guided by additional factors such as diffusion, reaction, absorption, solidification, etc. The true equilibrium state is rarely achieved in such systems. Wetting and spreading studies performed by previous researchers have shown that for millimeter sized droplets the spreading time in dissolutive wetting ranges from a few seconds to several hundred seconds $[50,51]$ which is more orders of magnitude higher than time taken for spreading in liquid metal/solid metal systems with negligible miscibility. Generally the time required for spreading in non reactive systems is around $10 \mathrm{~ms}[52,53]$.

Wetting in Bi-Sn is an example of dissolutive wetting without any formation of Intermetallic compounds [54], while wetting in Au-Sn system is an example of dissolutive wetting with the formation of Intermetallic compounds [55].

Figure 2.6(a), 2.6(b) and 2.6(c) shows examples of dissolutive wetting without formation of Intermetallic in the first case while with the formation of Intermetallic compounds in the two later cases.

\subsubsection{Au-Ti system}

$\mathrm{Au}$ and Ti react and form a series of intermetallic compounds as shown in the figure 1.2. Gold exhibit excellent wetting characteristics towards $\mathrm{Ti}$ although the intermetallic compounds (IMCs) formation is undesired during brazing as two of the intermetallic compounds (IMCs) can be predicted as brittle phases from their binary phase diagram. The formation of intermetallic compounds of gold and Ti has been observed by $\mathrm{S}$. Agathopoulos et. al., in their effort to braze tetragonal stabilized Zirconia (TZP) with Titanium using pure gold and gold titanium filler at $1100{ }^{\circ} \mathrm{C}$ [41]. They examined the 
brazed joint by using EDS/back-scattering analysis technique and the reaction zone consisted of the following layers (from TZP to $\mathrm{Ti}$ ): $\mathrm{TiO}_{2}, \mathrm{TiAu}_{6}, \mathrm{TiAu}_{2}, \mathrm{TiAu}, \mathrm{Ti}_{3} \mathrm{Au}$. According to older literature the phase $\mathrm{TiAu}_{6}$ was an equilibrium phase in $\mathrm{Ti}-\mathrm{Au}$ diffusion couples, although newer data do not show $\mathrm{TiAu}_{6}$ as an equilibrium phase but rather $\mathrm{TiAu}_{4}$ [56]. The binary phase diagram of gold and titanium also indicates that the solid solubility of titanium in gold is around $10 \%$ which suggest that there would be dissolution of the titanium substrate when gold melt on titanium surface.

\subsubsection{Au-Nb system}

The Gold-Niobium binary phase diagram is shown in figure 2.7 below [57]. The maximum solubility of $\mathrm{Nb}$ in gold is about $57 \%$ while the maximum solubility of gold in niobium is about $36 \%$.

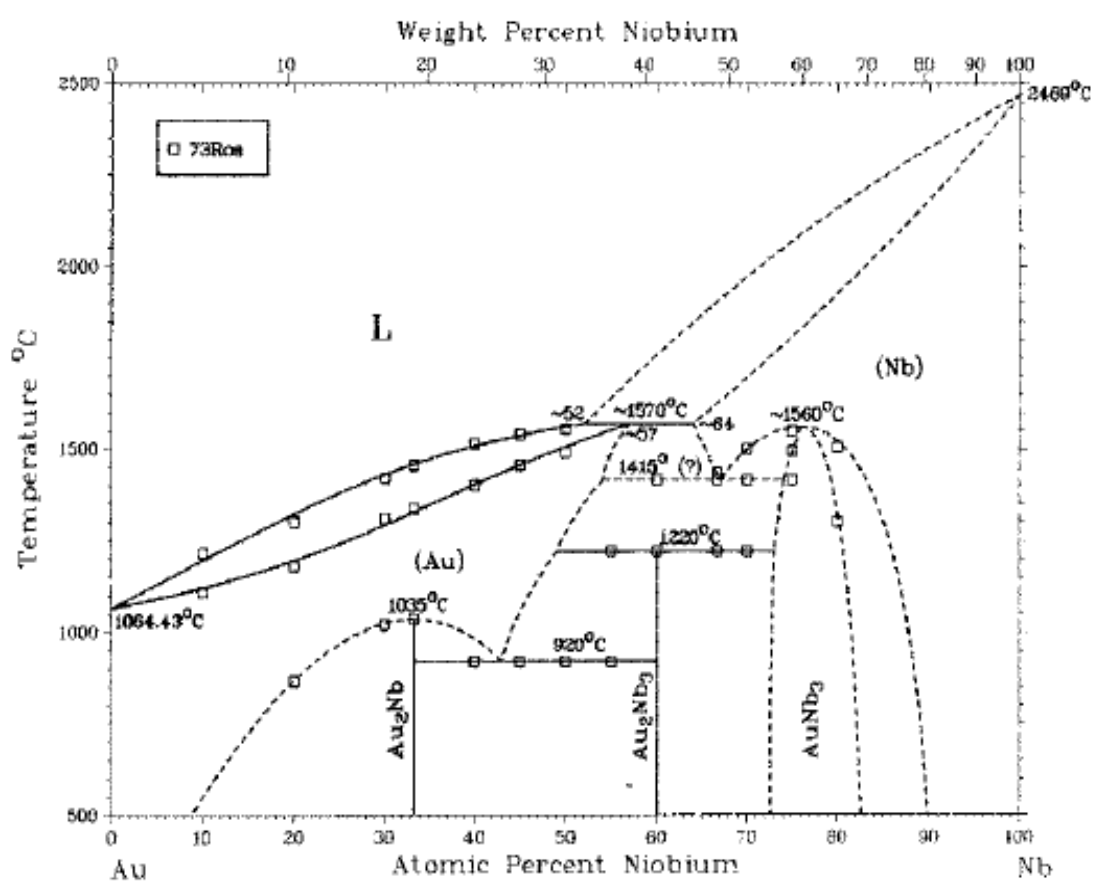

Figure 2.7: Au-Nb binary phase diagram 
Formation of intermetallic compounds (IMCs) like $\mathrm{Au}_{2} \mathrm{Nb}_{3}$ have been reported by Masahiro Kitada during heating of sputter deposited thin film of gold over $\mathrm{Nb}$ [58]. It has been reported by $\mathrm{M}$. S. Wire et. al. that the $\mathrm{Nb}_{3} \mathrm{Au}$ compound formed after quenching from the high temperature $\alpha$ solid solution phase field show superconducting properties [59].

\subsubsection{Gold Tungsten system}

Gold tungsten binary phase diagram does not show any formation of intermetallic compounds between the two components [60].

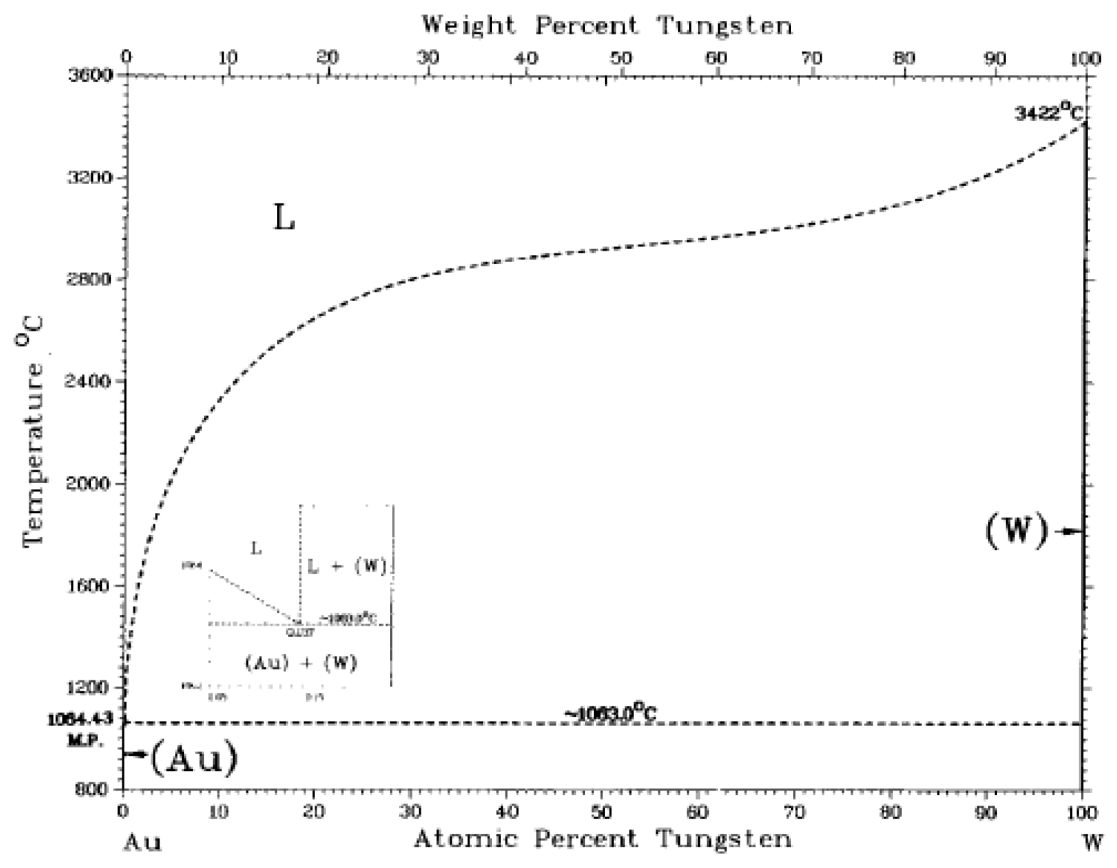

Figure 2.8: Au-W binary phase diagram

It has been observed from previous researchers that gold exhibit very good wetting to tungsten [61]. 


\subsection{Nanoscratch testing of thin films}

Nanoscratch testing has been used successfully by other researchers in order to characterize the adhesion of sputtered thin film on substrates [62-65].

Scratch testing can be performed by two ways:

1. Constant load Nanoscratch test.

2. Ramping force Nanoscratch test.

Apart from determining the adhesion of a film to the substrate nano scratch test is also used to determine the wear properties and coefficient of friction of the thin film [66].

\subsubsection{Constant load Nanoscratch test}

In this test a constant normal load is applied on the indenter tip throughout the length of the scratch while the indenter scratches the surface of the sample. Figure 2.9 shows an SPM image of a scratch made under constant load on an aluminum sample [65].

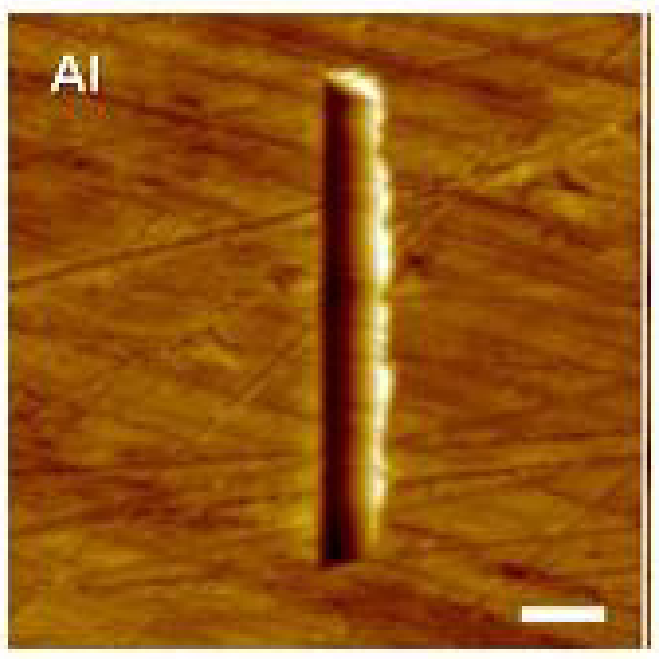

Figure 2.9: Scratch made on Al surface using constant load testing mode utilizing a Berkovich tip 


\subsubsection{Ramping force Nanoscratch test}

In this variation of the test a ramping vertical force is applied on the indenter tip across the length of the scratch. A representative $10 \mu \mathrm{m}, 2$-D topographical in-situ SPM image obtained after a $1000 \mu \mathrm{N}$ ramping force Nanoscratch test is shown in Figure 2.10.

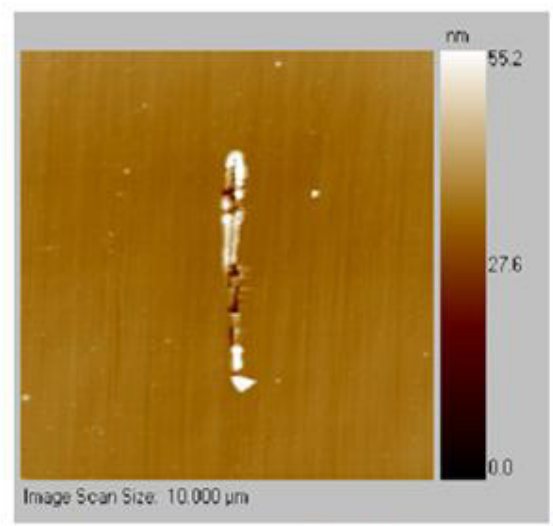

Figure 2.10: Scratch made on Al surface diagram using ramping load testing mode

The data of lateral force Vs time is plotted as shown in the figure 2.11.

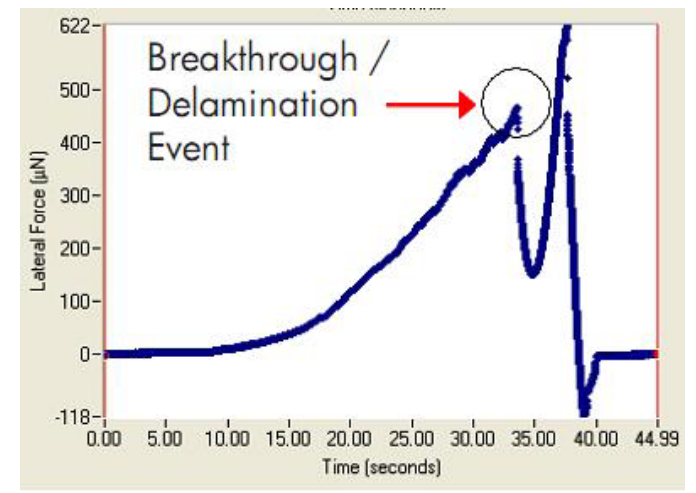

Figure 2.11: Representative plot of Lateral force Vs time for a Nanoscratch test

When an abrupt change of the Lateral force occurs, the location where the film fails can be determined and the lateral force recorded at that point is referred as the scratch critical load ( $\mathrm{L}_{\mathrm{c}}$ or $\left.\mathrm{P}_{\text {crit }}\right)$. Shou Yi. Chang et. al has demonstrated the use of nano scratch testing 
to determine the adhesion properties of $\mathrm{SiOCH} / \mathrm{SiCN}$ interface in a multilayer structure of $\mathrm{Si} / \mathrm{PEOX} / \mathrm{SiCN} / \mathrm{SiOCH} / \mathrm{SiCN}$ multilayered film [67]. Figure 2.12(a) shows the penetration depth Vs load curve of nano scratch test under a maximum applied load of 30 $\mathrm{mN}$. It can be seen that delamination of the film occur at the critical load of $9.5 \mathrm{mN}$ and at a depth of around $260 \mathrm{~nm}$. Figure 2.12 (b) shows a SEM image of scratch track.

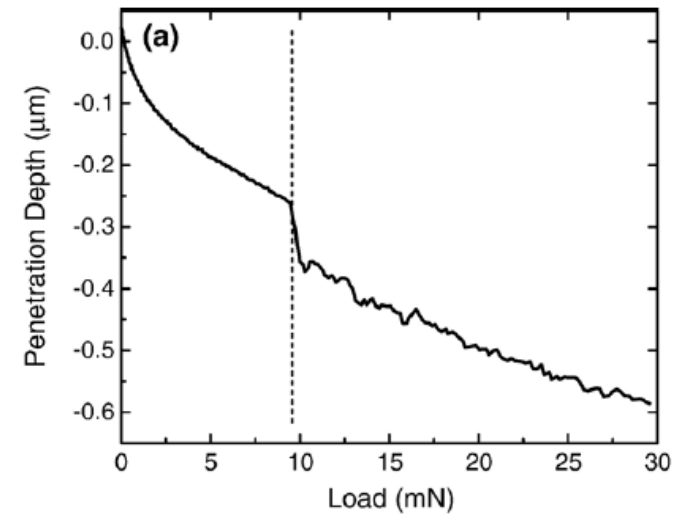

Fig. 2.12(a): Penetration depth versus load curve of nanoscratch test of $\mathrm{Si} / \mathrm{PEOX} /$ $\mathrm{SiCN} / \mathrm{SiOCH} / \mathrm{SiCN}$ film stack under a maximum applied load of $30 \mathrm{mN}$

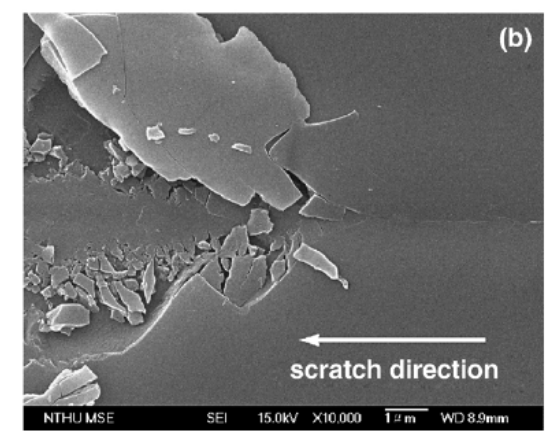

Fig. 2.12(b): SEM surface morphology along scratch track showing the beginning stage of interface

By using the following equations (4 and 5) they measured the critical stress for interface delamination $\sigma_{c}$ and the fracture energy release rate $G_{c}$

$$
\begin{aligned}
\sigma_{\mathrm{c}} & =\left(\frac{2 P_{\mathrm{c}}}{\pi d_{\mathrm{c}}^{2}}\right)\left[\frac{\left(4+v_{f}\right) 3 \pi \mu}{8}-\left(1-2 v_{f}\right)\right] \\
G_{\mathrm{c}} & =\frac{\sigma_{\mathrm{c}}^{2} t}{2 E_{f}} \quad \ldots \ldots \ldots \ldots \ldots \ldots \ldots \ldots \ldots \ldots \ldots \ldots \ldots \ldots \ldots \ldots
\end{aligned}
$$

Where, $P_{c}=$ Critical load; $d_{c}=$ scratch track with $\mu=$ measured friction coefficient of indenter sliding given by the Nanoscratch tester $=0.15 ; v_{\mathrm{f}}=$ Poisson's ratio of $\mathrm{SiOCH} / \mathrm{SiCN}$ bilayer; $\mathrm{t}=$ total thickness of bilayer $\mathrm{E}_{\mathrm{f}}=$ The average elastic modulus of the $\mathrm{SiOCH} / \mathrm{SiCN}$ bilayer 


\subsection{Modulus mapping at the Au-Ti interface}

Au-Ti binary system form a series of intermetallic compounds (IMCs) as shown in the phase diagram in figure 30. Modulus Mapping will result in the mechanical property data including the complex modulus map and a corresponding line profile map. Modulus Mapping would be used to characterize the mechanical properties of cross-sections of $\mathrm{Au}-\mathrm{Ti}$ and other interfaces. The maps will illustrate the variation in properties between the different compounds/elements present at the interface. Figure 2.13 shows Modulus Mapping of a Metal Oxide Film at the interface done by Hysitron Company [68].

The average value of elastic modulus of commercially pure Titanium as reported by $\mathrm{P}$. Majumdar et al by using nano indentation technique is $119 \pm 4.6 \mathrm{GPa}$ and by using ultrasonic technique is $121 \pm 0.87 \mathrm{GPa}$ [69]. After polishing the samples were etched with Kroll's reagent (10 vol. \% $\mathrm{HF}$ and 5 vol. $\% \mathrm{HNO}_{3}$ in water) prior to performing the

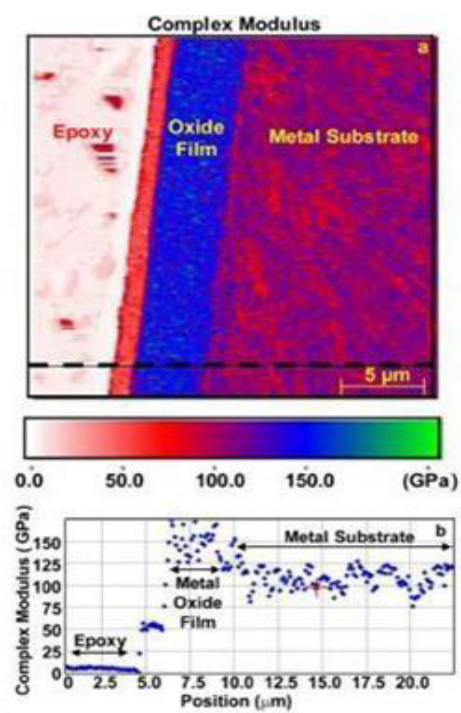

Figure 2.13: Map of complex modulus. Dotted line corresponds to line-profile map (b) Which illustrates the difference in mechanical properties across the cross-sectionom Figure 2.15: XRD analysis of the cast of the metal-oxide film and its substrate

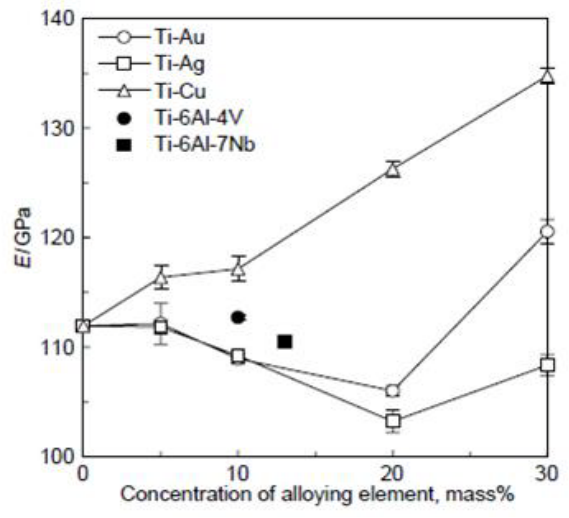

Figure 2.14: Young's moduli (E) of the Titanium alloys. Error Bar \pm SD

\begin{tabular}{lllll}
\hline Alloy & \multicolumn{4}{l}{ Concentration of alloying element } \\
\cline { 2 - 5 } & $5 \%$ & $10 \%$ & $20 \%$ & $30 \%$ \\
\hline $\mathrm{Ti}-\mathrm{Au}$ & $\alpha$ & $\alpha$ & $\alpha$ & $\alpha+\mathrm{Ti}_{3} \mathrm{Au}$ \\
$\mathrm{Ti}-\mathrm{Ag}$ & $\alpha$ & $\alpha$ & $\alpha$ & $\alpha+\mathrm{Ti}_{2} \mathrm{Ag}$ \\
$\mathrm{Ma} 1 \mathrm{Ti}-\mathrm{Cu}$ & $\alpha$ or $\alpha+$ & $\alpha+\mathrm{Ti}_{2} \mathrm{Cu}$ & $\alpha+\mathrm{Ti}_{2} \mathrm{Cu}$ & $\alpha+\mathrm{Ti}_{2} \mathrm{Cu}$ \\
& $\mathrm{Ti}_{2} \mathrm{Cu}$ & & & \\
\hline
\end{tabular}
alloys 
GPa [70]. The elastic modulus of $99.99 \%$ pure gold is 74.4 GPA as reported by NIST [71]. The elastic modulus of cast 5, 10, 20 and $30 \mathrm{wt} \%$ gold alloys have been studied by Masafumi Kikuchi et. Al. and the reported values of the modulus of elasticity were plotted by them which are shown in figure 2.14 [72].

They also characterized their cast alloys for phase identification by using XRD technique as shown in figure 2.15. They reported that the elastic modulus's values decreases till 20 wt. $\% \mathrm{Au}$ and then starts increasing which probably relate to the precipitation of $\mathrm{Ti}_{3} \mathrm{Au}$ phase for $30 \mathrm{wt} \% \mathrm{Au}$.

\subsection{Nanoindentation test}

The nanoindentation test is one of the most developed techniques, which can provide information about the mechanical behavior of the material when it is subjected to deformation at the sub-micron scale. The method developed by Oliver and Pharr allows determining the hardness and the elastic modulus from the nanoindentation loaddisplacement data [73]. This method is specially suited for mechanical characterization of thin films where mechanical characterization at macro level is more difficult and complex [74-78]. Figure 2.16 shows a typical load vs. depth curve during loading and unloading during a nano indentation experiment. Along with the Young's modulus, and hardness, the fracture toughness can also be determined as per equation 10 .

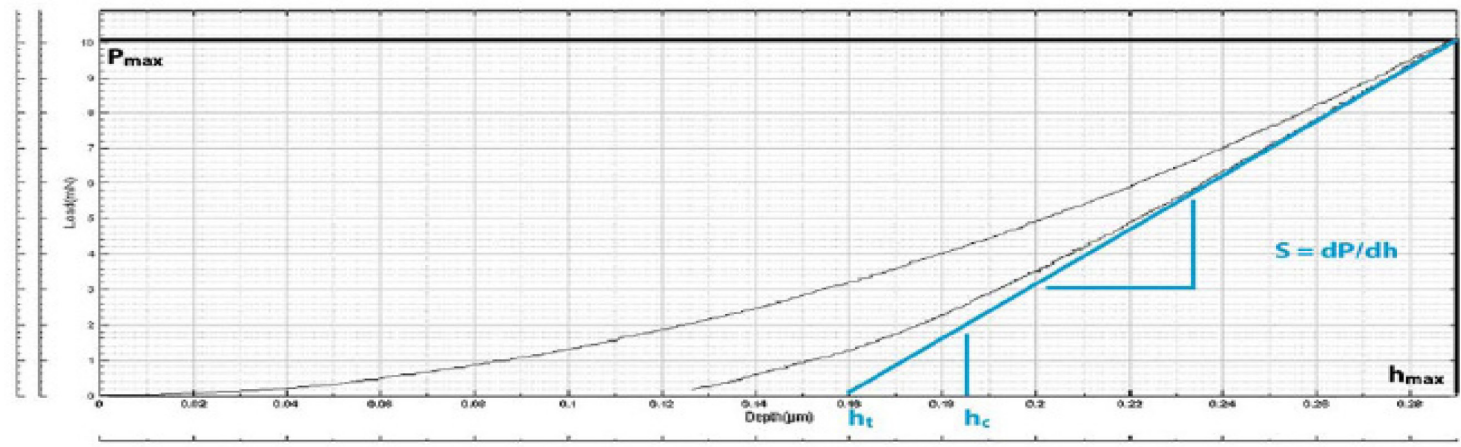

Figure 2.16: A typical curve showing loading and unloading during nano indentation 


$$
\begin{gathered}
H=\frac{P_{\max }}{A_{c}} \\
E_{r}=\frac{\sqrt{\pi}}{2} \frac{S}{\sqrt{A_{c}}} \\
\frac{1}{E_{r}}=\frac{1-v^{2}}{E}+\frac{1-v_{i}^{2}}{E_{i}} \\
h_{c}=h_{\max }-3 P_{\max } / 4 S \\
K_{c}=\alpha\left[\frac{\mathrm{E}}{\mathrm{H}}\right]^{\frac{1}{2}}\left[\frac{P}{C^{\frac{3}{2}}}\right]
\end{gathered}
$$

$\mathrm{P}_{\max }=$ Maximum load applied; $\mathrm{A}_{\mathrm{c}}=$ area function, for Berkovich tip $\mathrm{A}_{\mathrm{c}}$ is $=24.5 \mathrm{hh} c=$ Contact depth; $\mathrm{h}_{\max }=$ Maximum contact depth shown in Figure 1; $\mathrm{E}_{\mathrm{r}}=$ Reduced modulus; $\mathrm{S}=$ Slope during unloading; $v_{\mathrm{i}}=$ Poisson's coefficient of the indenter; $v=$ Poisson's coefficient of the sample; $E_{i}=$ Young's modulus of indenter $E=$ Young's modulus of sample; $\mathrm{K}_{\mathrm{c}}=$ Fracture toughness; $\alpha=$ empirical constant for a specific indenter; $\mathrm{E}=$ Young's modulus calculated above; $\mathrm{H}=$ Hardness calculated above; $\mathrm{c}=$ crack length (can be measured using SEM); $\mathrm{P}=$ applied load Nanoindentation technique has been successfully used to characterize the mechanical properties of thin films deposited on a substrate. Figure 2.17 below shows an AFM image of a nanoindentation mark on an AlN thin film. The type of indenter tip used is Berkovich [79]. 


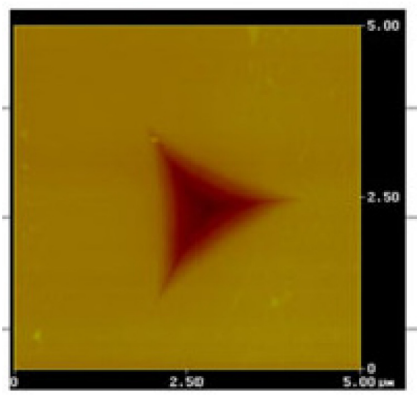

Figure 2.17: An AFM image of a Berkovich indentation on AIN thin films obtained at an indentation load of $50 \mathrm{mN}$.

Table 2.3: Comparison of hardness values from partial unloading experiments at indentation depths of $10 \%$ and $20 \%$ of the film thickness. $\mathrm{E}_{\mathrm{r}}$ corresponds to modulus value at $10 \%$ of the film thickness and $E_{s}$ corresponds to reduced modulus at $20 \%$ of film thickness [82].

\begin{tabular}{lcllll}
\hline$t(\mathrm{~nm})$ & $E_{\mathrm{r}}^{\mathrm{a}}(\mathrm{GPa})$ & $E_{\mathrm{s}}^{\mathrm{a}}(\mathrm{GPa})$ & $E_{\mathrm{Hertz}}^{\mathrm{b}}(\mathrm{GPa})$ & $H^{\mathrm{a}}(\mathrm{GPa})$ & $H_{\mathrm{f}}^{\mathrm{c}}(\mathrm{GPa})$ \\
\hline 134 & $85(70)$ & $74(60)$ & $54 \pm 9$ & $2.50(1.70)$ & 1.98 \\
207 & $111(87)$ & $99(76)$ & $73 \pm 6$ & $2.79(1.81)$ & 2.57 \\
429 & $103(86)$ & $91(75)$ & $78 \pm 20$ & $1.76(1.25)$ & 1.96 \\
858 & $79(68)$ & $68(58)$ & $86 \pm 12$ & $1.07(0.71)$ & 1.58 \\
\hline
\end{tabular}

Dietiker et.al. have studied the Nanoindentation of single-crystalline gold thin films [80]. They observed the trend that metallic thin films exhibit a size-dependent hardening effect. They investigated the properties of Au films in the thickness range from 31 to 858 $\mathrm{nm}$ by nanoindentation. They measured the average reduced modulus as $79 \mathrm{GPa}$ for $\mathrm{Au}$ film of $858 \mathrm{~nm}$ thickness while the reduced modulus was measure as $111 \mathrm{GPa}$ for film thickness of $207 \mathrm{~nm}$. The hardness of $858 \mathrm{~nm}$ thin film was measured as $1.07 \mathrm{GPa}$ while $207 \mathrm{~nm}$ thin gold film yields a hardness value of $2.79 \mathrm{GPa}$. All these values were measured at $10 \%$ of the film thickness. Table 2.3 shows the variation of the reduced modulus and the hardness values at $10 \%$ and $20 \%$ of the thickness of the film. 


\subsection{Four Point Bend Flexural Testing for Mechanical Properties of alumina}

Knowledge of the inherent mechanical strength of the fired alumina is critical to insure that the feedthrough component meets the historical performance of cofired alumina and that the strength indicates proper firing and excellent adhesion between the sintered alumina particles. Because ceramics have limited ductility but high compressive strength, the standard mechanical testing method is 3 or 4 point flexure testing, which yields a flexural strength at failure. Alumina being one of the most important electro ceramic [8185]. There are different standards for doing flexural testing of ceramic "JIS Testing Method for Flexural Strength (Modulus of Rupture) of High Performance Ceramics (R1601-1981) (Japan) ”, DIN 51110-3(Germany), MIL-STD-1942(MR) (US) However, the dominate standard is ASTM C 1161 is used to perform flexural strength testing of advance ceramic [86].

\subsubsection{ASTM C 1161 Specification}

The flexural strength is computed based on simple beam theory and it is assumed that the material is isotropic and homogeneous, and the modulus of elasticity in tension and compression are identical and the material is linearly elastic. The average grain size should be no greater than the one fifth of the beam thickness. Table 2.4 shows the possible fixture spans as per ASTM C 1161. Table 2.5 shows the possible dimensions for the sample sizes. Figure 2.18 shows a picture of the loading span for both the three and four point loading fixtures for ASTM C 1161 standard. 

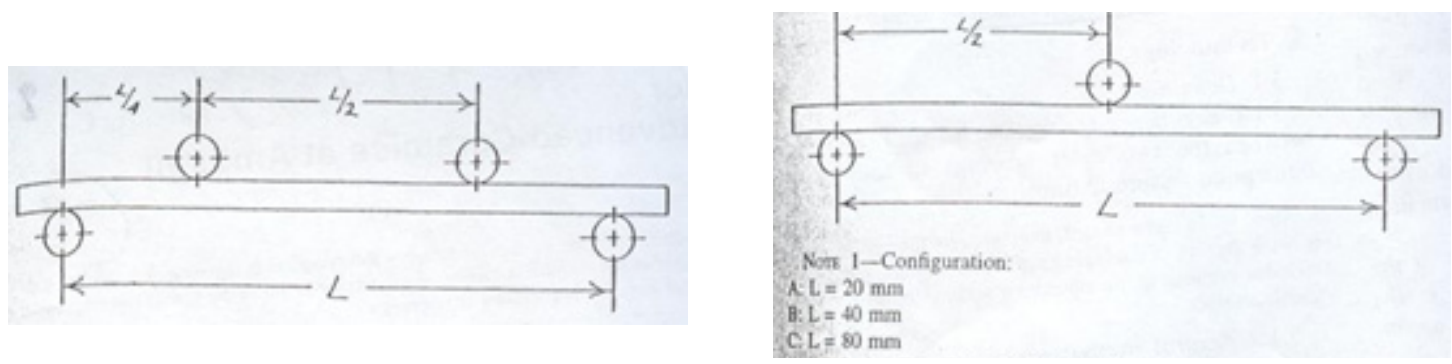

Figure 2.18: The four point and thee point fixture configuration as per ASTM C 1161

Table 2.4: Fixture span as per ASTM C 1161

\begin{tabular}{|l|l|l|}
\hline Configuration & Support Span $(\mathrm{mm})$ & Loading Span $(\mathrm{mm})$ \\
\hline A & 20 & 10 \\
\hline B & 40 & 20 \\
\hline C & 80 & 40 \\
\hline
\end{tabular}

Table 2.5: Sample size as per ASTM C 1161

\begin{tabular}{|l|l|l|l|}
\hline Configuration & Width $(\mathrm{mm})$ & Depth $(\mathrm{mm})$ & Length $(\mathrm{mm})$ \\
\hline A & $\sim 2$ & 1.5 & 25 \\
\hline B & 4 & 3 & 45 \\
\hline C & 8 & 6 & 90 \\
\hline
\end{tabular}

\section{Nomenclature and formulas used}

Flexural Strength $\mathrm{S}=3 * \mathrm{P} * \mathrm{~L} /\left(2 * \mathrm{~b} * \mathrm{~d}^{2}\right)$

Where $\mathrm{S}=$ Strength of ceramic beam in 3 point flexure; $\mathrm{P}=$ break force; $\mathrm{L}=$ Outer (support) span; $\mathrm{b}=$ specimen width and; $\mathrm{d}=$ specimen thickness

The strain rate of loading is calculated as follows:

$$
\varepsilon=6 \mathrm{ds} / \mathrm{L}^{2}
$$

Where $\varepsilon=$ strain rate; $\mathrm{d}=$ specimen thickness; $\mathrm{s}=$ crosshead speed, and $\mathrm{L}=$ Outer (support) span. 
The cross head speeds for different testing configurations are given in table 2.6.

Table 2.6: Cross head speeds for different configurations

\begin{tabular}{|l|l|}
\hline Configuration & Crosshead Speeds, $\mathrm{mm} / \mathrm{min}$ \\
\hline A & 0.2 \\
\hline B & 0.5 \\
\hline C & 1.0 \\
\hline
\end{tabular}




\section{EXPERIMENTAL PROCEDURE AND RESULTS}

\subsection{Fabrication and Flexural strength testing of $96 \%$ alumina-High temperature cofired ceramic (HTCC) samples}

High temperature co-fired ceramic (HTCC) was processed as per the conventional cofired tape processing technique. HTCC tape was supplied by Maryland Ceramic \& Steatite Co., INC. Street, Maryland, USA. A 96\% alumina content formulation was used, with $2 \%$ talc and $2 \%$ kaolinite clay as the glass component. The composition of the slip used fabricate the green tape supplied from the manufacturer is mentioned in table 3.1.

Table 3.1: Composition of HTCC tape

\begin{tabular}{|l|l|}
\hline A-16 alumina & 960.0 grams \\
\hline EPK Kaolin & 20 grams \\
\hline Nytal 400 talc & 40.0 grams \\
\hline Fish Oil, Z-3 & 40.0 grams \\
\hline Xylenes & 214.3 grams \\
\hline Ethyl Alcohol & 214.3 grams \\
\hline Benzyl Butyl phthalate & 66.5 grams \\
\hline Polyalkylene Glycol & 66.5 grams \\
\hline Polyvinyl Butyral, B-98 & 78 grams \\
\hline
\end{tabular}

The tape thickness was 5 mils and exhibited firing thickness of around $20 \%$ in the X-Y direction and $12.8 \%$ in the $\mathrm{Z}$ direction. Thermal gravinometric analysis (TGA) was used to determine the firing cycle of the tape. The TGA curve for the tape is shown in the figure 3. 1 Based on the TGA analysis the firing cycle is shown in the figure 3.2. This 
optimized firing cycle causes maximum organics burn up at low temperature which avoids the problem of delamination in the fired samples.

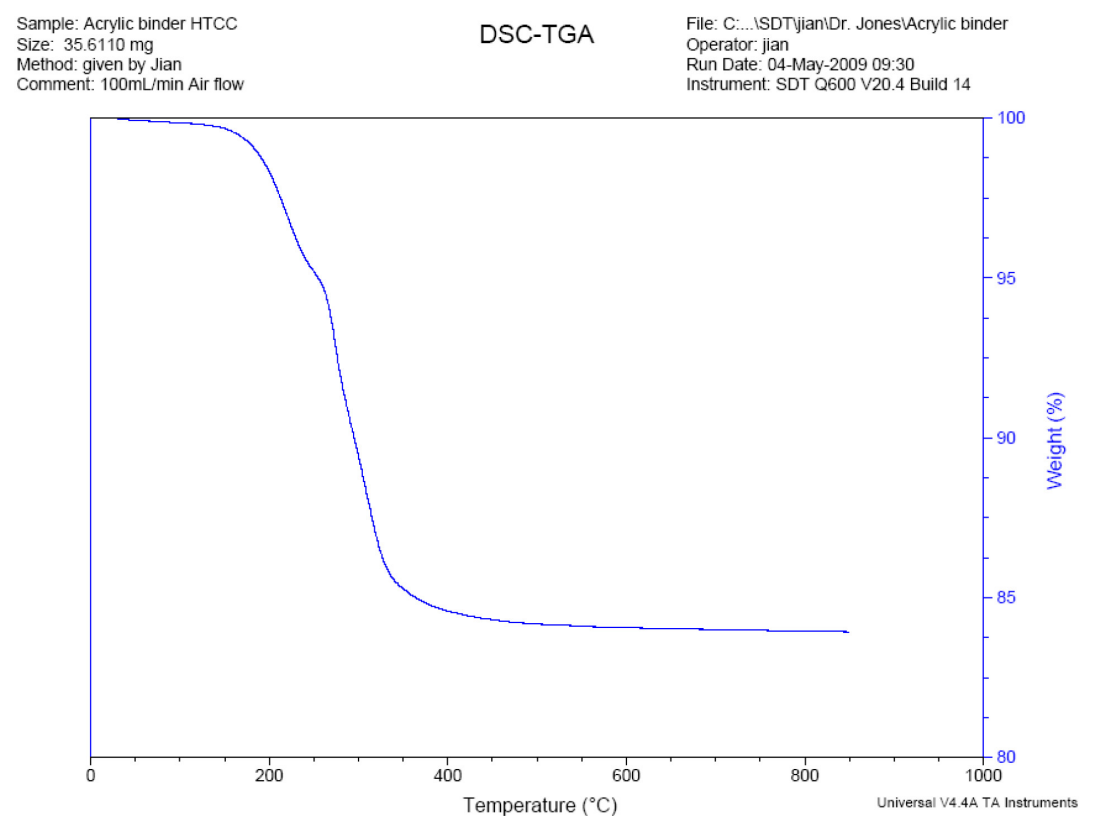

Figure 3.1 Thermo graviometric analysis (TGA) curves for the HTCC tape

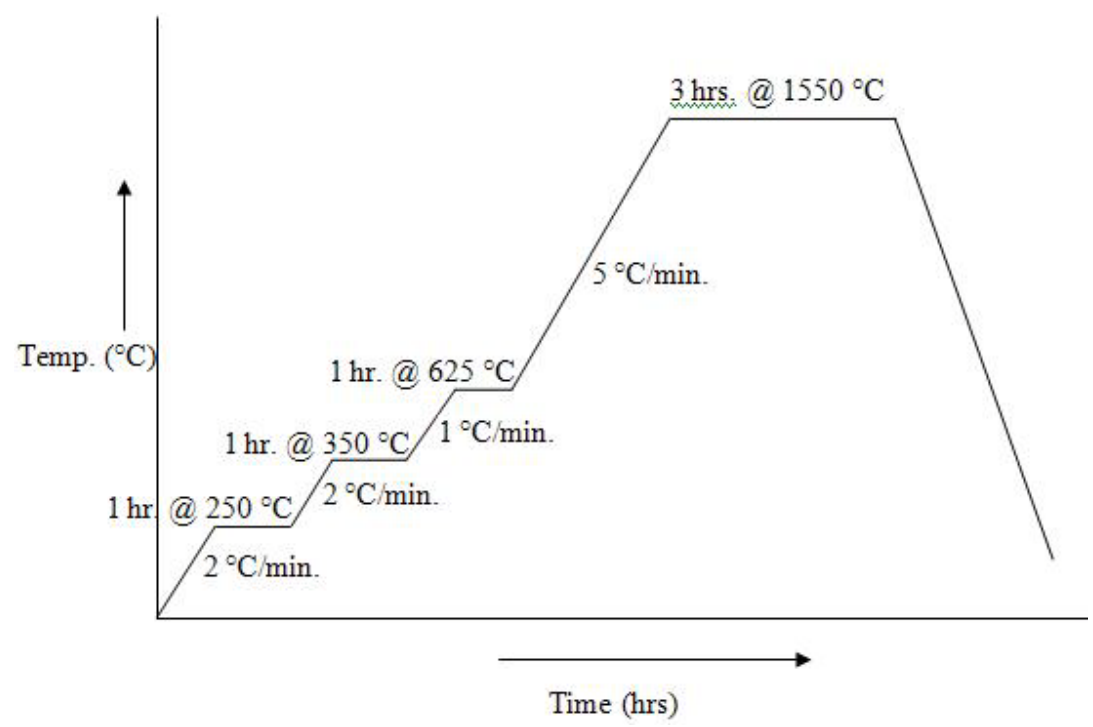

Figure 3.2: Firing cycle of green tape 
The processing steps for fabrication of samples are mentioned in the figure 3.3 below.

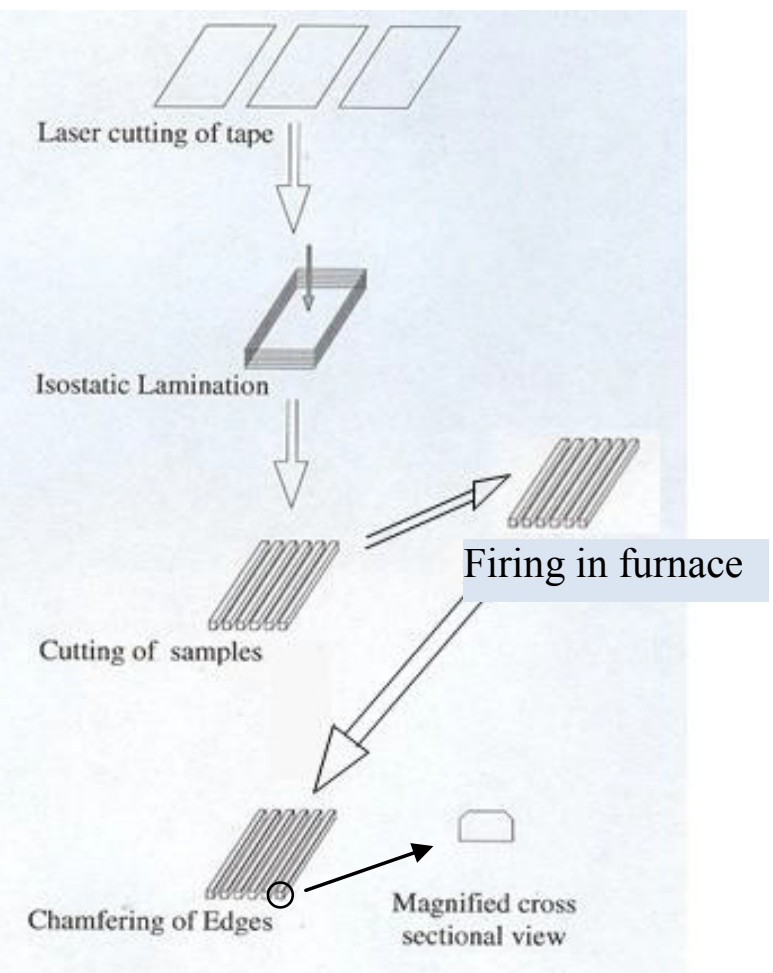

Figure 3.3: Processing steps for the fabrication of samples

There are five steps involved to fabricate the finished samples. First step is the laser cutting of the green tape to the required size of sheet. Green tape was cut into size using Class 3 laser from Universal Laser systems, Scottsdale, Arizona, USA, machine using wavelength of 630-680 nm. These sheets were then stacked together, placing the green sheets over an aluminum plate and vacuum sealing in a polythene bag. The stacked sheets inside the vacuum sealed bag were then subjected to isostatic lamination at $3000 \mathrm{psi}$ and at $70{ }^{\circ} \mathrm{C}$. After lamination the laminated tape was taken out of the vacuum sealed bag and mechanical cut. The mechanical cutting system is shown in figure 3.5 (a). It has a micrometer at the base where the sample is kept. Calculations were made for the prefired dimensions of the laminate which incorporated the shrinkage into account. After cutting, the samples were fired as per the 
firing cycle. The fired samples were then subjected to edge chamfering using slurry of 600 grit $\mathrm{SiC}$ particles suspended in glycerin. For chamfering the edges a special mounting holder shown in figure 3.5 (b) and 3.5 (c) was manufactured by machining which have grooves at 45 degrees, the sample was fixed to that groove using wax which melts at 70 ${ }^{\circ} \mathrm{C}$ and keep the sample adhered to the holder when cooled. The average grain size of the alumina grains are 2.1 microns (which is much less than one fifth of the beam thickness as it is a requirement of the ASTM C 1161) as shown in figure 3.4.

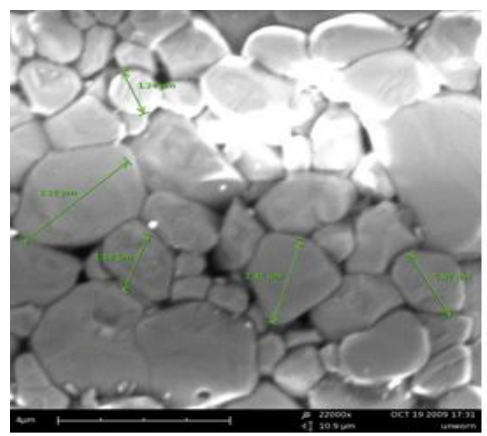

Figure 3.4: SEM micrograph of alumina sample

Chamfering was done only on the two long edges of one face. The chamfered face was the bottom face when placed in the testing fixture. The testing fixture is shown in figure 3.5 (e). A broken sample is shown in the figure 3.5(d) showing the chamfered edges.

\subsubsection{Experimental Setup and fixtures used}

Flexural strength test samples were tested on EnduraTec model ELF 3200 series. Enduratec ELF 3200 is a DMA that perform dynamic tests on a wide range of materials, from very soft rubber to stiff nylons. The Dynamic mechanical analyzer (DMA) has the capability to measure properties in compressive, tensile, and flexural modes. The load cell goes up to $200 \mathrm{~N}$. Figure 3.5 (f) shows a picture of the experimental setup of the machine. 


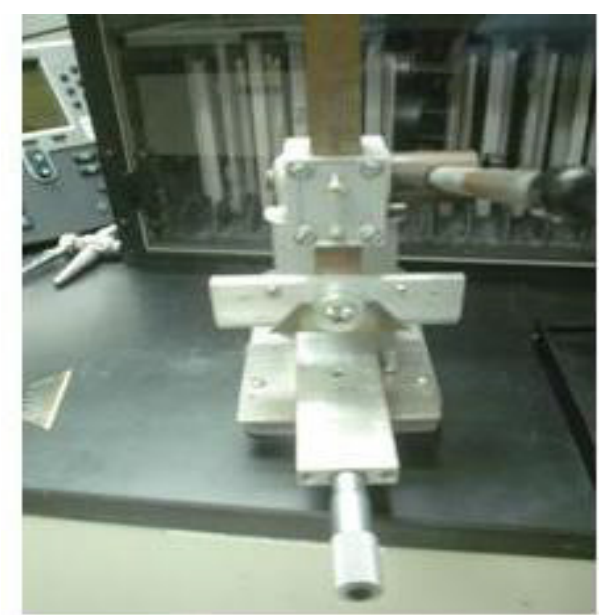

Figure 3.5(a): Fixture used for cutting green laminated tape

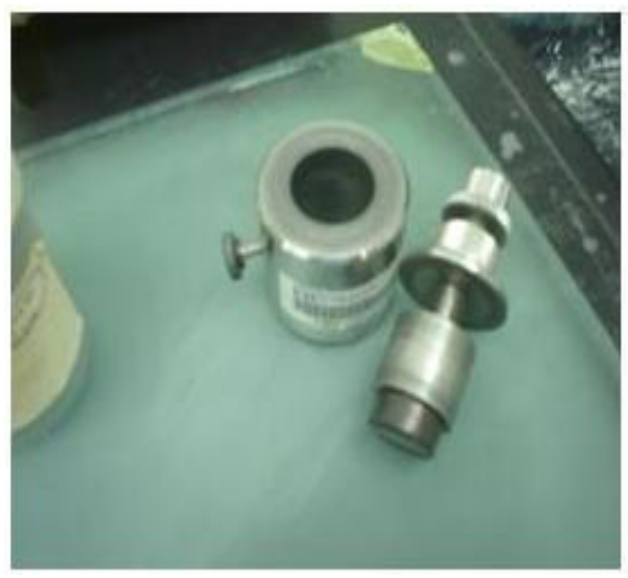

Figure 3.5(c): Setup used for chamfering the samples

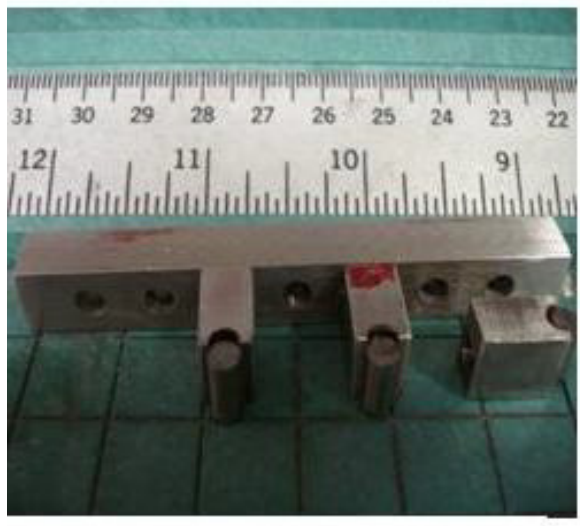

Figure 3.5(e): Loading fixture

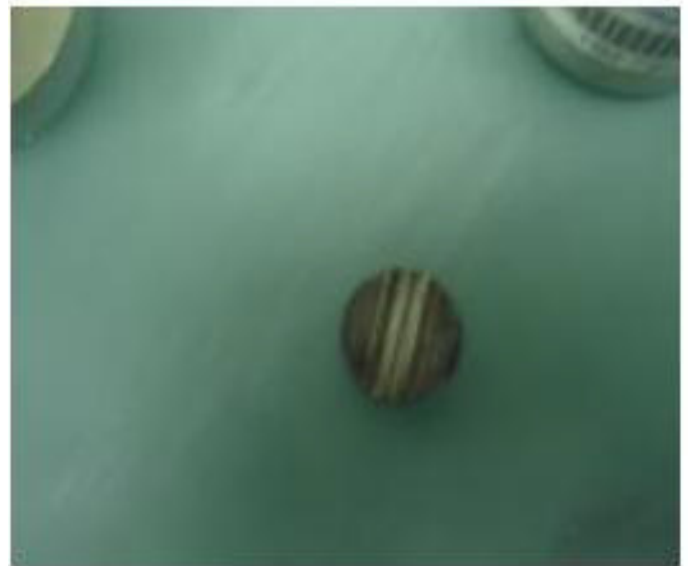

Figure 3.5(b): Steel stub with the groove over which the samples were glued for chamfering

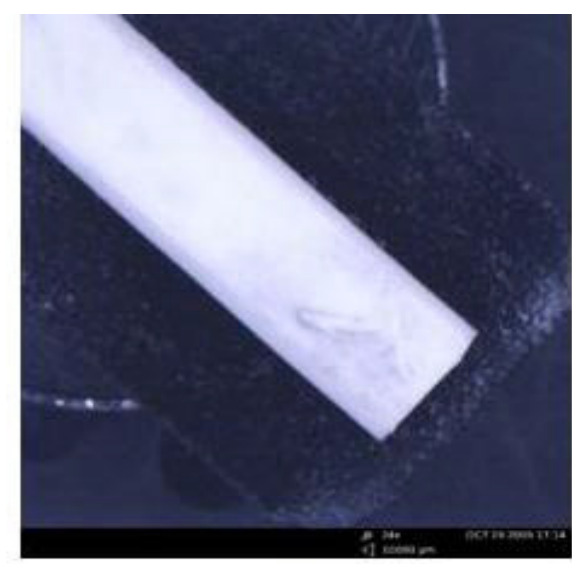

Figure 3.5(d): Chamfered sample

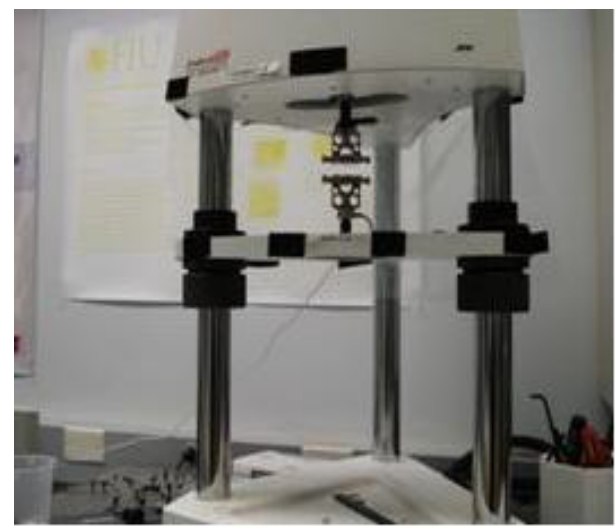

Figure 3.5(f): Endura tech machine used for testing samples 


\subsubsection{Flexural Strength Values}

After careful chamfering of the edges to $0.12 \pm 0.03 \mathrm{~mm}$ the values obtained are shown in figure 3.6 which range from 309 MPa to $377 \mathrm{MPa}$.

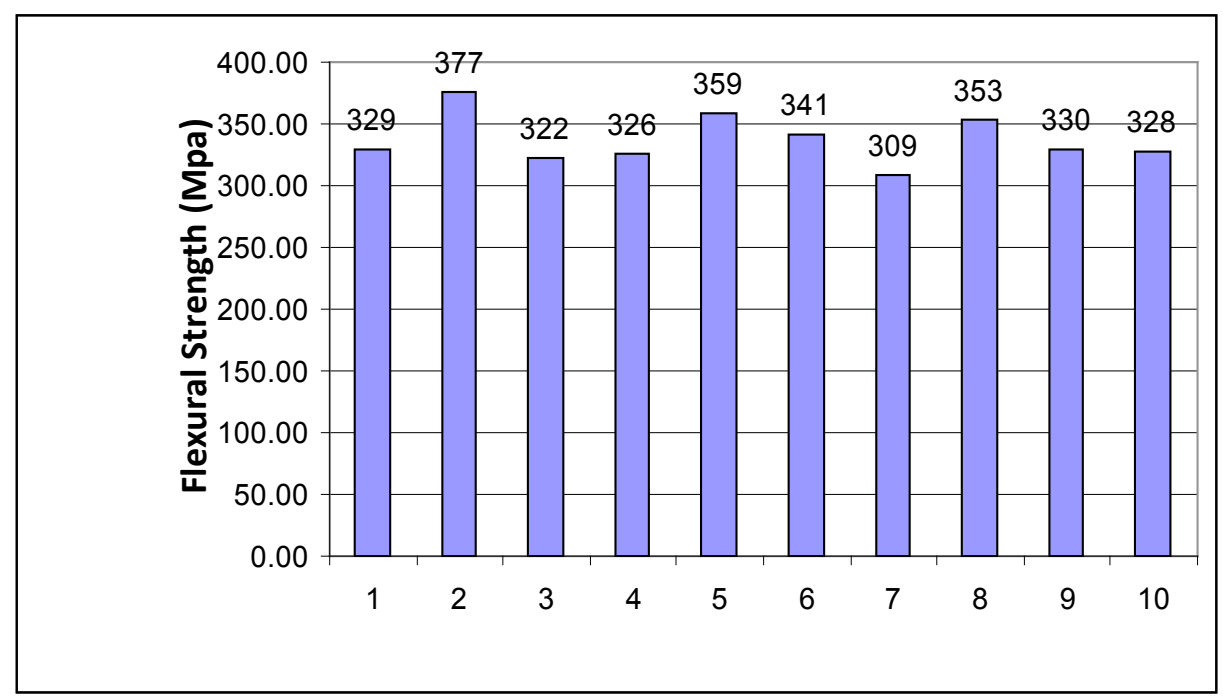

Figure 3.6: Flexural strength values of chamfered specimens tested as per ASTM C1161

Mean value of Flexural strength $=337.3 \mathrm{MPa}$; Standard deviation $=30.27 \mathrm{MPa}$.

Testing was done by ASTM C 116, test condition A, using a sample length of $25 \mathrm{~mm}$.

\subsection{Fabrication of Ceramic disk and its metallization by sputtering}

Brazing of alumina ceramic to titanium metal using a pure gold filler metal is discussed in this section. Figure 1.2 shows the binary phase diagram of gold and titanium which depicts formation of 4 intermetallic compounds namely $\mathrm{Ti}_{3} \mathrm{Au}$, $\mathrm{TiAu}, \mathrm{TiAu}_{2}$, and $\mathrm{TiAu}_{4}$. Furnace brazing which brings $\mathrm{Ti}$ and $\mathrm{Au}$ for prolonged period of time in contact would not be good for two reasons.

(1) Formation of interface layers of these intermetallic compounds thermodynamically, two of which can be predicted as brittle as they have minimal 
solid solubility. The formation of intermetallic phases has been shown by previous researchers during brazing of Ti with gold [41]. Presence of large amount of these brittle phases in the brazed joint interface is very deteriorating for the performance of brazed assembly.

(2) The second reason is gold melts at $1064{ }^{\circ} \mathrm{C}$ so the brazing temperature has to be higher than $1064{ }^{\circ} \mathrm{C}$, while Ti undergoes allotropic transformation from $\alpha(\mathrm{HCP})$ to $\beta$ (BCC) at $883{ }^{\circ} \mathrm{C}$. The grain growth in beta phase titanium is more than an order of magnitude faster than in the alpha phase. If Titanium is maintained at temperatures above the allotropic transformation temperature for a time of a few minutes in the beta phase field, then grain grows to approximately $\mathrm{mm}$ size and this causes the metal to become soft. Since furnace brazing process is slow, this effect is more prominent in furnace brazing. Brazing using faster ramps using resistance heating should be processed in less than one minute minimizes grain growth.

96\% alumina ceramic was prepared by high temperature cofired ceramic (HTCC) processing. Green tape was purchased from Maryland ceramics. HTCC exhibits $20 \% \mathrm{x}-\mathrm{y}$ shrinkage and a $12.8 \% \mathrm{z}$ axis shrinkage. The tape was 5 mils thick in green state. Ceramic disk was manufactured in a similar way as the samples for flexural strength testing. All the calculation were made considering $\mathrm{x}, \mathrm{y}$ and $\mathrm{z}$ axis shrinkage into account. After firing the disks were rough and were centreless grounded to give them a smooth lateral surface for sputtering. Centreless grounding needed a tolerance of 25 mils so the 
dimensions of as fired ceramic disks were 313 mils which yielded a 288 mils diameter ceramic disk after centreless grounding.

A picture of as fired ceramic disk and centreless grounded disk are shown in figure 3.7

(a) and 3.7 (b) respectively.

1. Centreless grinding was performed at Ferro Ceramic Inc. of Boston to 288 mils using 800 grit diamond wheel.

2. These disks were then metallized by the sputtering technique. The disks were masked with kapton to protect the vias and were prepared for the next step of sputtering the $500 \mathrm{~nm}$ thin film of $\mathrm{Nb}$ to metalize the ceramic in order to improve the wettability of ceramic towards the braze filler metal. Only approximately 5 mils in radial direction on each side of a diameter was left unprotected on one face, where sputtering needed to be done along with the lateral surface.

3. $\mathrm{Nb}$ sputtering of $500 \mathrm{~nm}$ was done at Cornell Nano Science (CNS) facility over the lateral surface and the unexposed surface on one side only. A picture of thin film sputtered masked disk is shown in the figure 3.1 (c). After sputtering the masking is removed and the disk was cleaned. 


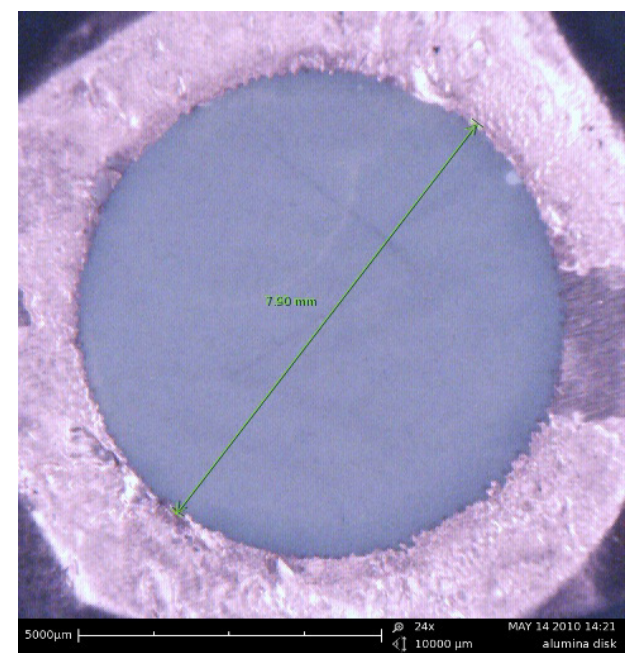

Figure 3.7(a): Fired Laser drilled ceramic Disk showing rough circumference

Since alumina ceramic is non-wetted by gold, a sputter coating of $\mathrm{Nb}$ of 500 $\mathrm{nm}$ thickness was done at Cornell Nano Science facility. $\mathrm{Nb}$ has almost same thermal conductivity as that of

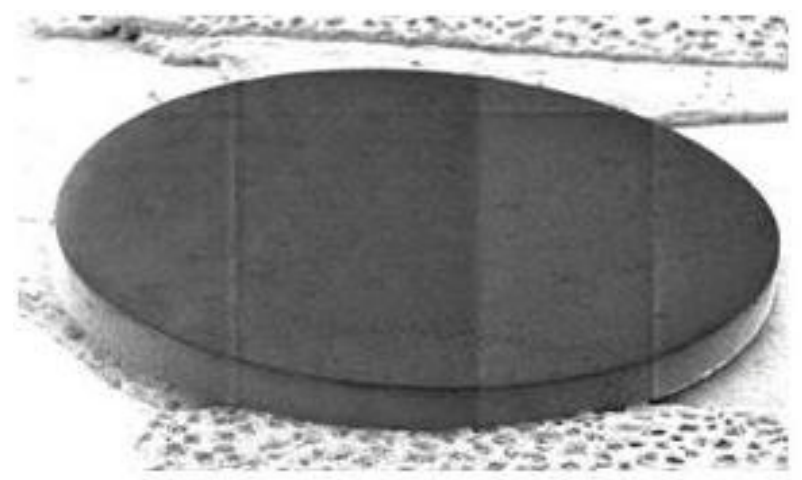

Figure 3.7 (b): Centreless grounded disk

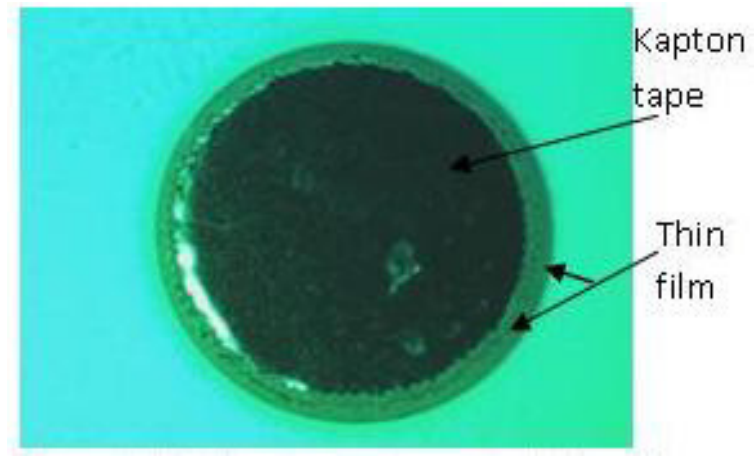

Figure 3.8: $500 \mathrm{~nm} \mathrm{Nb}$ thin film Sputtered ceramic disk with kapton masking on one face

alumina and hence there is no thermal stresses generated because of thermal mismatch between the sputtered thin film and the substrate. Also $\mathrm{Nb}$ shows the best wetting behavior towards gold (which is shown in next section) and hence chosen to metallize the ceramic

\subsection{Wetting Studies}

Wetting angle determination experiment is performed in JEOL Model JEE-4X thermal evaporator. A technique similar to sessile drop technique is utilized to determine the wetting angle of liquid gold on different surfaces. Ti, W, Ta and $\mathrm{Nb}$ electrodes were cut in the shape shown in figure 3.9. Ti electrode is different in dimensions than other 
electrodes in thickness. The Ti electrode is 20 mils thick while, $\mathrm{W}$ and Ta are 5 mils thick and $\mathrm{Nb}$ is 4 mils thick. These electrodes are heated resistively very slowly and held at all incremental values of power for 50 seconds to stabilize the temperature until the gold melts on top of these electrodes The voltage increments was 0.1 volt each time. The experiment is performed in vacuum of the order of $2 \times 10^{-3}$ Pascal. The duration the liquid gold was kept molten at these heating electrodes were 1 seconds (just when the gold melts), 30 seconds, and 90 seconds. In case of Au-Ti system an additional data point is collected at 300 seconds. For every individual time 3 samples are made. The samples were cross sectioned for further analysis to determine possible reaction at the interface and formation of Intermetallic compound (if any) which is specially critical for Au-Ti interface as the binary phase diagram dictates formation of 4 different Intermetallic compounds (IMCs). Temperature measurement is done by using a disappearing filament optical pyrometer model DFP 2000, manufactured by spectrodyne Inc. Range $1\left(760{ }^{\circ} \mathrm{C}\right.$ to $1240{ }^{\circ} \mathrm{C}$ ) was used to determine the temperature of the electrode. The manufacturer's claimed accuracy of the pyrometer for range 1 is $0.25 \%$ of reading. Ansys simulation corresponding to this electrode is shown in figure 3.9. Pure gold cylindrical samples of 99.95\% purity, of approximately $1 \mathrm{~mm}$ diameter and $1 \mathrm{~mm}$ height were cut out from a wire of $1 \mathrm{~mm}$ diameter and placed at the center of the heating elements. The pyrometer was targeted at the center of the electrode. Current and power calibrations were performed first without any gold to determine the power required to increase the temperature at the center of heating element to $1100{ }^{\circ} \mathrm{C}$. The purpose of wetting studies was to determine the best thin film for metallization of alumina ceramic as alumina ceramic does not show any wetting towards gold. In the results section angles $\theta_{1}$ and $\theta_{2}$ 
are referred as the contact angles measured at two diametrically opposite points of the solidified gold drop cross sectioned across its center.

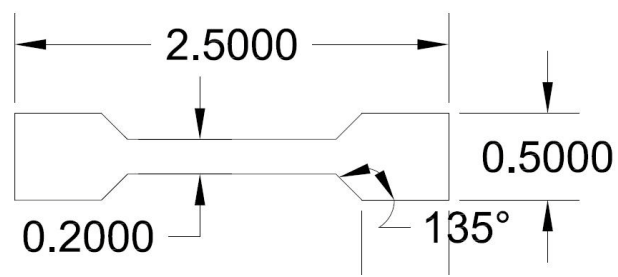

Figure 3.9: Two dimensional drawing of electrode used for wetting studies (All the dimensions are in inches).

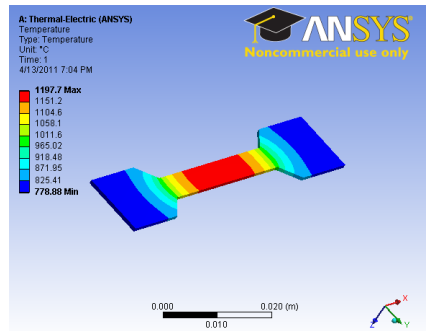

Figure 3.10: Ansys simulation of electrode used for wetting studies

\subsubsection{Au-Ti system}

Au-Ti binary phase diagram is shown in figure 1. Gold exhibit very good wetting and spreading on Ti surface as can be seen from the measured value of wetting angle shown in table 3.2 .

Table 3.2: Contact angle values of different sample for $\mathrm{Au}$ on $\mathrm{Ti}$

\begin{tabular}{|l|r|r|r|r|r|r|r|r|r|r|r|r|}
\hline & \multicolumn{2}{|l|}{$\begin{array}{l}\text { Ti-1 second- } \\
\text { sample number }\end{array}$} & \multicolumn{2}{l|}{$\begin{array}{l}\text { Ti-30 second } \\
\text { sample number }\end{array}$} & \multicolumn{2}{l|}{$\begin{array}{l}\text { Ti-90second- } \\
\text { sample number }\end{array}$} & \multicolumn{2}{l|}{$\begin{array}{l}\text { Ti-300second- } \\
\text { sample number }\end{array}$} \\
\hline & \multicolumn{1}{|c|}{$1^{\text {st }}$} & $2^{\text {nd }}$ & $3^{\text {rd }}$ & \multicolumn{1}{l|}{$1^{\text {st }}$} & $2^{\text {nd }}$ & $3^{\text {rd }}$ & $1^{\text {st }}$ & $2^{\text {nd }}$ & $3^{\text {rd }}$ & $1^{\text {st }}$ & $2^{\text {nd }}$ & $3^{\text {rd }}$ \\
\hline$\theta_{1}$ & 62 & 60 & 68 & 46 & 59 & 56 & 45 & 45 & 32 & 33 & 40 & 37 \\
\hline$\theta_{2}$ & 63 & 57 & 66 & 47 & 54 & 55 & 46 & 45 & 28 & 33 & 32 & 41 \\
\hline$\theta_{\text {(avg) }}$ & 62.5 & 58.5 & 67 & 46.5 & 56.5 & 55.5 & 45.5 & 45 & 30 & 33 & 36 & 39 \\
\hline
\end{tabular}




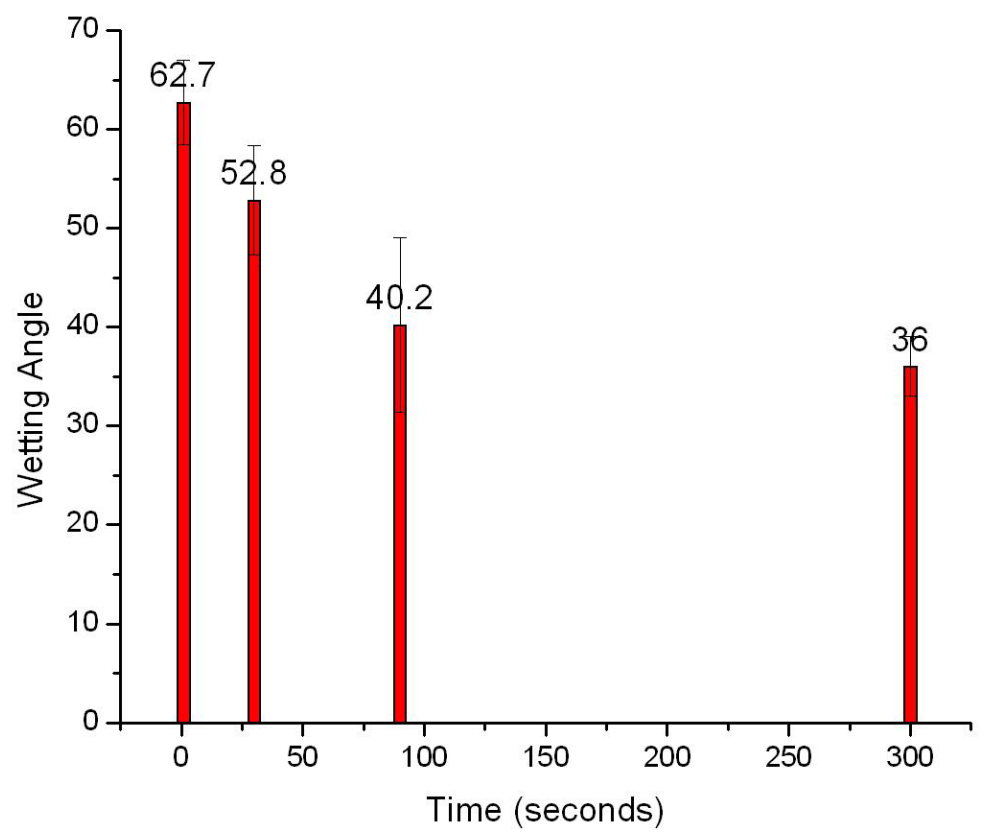

Figure 3.11: Graph showing the variation of contact angle with time at $1075 \pm 10^{\circ} \mathrm{C}$

Standard deviation for $\theta_{1}=4.25 ; \theta_{30}=5.5 ; \theta_{90}=8.8 ; \theta_{300}=3$.

SEM analysis indicates the dissolution of the substrate with time. Figure 3.14 shows the variation of the substrate dissolution with time. SEM imaging revealed fracture at the AuTi interfaces for samples in which gold and Ti interacted for 300 seconds. Figure 3.12 (e) and 3.12 (f) shows fractured interface. Figure 3.13 also shows voids formation at the interface along with complete fracture at the interface. These voids were also found in some samples in which gold interacted with Ti for a smaller period of time like for 90 seconds. The voids could be kirkendall voids in the intermetallic compounds and could have formed during the IMC formation. 


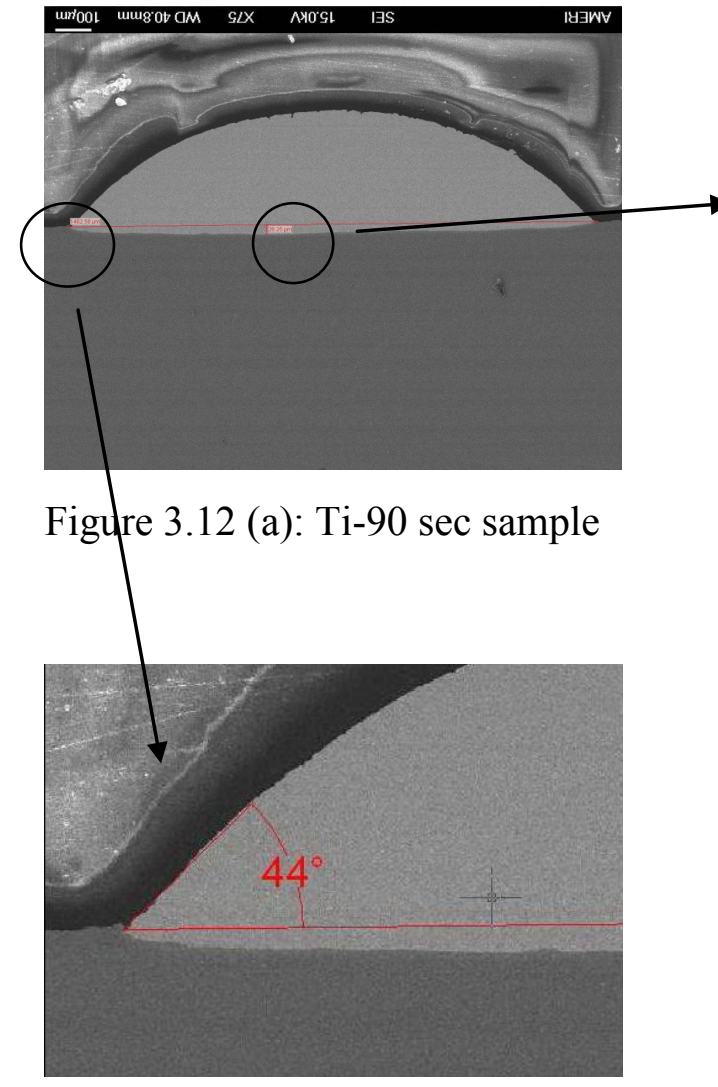

Figure 3.12 (c): Magnified view of solidified drop end showing wetting angle

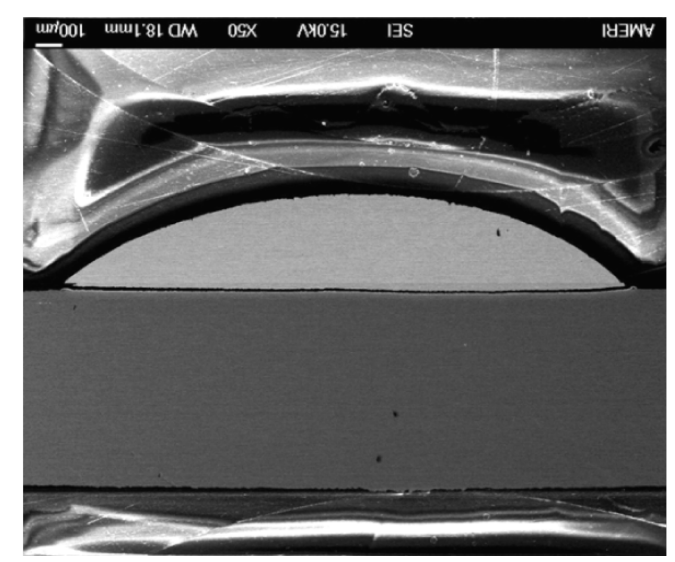

Figure 3.12 (e): T-300 sec sample showing fracture at interface

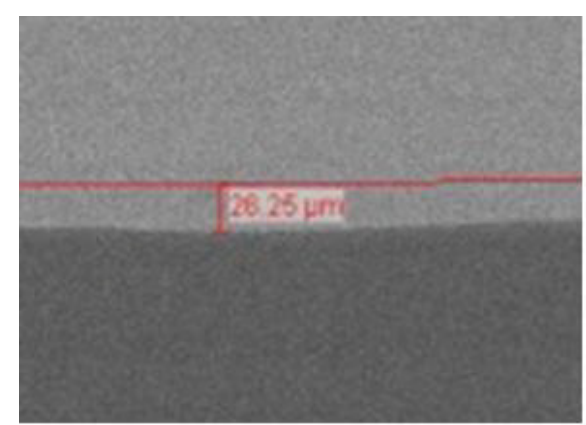

Figure 3.12 (b): Magnified view of solidified drop center showing substrate dissolution

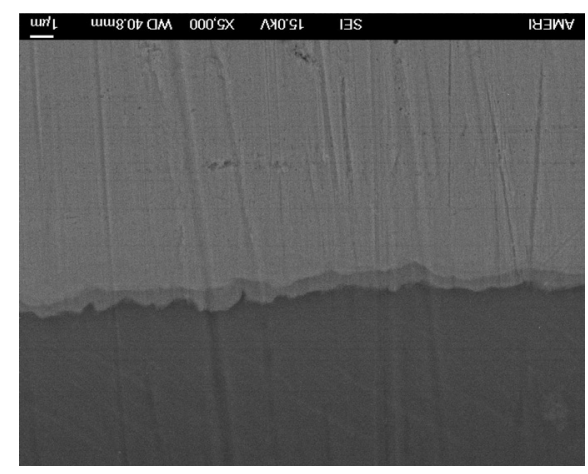

Figure 3.12 (d): Sample Ti-90 sec sample showing IMC formation

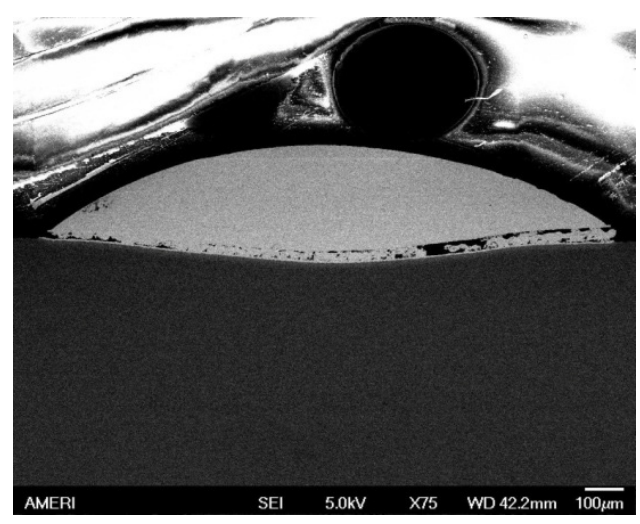

Figure 3.12 (f): T-300 sec sample showing fracture and void formation at interface 


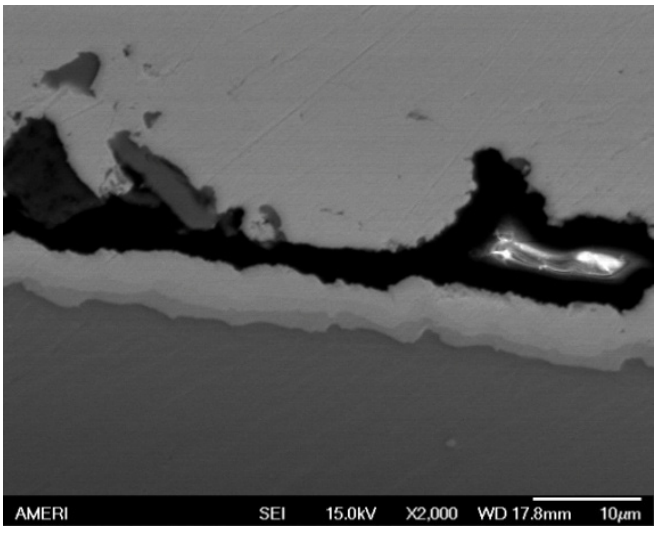

Figure 3.13: Magnified view of the circle shown in figure 3.25 (f) showing a clearer image of void formation and fracture at interface at $2000 \mathrm{X}$

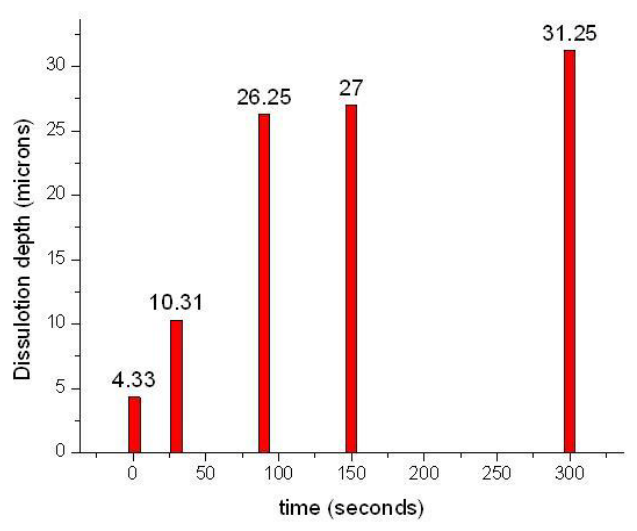

Figure 3.14: Graph showing variation of Ti substrate dissolution depth with time

\subsubsection{Au-Nb system}

$\mathrm{Au}$ shows excellent wetting towards $\mathrm{Nb}$ metal. Wetting angle drops down very rapidly from 1 second to 30 seconds and then it changes very slightly till 90 seconds.

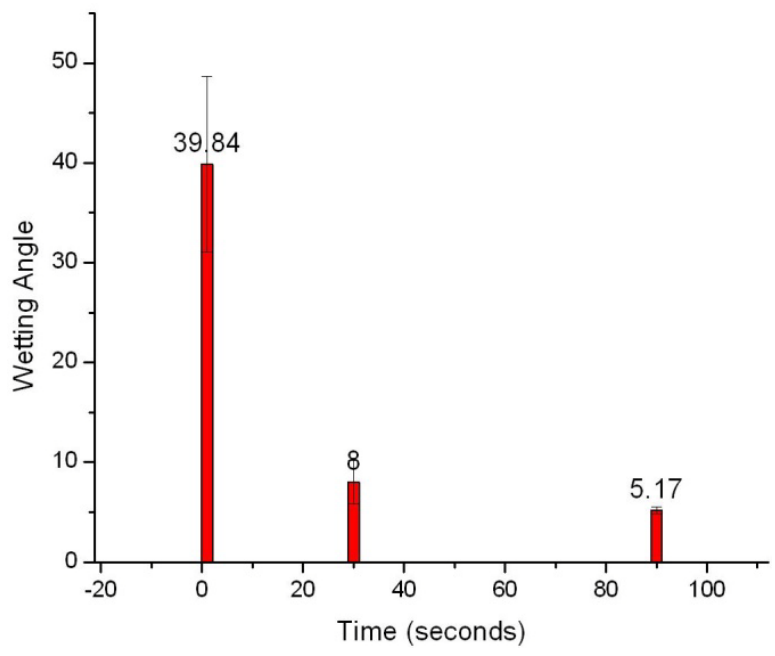

Figure 3.15: Variation of wetting angle with time of gold on $\mathrm{Nb}$ at $1090 \pm 10{ }^{\circ} \mathrm{C}$

Standard deviation for $\theta_{1}=8.81$, for $\theta_{30}=2.18$, for $\theta_{90}=0.35$. 
Table 3.3: Contact angle values of different sample for $\mathrm{Au}$ on $\mathrm{Nb}$

\begin{tabular}{|l|r|r|r|r|r|r|r|r|r|}
\hline & \multicolumn{3}{l|}{$\begin{array}{l}\text { Nb-1second-sample } \\
\text { number }\end{array}$} & \multicolumn{2}{l|}{$\begin{array}{l}\text { Nb-30 second sample } \\
\text { number }\end{array}$} & \multicolumn{2}{l|}{$\begin{array}{l}\text { Nb-90second- } \\
\text { sample number }\end{array}$} \\
\hline & $1^{\text {st }}$ & $2^{\text {nd }}$ & $3^{\text {rd }}$ & $1^{\text {st }}$ & $2^{\text {nd }}$ & $3^{\text {rd }}$ & $1^{\text {st }}$ & $2^{\text {nd }}$ & $3^{\text {rd }}$ \\
\hline$\theta_{1}$ & 43 & 36 & 34 & 7 & 5 & 13 & 7 & 5 & 4 \\
\hline$\theta_{2}$ & 57 & 34 & 35 & 7 & 8 & 8 & 5 & 6 & 4 \\
\hline$\theta_{(\text {avg })}$ & 50 & 35 & 34.5 & 7 & 6.5 & 10.5 & 6 & 5.5 & 4 \\
\hline
\end{tabular}

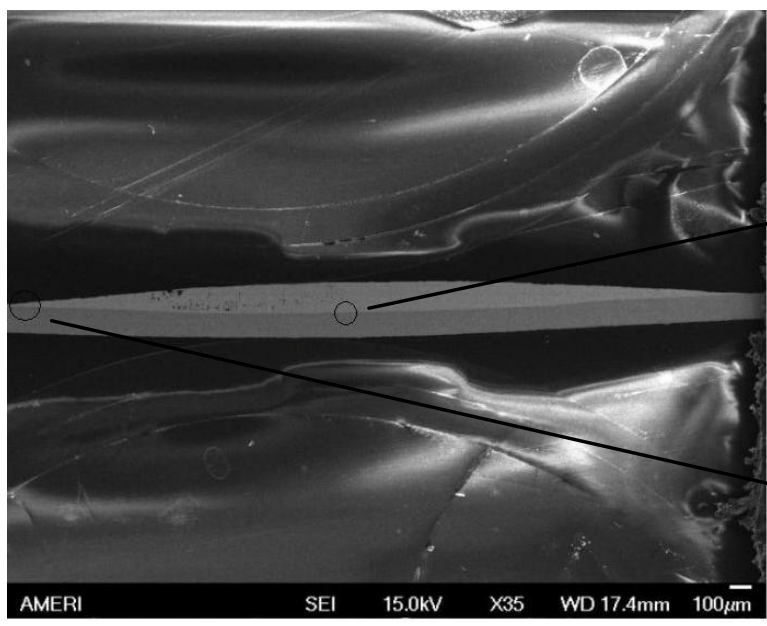

Figure 3.16(a): Sample Nb-90 seconds sample $(3 \mathrm{C} 2)$

High magnification images at the $\mathrm{Au}-\mathrm{Nb}$ also show intermediate layers as shown in figure 3.17 which are probably of the intermetallic compounds shown in the $\mathrm{Au}-\mathrm{Nb}$ binary phase diagram.

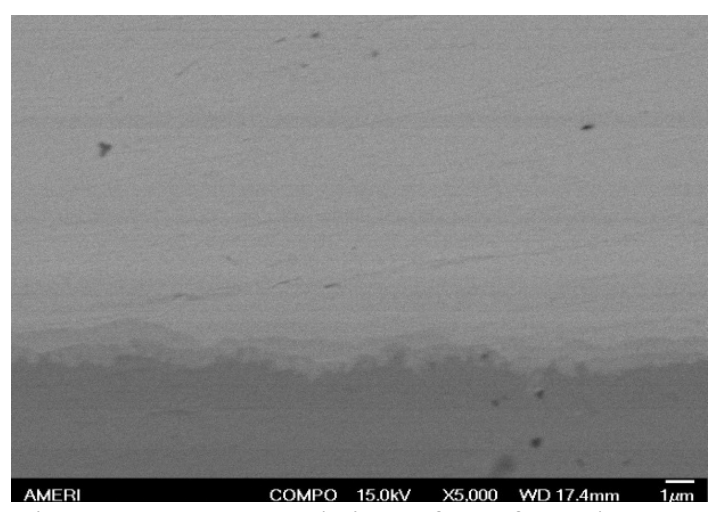

Figure 3.17: $\mathrm{Au}-\mathrm{Nb}$ interface for $\mathrm{Nb}-90$

secs sample (3C-2) at 5000X 


\subsubsection{Au-W system}

Gold does not show very good wetting towards Tungsten. Although the wetting angle decreases with time at a temperature of $1090 \pm 10{ }^{\circ} \mathrm{C}$ as shown in figure 3.18 .

Table 3.4: Wetting angle values of gold on tungsten metal at $1090 \pm 10^{\circ} \mathrm{C}$

\begin{tabular}{|l|r|r|r|r|r|r|r|r|r|}
\hline & \multicolumn{2}{|l|}{$\begin{array}{l}\text { W-1 second-sample } \\
\text { number }\end{array}$} & \multicolumn{2}{l}{$\begin{array}{l}\text { W-30 second-sample } \\
\text { number }\end{array}$} & \multicolumn{3}{l|}{$\begin{array}{l}\text { W-90 } \\
\text { sample number }\end{array}$} \\
\hline & \multicolumn{1}{|l|}{$1^{\text {st }}$} & $2^{\text {nd }}$ & $3^{\text {rd }}$ & \multicolumn{1}{l|}{$1^{\text {st }}$} & $2^{\text {nd }}$ & $3^{\text {rd }}$ & $1^{\text {st }}$ & $2^{\text {nd }}$ & $3^{\text {rd }}$ \\
\hline$\theta_{1}$ & 122 & 107 & 127 & 127 & 113 & 106 & 90 & 97 & 99 \\
\hline$\theta_{2}$ & 110 & 107 & 127 & 116 & 109 & 107 & 94 & 97 & 89 \\
\hline$\theta_{(\text {avg }}$ & 116 & 107 & 127 & 121.5 & 111 & 106.5 & 92 & 97 & 94 \\
\hline
\end{tabular}

Standard deviation for $\theta_{1}=10.02$, for $\theta_{30}=7.70$, for $\theta_{90}=2.52$

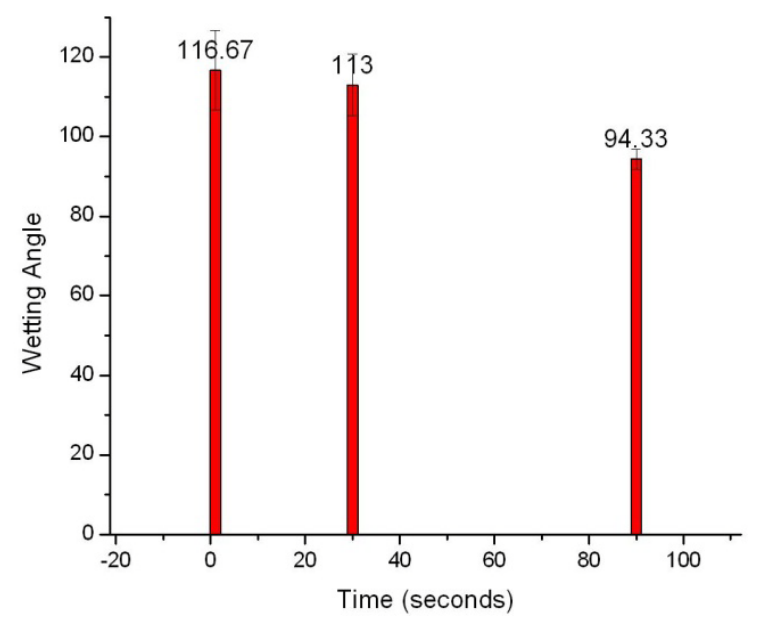

Figure 3.18: Graph showing the variation of wetting angle of gold to Tungsten with time at a contact temperature of $1090 \pm 10{ }^{\circ} \mathrm{C}$.

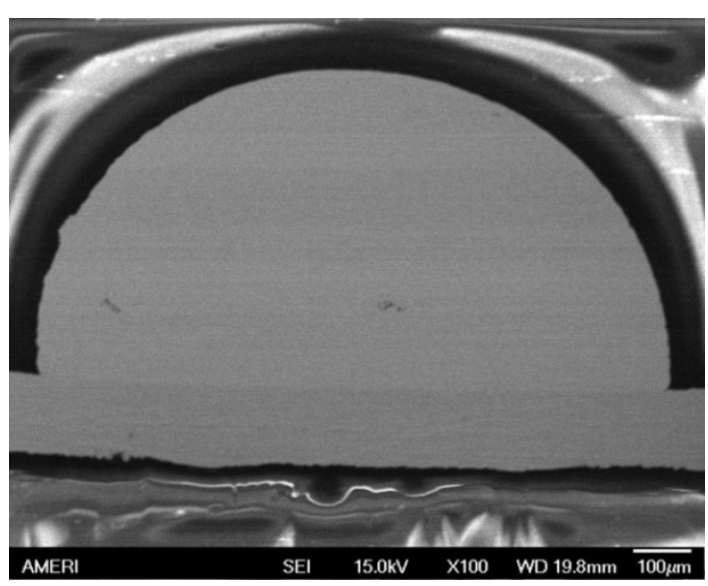

Figure 3.19: Sample number W-90 seconds sample (1C2)

\subsubsection{Au-Ta system}

Figure 3.20 shows the Au-Ta binary phase diagram [87]. 


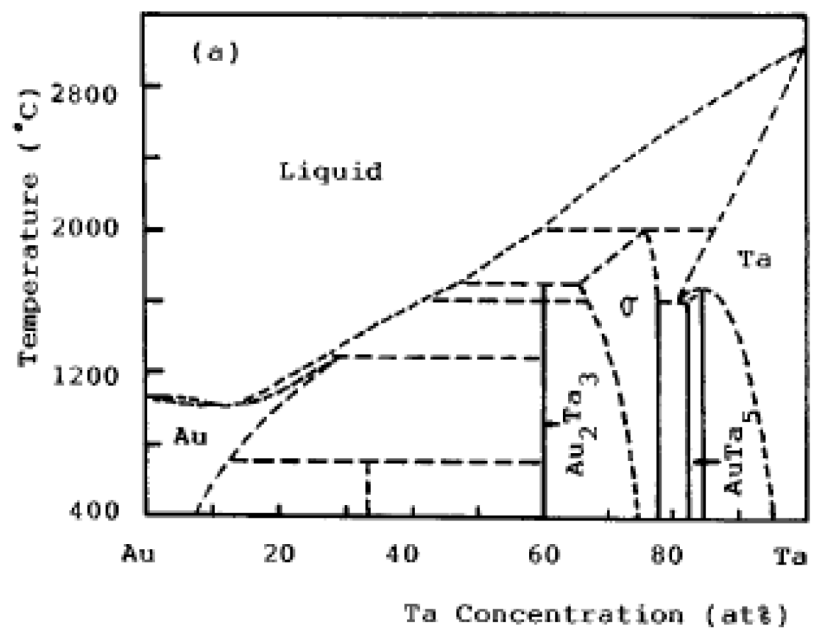

Figure 3.20: Au-Ta binary phase diagram

The wetting of liquid gold towards tantalum metal is excellent and the measured wetting angle is very low. Figure 3.21 shows an image of molten gold on Ta substrate at 1090 ${ }^{\circ} \mathrm{C}$ for a period of 90 seconds. The measured average contact angle for this sample is 12 degrees.

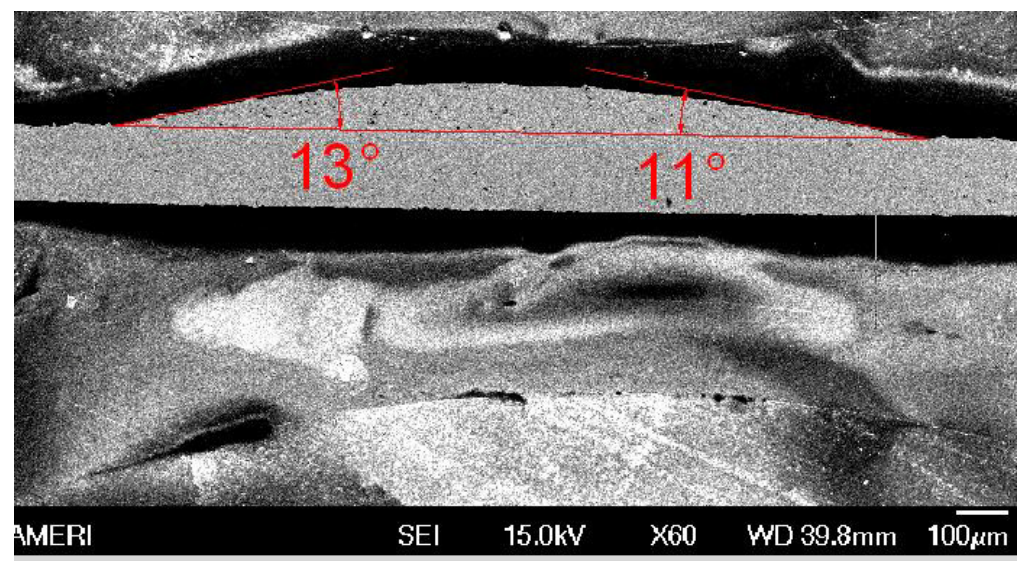

Figure 3.21: Sample number Ta-90 sec sample 


\subsection{Scratch testing of sputtered thin Nb films over alumina substrate}

Nanoscratch experiment was conducted on sputtered thin films over polished alumina ceramic using Hysitron TriboIndenter TI 900 (Hysitron Inc., Minneapolis, USA). It has a horizontal capacitive transducer for applying normal load and two vertical capacitive transducers for measuring the lateral force experienced by the indenter during scratching. The Berkovich tip used for scratch testing the samples is in the form of a triangular pyramid with total included angle of 142.3 degrees and the radius of curvature of tip is $100 \mathrm{~nm}$. Thin film of $\mathrm{Nb}$ metals of thicknesses $60 \mathrm{~nm}$ (sample number 5A) and $540 \mathrm{~nm}$ (sample number 5B) were sputtered in Cornel Nanoscience facility. Alumina disks of roughly $8 \mathrm{~mm}$ in diameter and roughly $1.5 \mathrm{~mm}$ in thickness were polished before sputtering and their surface roughness was measured by using optical profilometery. The polishing sequence that was followed to polish alumina ceramic disk is first 9 microns diamond suspension was used and was subsequently polished by 1 microns diamond suspension on cloth with manual polishing at a speed of $250 \mathrm{rpm}$. The polishing was done at each step for 15 minutes. A total of 5 reading were taken for each disks to find the average value of surface roughness as shown in table 3.4 below.

Table 3.5: Surface roughness measured by optical profilometery for samples 5A and 5B

\begin{tabular}{|l|c|c|}
\hline Roughness at & 5A & 5B \\
\hline & $\mathrm{Ra}(\mathrm{nm})$ & $\mathrm{Ra}(\mathrm{nm})$ \\
\hline Point 1 & 315 & 313 \\
\hline Point 2 & 277 & 320 \\
\hline Point 3 & 308 & 306 \\
\hline Point 4 & 299 & 294 \\
\hline Point 5 & 310 & 298 \\
\hline & & \\
Average & 302 & 306 \\
\hline
\end{tabular}


A picture of sputtered alumina disk is shown in figure 3.22.

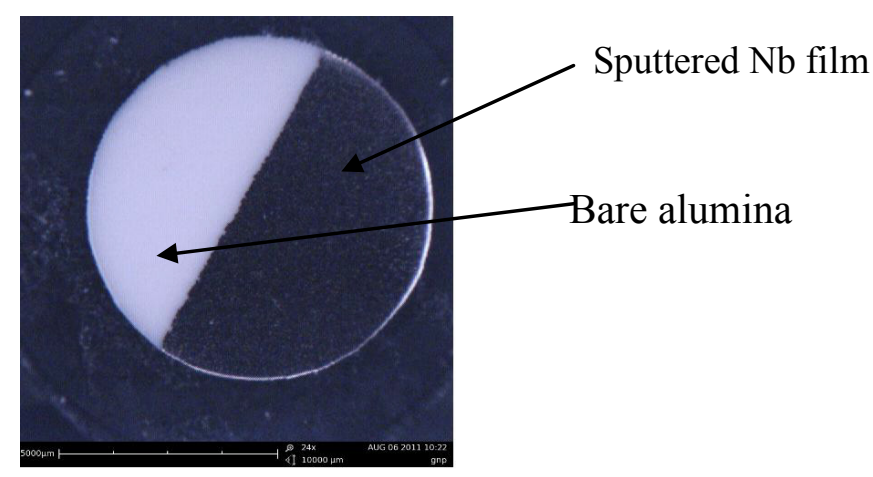

Figure 3.22: Scratch test disk with $\mathrm{Nb}$ sputtering and some bare alumina regions

Some area of the sample was masked to produce a bare surface. Scratched of lengths of 15 microns were made at across the interface. The vertical force was kept constant at $8000 \mu \mathrm{N}$. After the load has reached the set value, the indenter starts scratching the sample at a speed of $0.5 \mu \mathrm{m}$ per second. When the scratch length has reached $15 \mu \mathrm{m}$, the load is released. Figure 3.24 shows the lateral force vs. displacement plot corresponding to scratch 3 on disk $5 \mathrm{~A}$ of scratch tests performed at samples $5 \mathrm{~A}$ and $5 \mathrm{~B}$. The formula used to determine the adhesion strength is as follows:

Adhesion strength=Maximum lateral force for delamination/area at delamination

$\mathrm{Y}=8 \mathrm{X}$ depth of indenter into the sample at

$\begin{array}{lll}\text { delamination }=8 * \mathrm{x} & \begin{array}{l}\text { Depth of indenter tip into the } \\ \text { sample at delamination }=\mathrm{X}\end{array} & \begin{array}{l}\text { Figure } \\ \text { sectional } \\ \text { scratch }\end{array}\end{array}$

Considering that the tip has conoshpherical geometry

Lateral surface area of a cone $=\pi \mathrm{rl}$

Where, $r=$ radius of cone, $1=$ slant height of cone, and $1^{2}=r^{2}+h^{2}$, Where $h=$ vertical 
height of cone, in the present case. $r=\left(\frac{Y}{2}\right)=4 \mathrm{x}$ and, $1^{2}=\mathrm{r}^{2}+\mathrm{h}^{2}=(4 \mathrm{x})^{2}+\mathrm{x}^{2}=17 \mathrm{x}^{2}$

Lateral surface area of a cone $=\pi \mathrm{rl}=\pi^{*} 4 \mathrm{x}^{2} *(17)^{1 / 2}=51.78 \pi \mathrm{x}^{2}$

Area at delamination that would be use in equation (1) would be half of this area.

Area $=\left(\frac{1}{2}\right) * 51.78 \pi \mathrm{x}^{2}=25.89 \mathrm{x}^{2}$

Table 3.6 shows adhesion strengths values obtained for samples 5A. Sample 5B did not yield any predictable values for adhesion strengths.

Table 3.6: Adhesion strengths for sample 5A

\begin{tabular}{|r|rr|l|l|l|}
\hline $\begin{array}{l}\text { Scratch } \\
\text { number }\end{array}$ & \multicolumn{2}{|l|}{$\begin{array}{l}\text { Indenter tip depth at } \\
\text { the point of } \\
\text { delamination }\end{array}$} & $\begin{array}{l}\text { Lateral area } \\
\text { (denominator in } \\
\text { equation 15) }\end{array}$ & $\begin{array}{l}\text { Lateral force } \\
\text { for } \\
\text { delamination }\end{array}$ & $\begin{array}{l}\text { Adhesion } \\
\text { strength } \\
\text { (MPa) }\end{array}$ \\
\hline 2 & 308 & 2456029 & 1550 & 631 \\
\hline 3 & 177 & 811108 & 1950 & 2404 \\
\hline 4 & 182 & 857580 & 1450 & 1691 \\
\hline
\end{tabular}

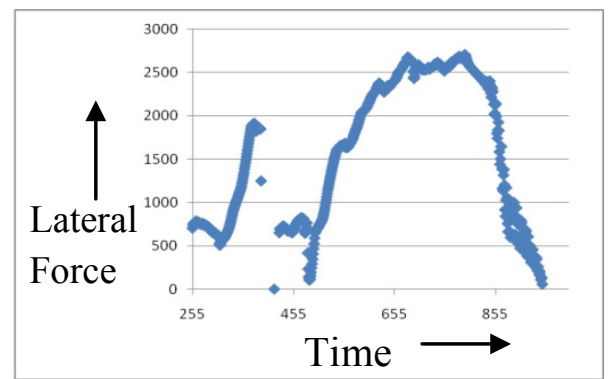

Figure 3.24: Lateral force $(\mu \mathrm{N})$ vs. Lateral Displacement

Figure 3.25 shows an image of coating measured by SPM. The sputtered film has variation in thickness of the coating and hence the variation in the delamination force is observed. 


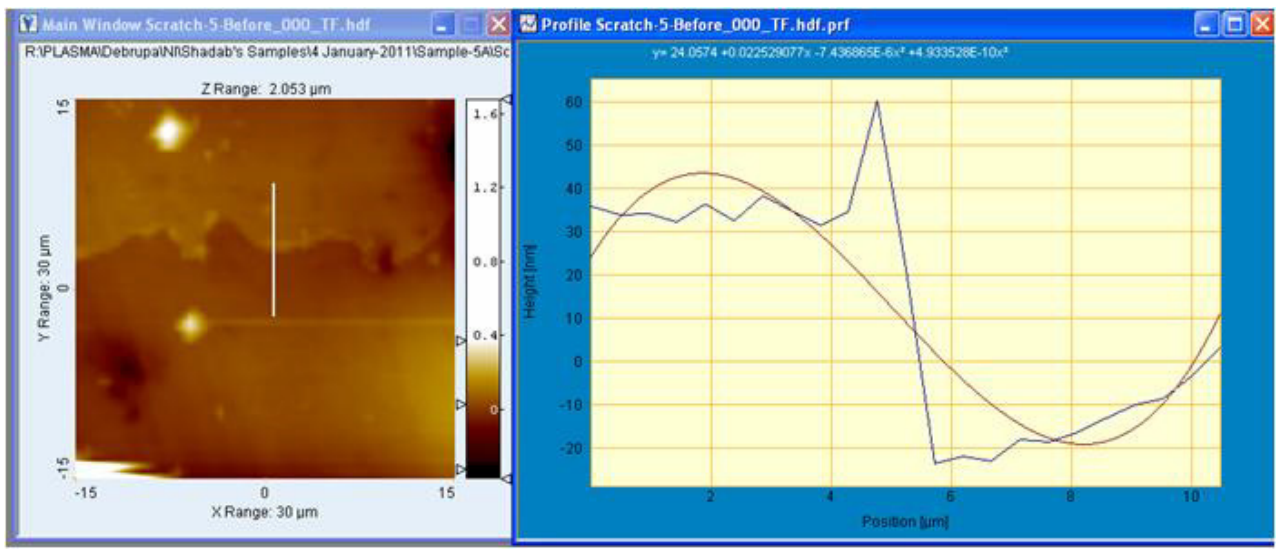

Figure 3.25: Thickness profile measured by SPM attached with the nanoindentor for sample 5A

Discussion: The large variation in the adhesion strength could be attributed to two reasons.

1. There is variation in the thickness of coating at different places.

2. The surface of the alumina substrate is not perfectly smooth and the scratch was penetrating the coating, changing the adhesion strength.

\subsection{Braze Development}

Figure 3.26 shows the experimental setup of JEOL JEE-4X model thermal evaporator used for brazing the ceramic disk to the Ti ferrule. The experiment is performed under high vacuum of $3 \times 10^{-4}$ Pascal to avoid any formation of oxides of Ti. Ti ferrule, 99.99\% pure gold perform and Ta electrode are shown in picture 3.27 (a), 3.27 (b) and 3.27 (c) respectively. 


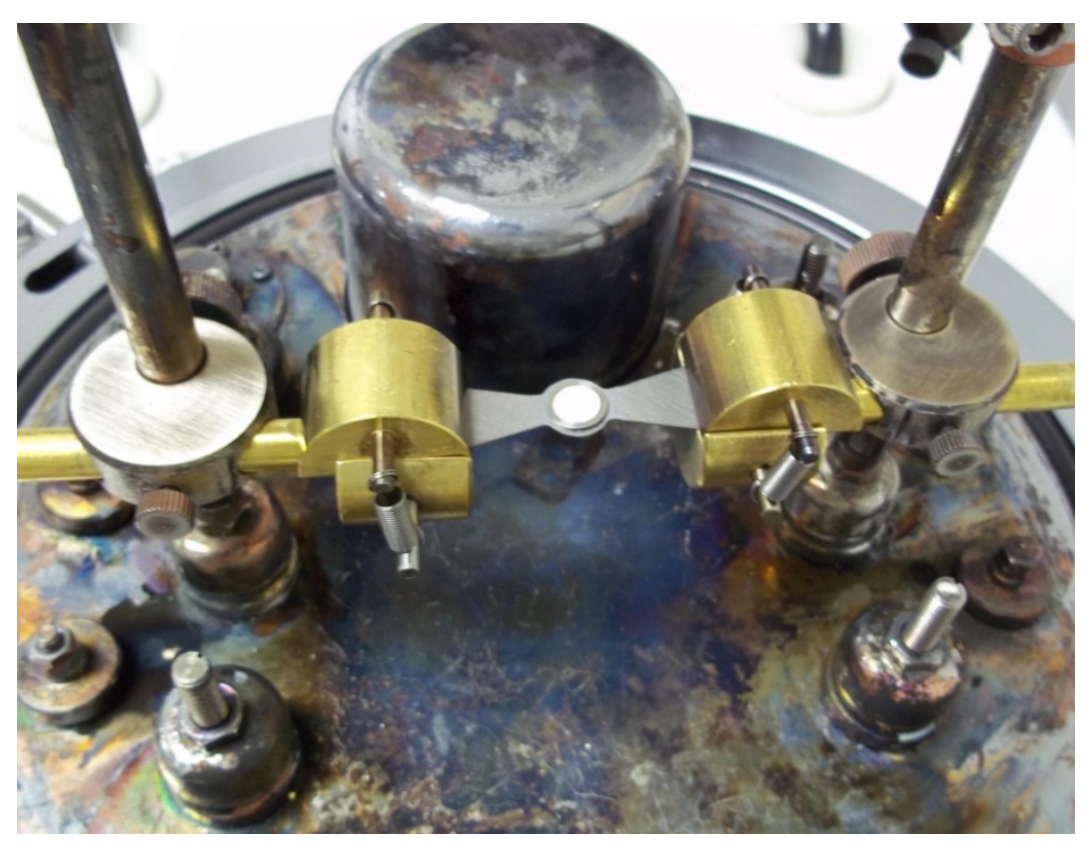

Figure 3.26: JEOL model JEE-4X Thermal evaporator with the Ta electrode and parts to be brazed arranged before brazing

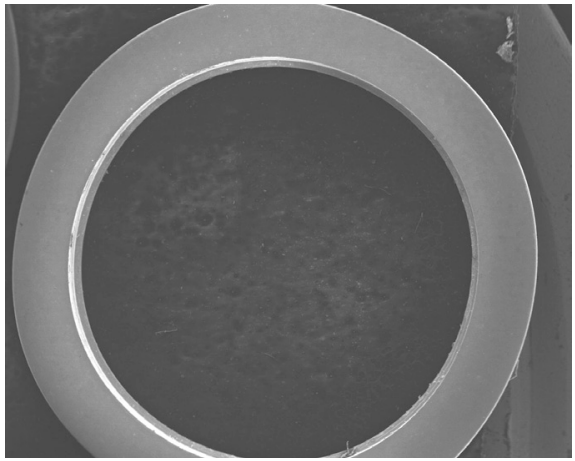

Figure 3.27: (a)

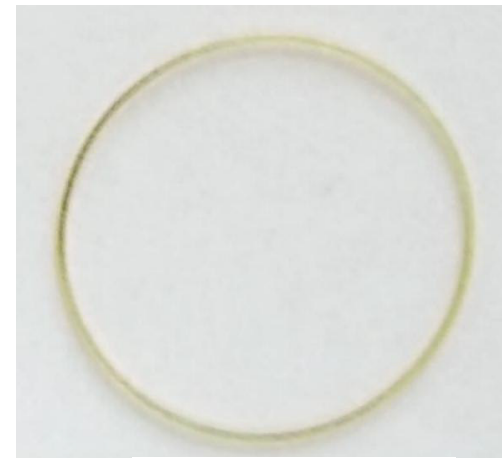

Figure 3.27: (b)

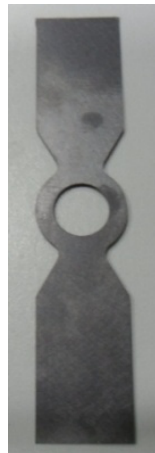

Figure 3.27: (c)

Figure 3.27: (a) Top view of the Ti ferrule (b) $99.99 \%$ pure gold perform (c) Ta electrode used for brazing

The top, bottom and cross sectional view of Ti ferrule drawing are shown in figure 3.28. 

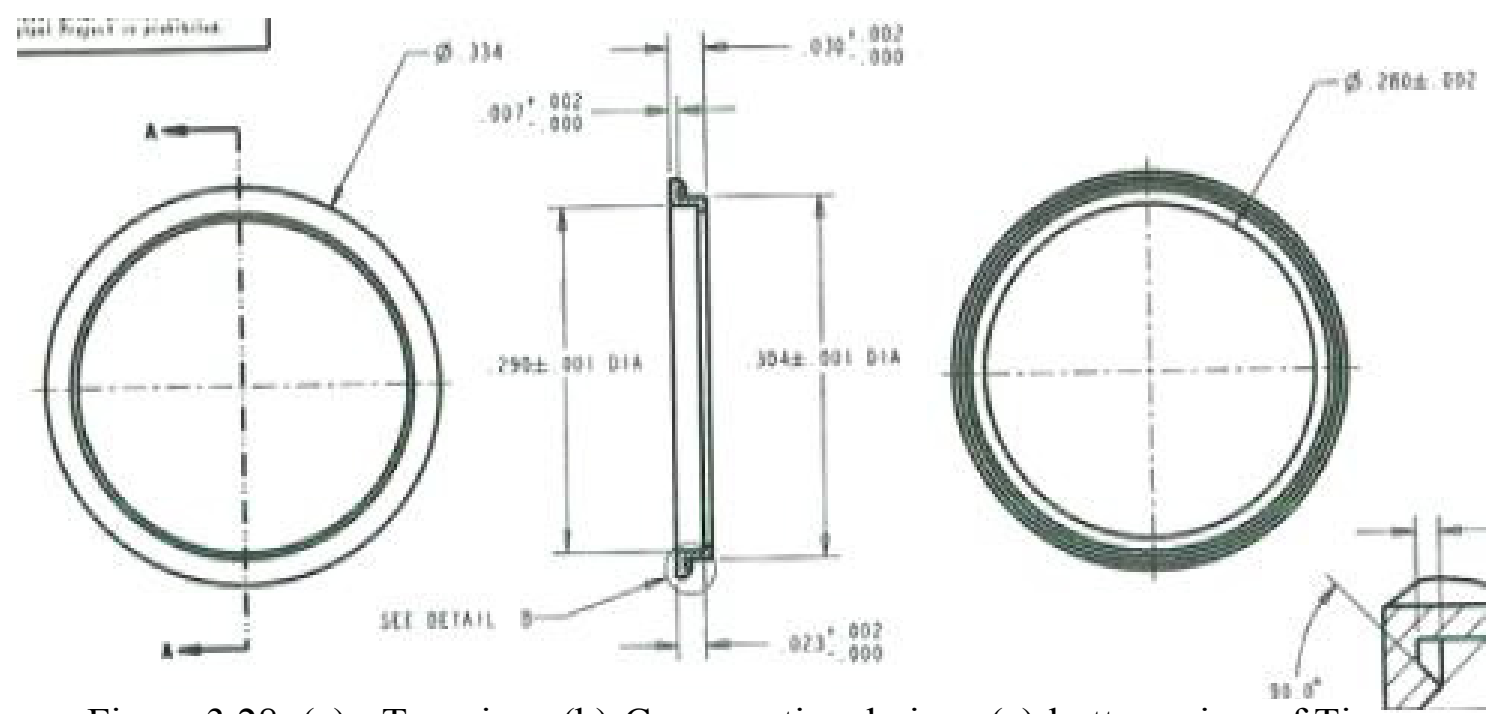

Figure 3.28: (a) - Top view, (b)-Cross sectional view, (c)-bottom view of Ti ferrule shown in figure 3.27 (a)

The recess in Ti ferrule has inner diameter of 290 mils as can be seen in figure 3.28 (b), and the outer diameter of ceramic disk is 288 mils. So effectively there is a gap of 1 mil radially on both sides along any diameter. Gold perform wicks up in the gap between the ceramic disk and the Ti ferrule due to capillary action when melting occurs.

The dimensions of pure gold perform shown in figure 3.27 (b) is as follows:

Outer Diameter $=287$ mils; Inner Diameter $=264$ mils; Thickness $=10$ mils

Before brazing all the parts going to be brazed are ultrasonically cleaned in 3 step cleaning by isopropanol, methanol and acetone in the same order for 5 minutes at each step. The parts are dried and then the pure gold perform was placed in the hole of $\mathrm{Ti}$ ferrule, resting on the lip of the ferrule. Then the thin film $\mathrm{Nb}$ coated alumina ceramic disk was placed over the gold perform and pressed to make intimate contact. The unbrazed assembly is placed inside the hole of Ta electrode. An image of Ta electrode is shown in figure 3.27 (c). Ta electrode was machined out of a Ta sheet of 5 mils thickness. The hole at the center of the Ta electrode is 305 mils in diameter. This 
unbrazed assembly was connected between the two vertical posts inside the thermal evaporator. Electrical connections were made specially designed spring mechanism based clamps as shown in figure 3.26. The thermal evaporator was connected with an external DC power supply to control the power input using lab view software. Temperature measurements for the temperature rise and fall of the Ta electrode were made using a $\mathrm{R}$ type thermocouple. The tip of thermo couple was coated with high temperature alumina glue and was cured at $450{ }^{\circ} \mathrm{C}$ for 4 hours. This coating is required to avoid electrical connection between the Ta electrode and thermocouple. Figure 3.29 shows the experimental setup of the temperature measurement for the Ta electrode, and figure 3.30 (a) through 3.30 (d) shows the data obtained were plotted with time using lab view software.

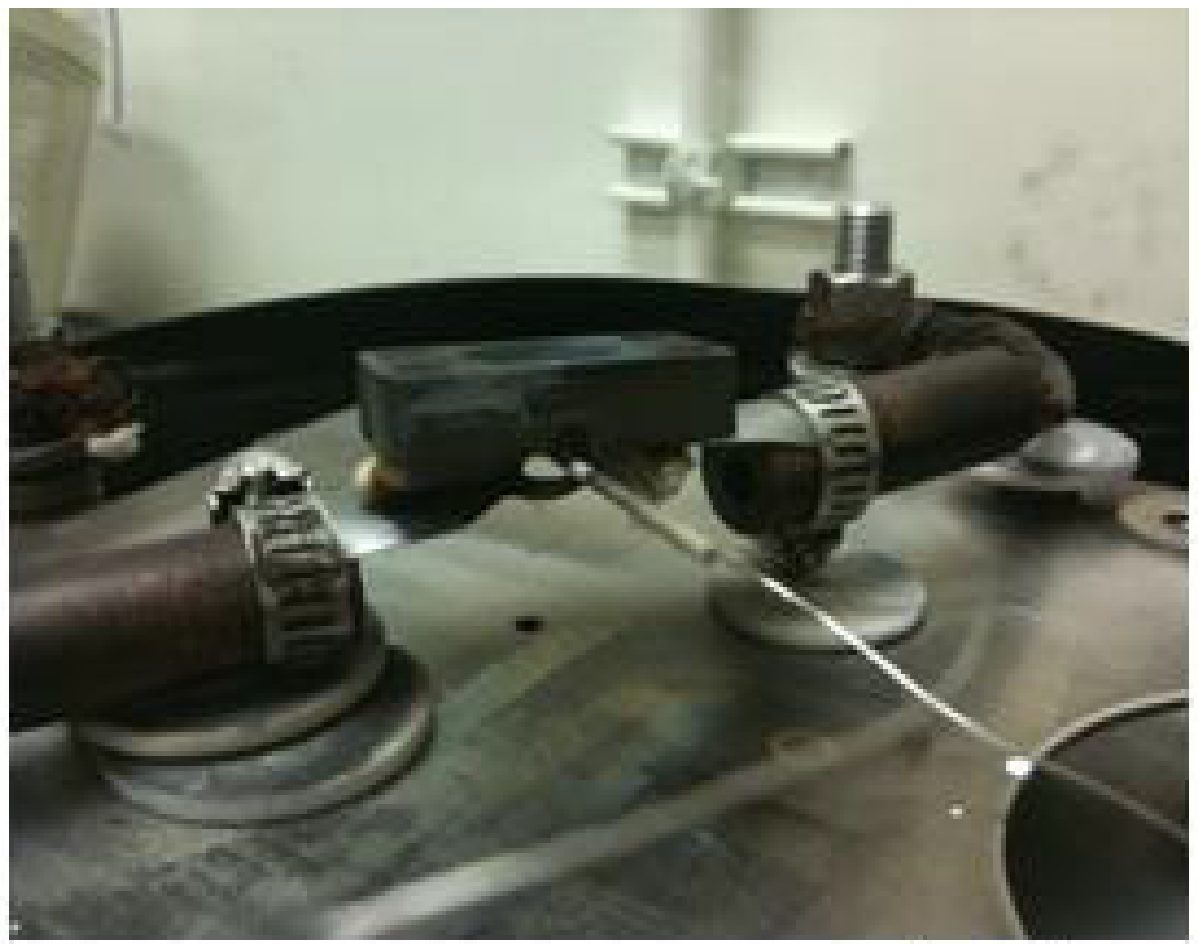

Figure 3.29: Temperature measurement setup of the Ta electrode 


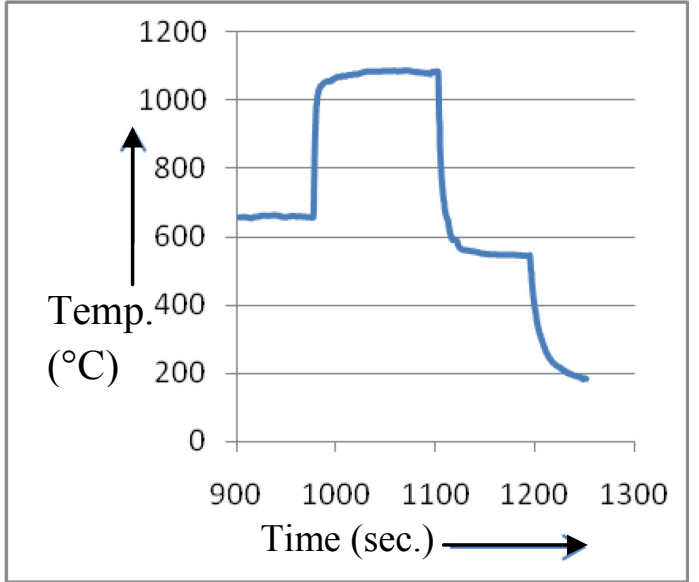

Figure 3.30 (a): Temperature vs. time plot

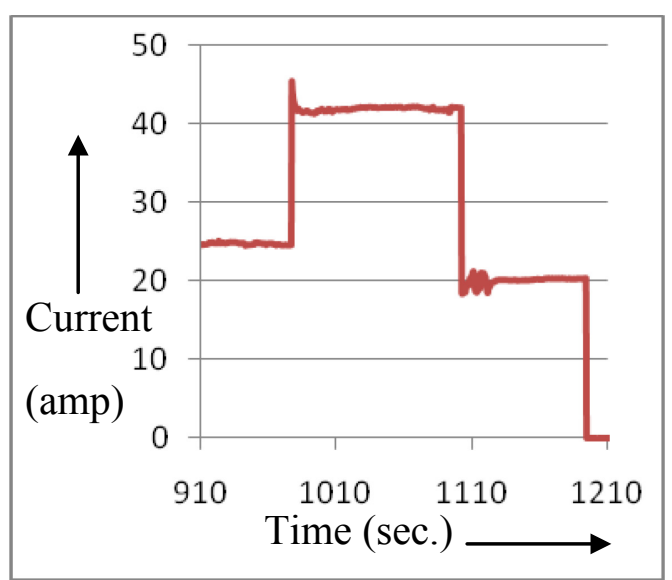

Figure 3.30 (c): Current vs. time plot

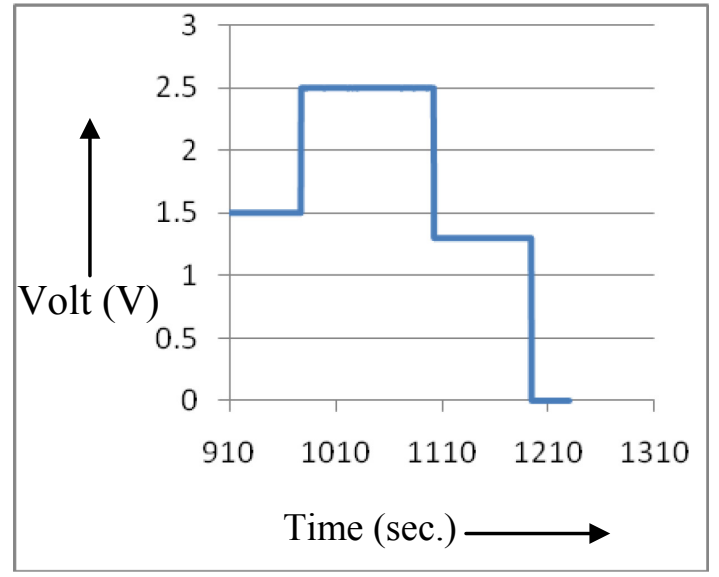

Figure $3.30(\mathrm{~b})$ : Voltage vs. time plot

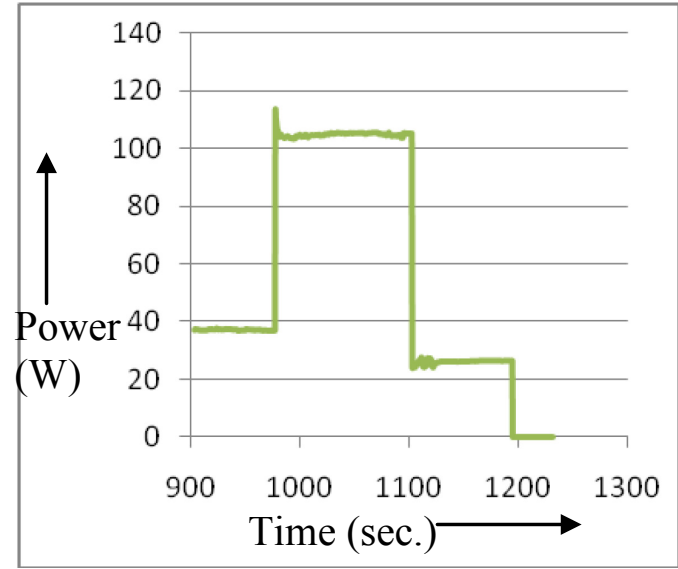

Figure $3.30(\mathrm{~d})$ : Power vs. time plot

After the cycle is complete and brazing is done, the sample and the Ta electrode is allowed to cool down. The bell jar is vented and sample is removed from the system. Figure 3.31 (a) and 3.31 (b) shows front and back side of a brazed assembly. 


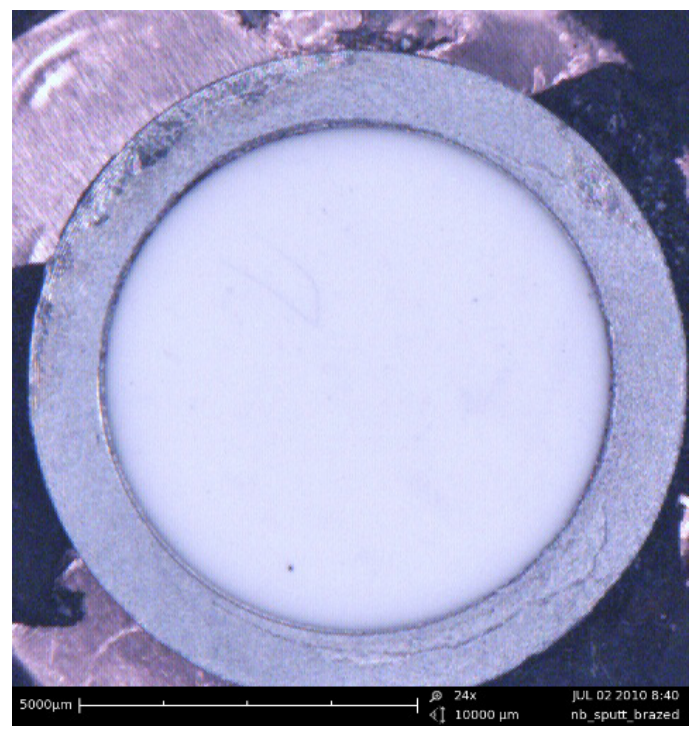

Figure 3.31 (a): Front side of the brazed assembly

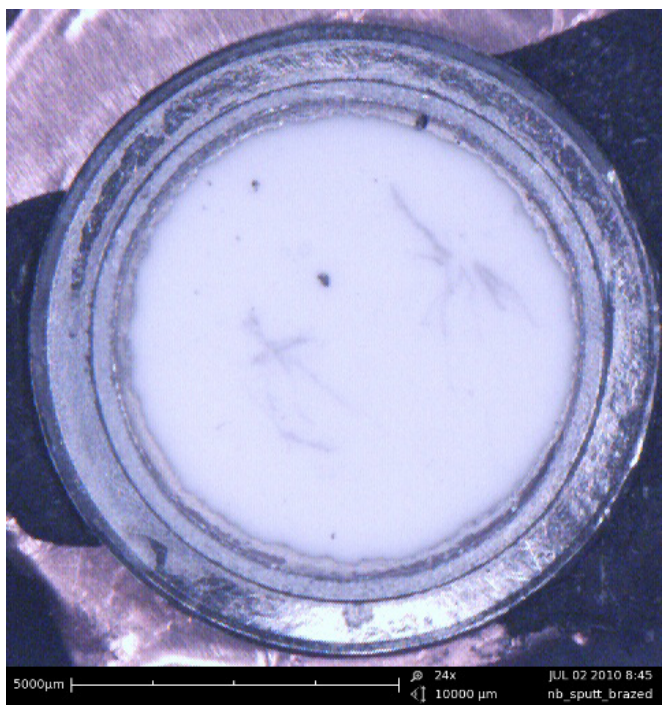

Figure 3.31 (b): Back side of the brazed assembly

The brazed assemblies were tested for hermeticity discussed in section 3.6.

The brazed samples were cross sectioned using diamond wafering blade for further analysis. Figure below 3.32 (a) and 3.32 (b) shows a picture of the sectioned sample viewed through SEM showing the gold/titanium and gold/Nb/Alumina interfaces in later image.

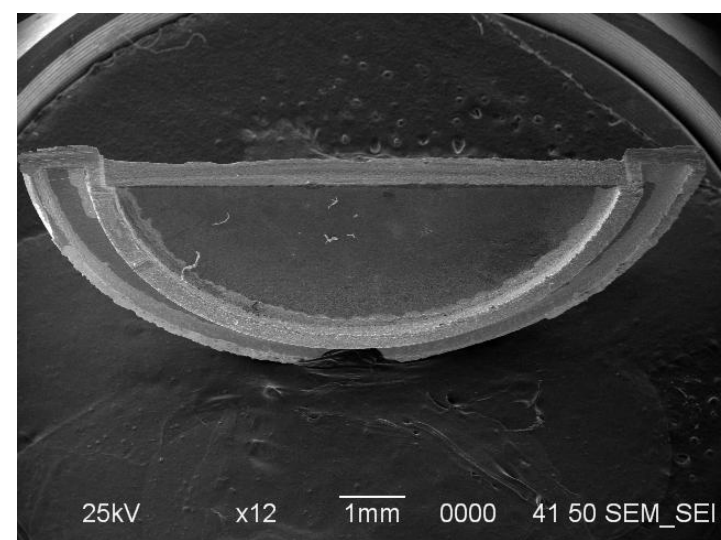

Figure 3.32(a): Cross Sectioned brazed assembly

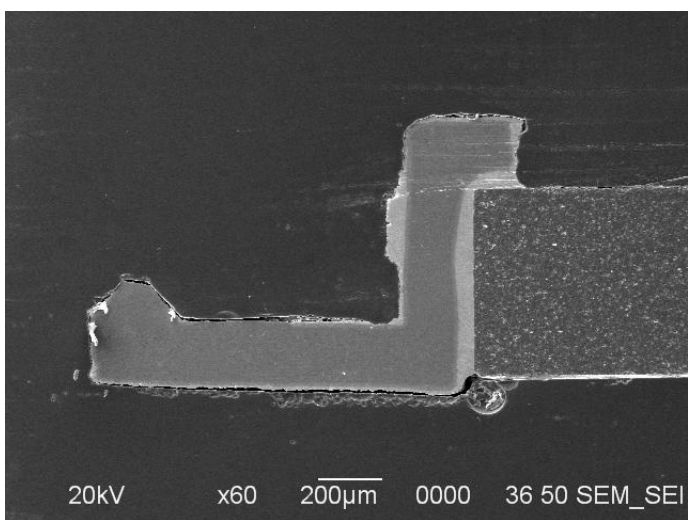

Figure 3.32 (b): Au-Ti interface

Observing the gold/Ti interface in the backscattered compositional mode of SEM, two intermetallic compounds formation in figure 3.33 (a) can be seen, although when Focused 
Ion Beam (FIB) analysis of thin $\mathrm{Au}$-Ti interface was done all the four intermetallic compounds where detected at the interface.

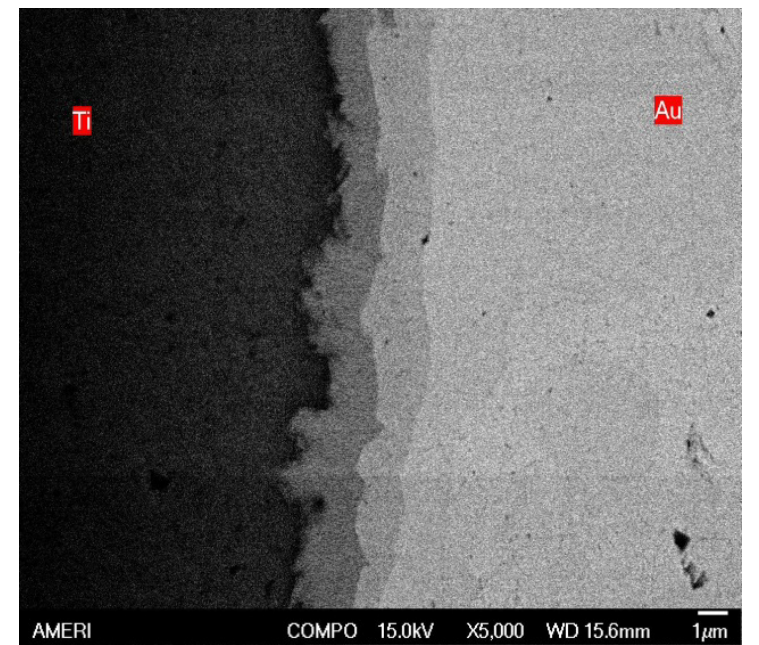

Figure 3.33 (a): BSC image showing

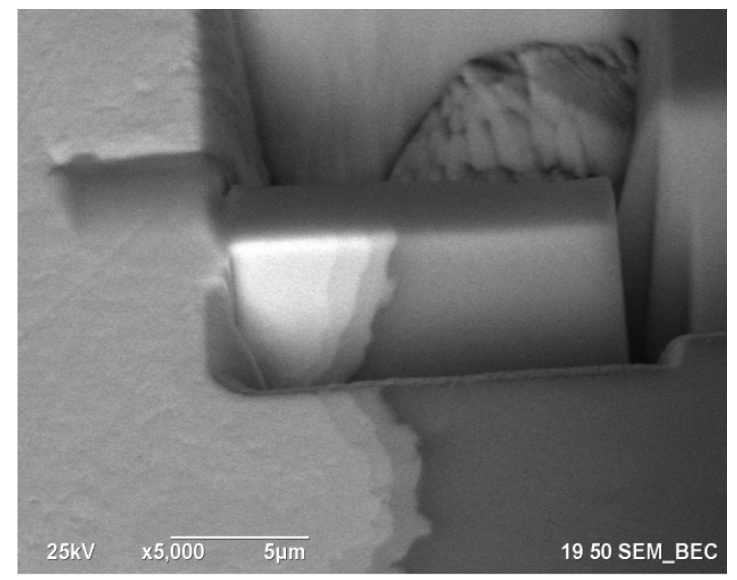

Figure 3.33 (b): FIB extracted sample showing Au-Ti interface

Au-Ti interface at 5000X

\subsection{EDX Analysis of the brazed samples for Au-Ti interface}

For the present study for developing a biocompatible feedthrough brazing assembly of alumina ceramic to alumina, the Au-Ti interface is most critical because of formation of 4 different Intermetallic compounds between gold and Titanium. Out of these 4 IMCs, two should be brittle as they do not show any solid solubility as per the Au-Ti binary phase diagram in figure 1. FIB technique was utilized to extract a thin lamella of less than 100 $\mathrm{nm}$ and EDX technique was done on this lamella to avoid spreading of the electron beam and to avoid the effect of mixing of signals in the results. Figure 3.34 (a) through 3.34 (e) shows the Au-Ti interface for the thin lamella and the EDX data obtained from the point and shoot feature of the machine. FIB extracted samples showed very clear interlayers forming at the Au-Ti interface. 


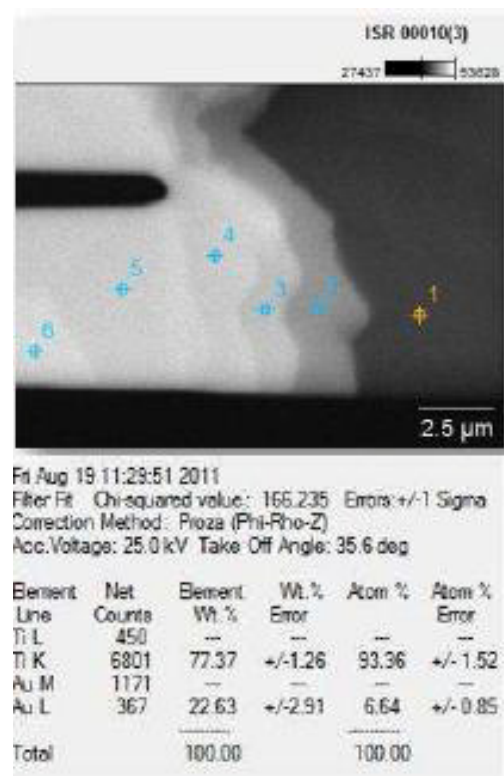

Figure 3.34 (a)

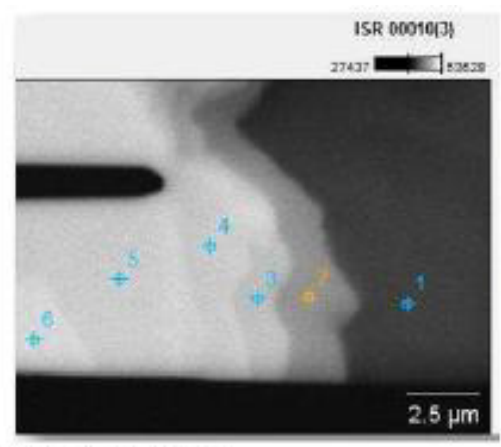

Fii Aug $1912: 14: 342011$

Fiter Fe Ch-gquared valug: 112366 Emora:ti-1 Sigma Correction Methed: Prozs (Pri-tho-2) Acc Votage: 25 okV Take OH Ande: 35.6 deg

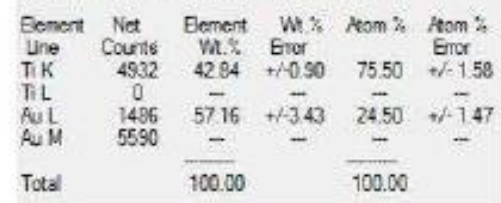

Figure $3.34(b)$

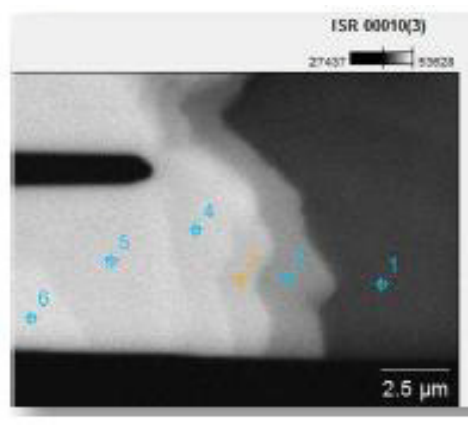

Fri Aug 19 12:15:102011

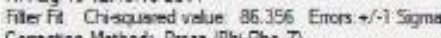
rons (Phi.Pho.Z)

Acc.Votage: 25.0kV Take Off Angle: 35.6 den

Bersent Net Benert $m . z$ Rom $\%$. Atom $z$ Ine Caurts Wis: Enor Ror

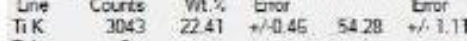

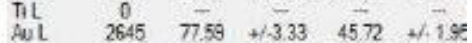
Au M 9316 Tota

\section{Figure $3.34(\mathrm{c})$}

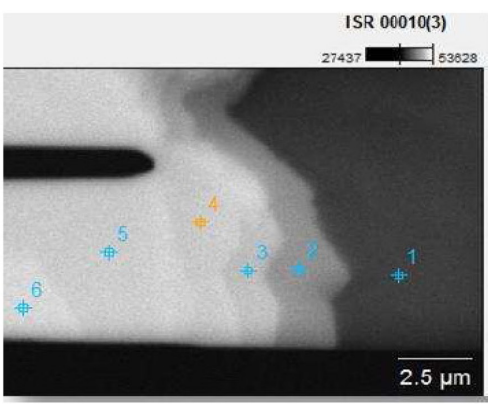

Fri Aug 19 12:15:44 2011

Fitter ft Chisquared value: 85.127 Erors: $+/-1$ Sigma

Acc. Votage: $25.0 \mathrm{kV}$ Take Off Angle: $35.6 \mathrm{deg}$

\begin{tabular}{|c|c|c|c|c|c|}
\hline $\begin{array}{l}\text { lement } \\
\text { Line } \\
\text { in K }\end{array}$ & $\begin{array}{l}\text { Net } \\
\text { Counts } \\
1494\end{array}$ & $\begin{array}{c}\text { Bement } \\
\text { Wt.\% } \\
11.57\end{array}$ & $\begin{array}{l}\text { Wt.\% } \\
\text { Enror } \\
+1-0.38\end{array}$ & Atom \% & $\begin{array}{l}\text { Atom \% } \\
\text { Error } \\
+/-1.15\end{array}$ \\
\hline & $\begin{array}{c}0 \\
3017\end{array}$ & $\overline{88.43}$ & $+\overline{-3.53}$ & $\overline{65.03}$ & $+1-2.59$ \\
\hline & 11171 & - & - & - & \\
\hline & & 0 & & 100.00 & \\
\hline
\end{tabular}

Figure 3.34 (d)

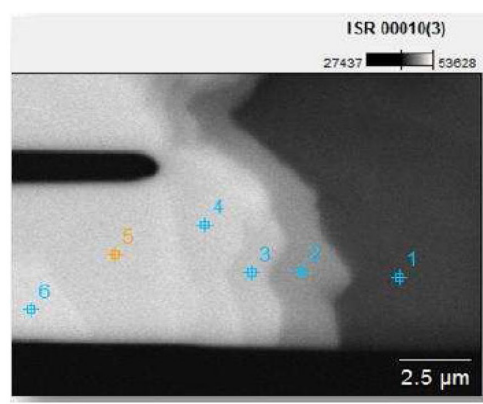

Fir Aug 19 12:16:35 2011

Filter fit Chisquared value: 88.569 Enors; +/-1 Sigma Correction Method, Proza (Phiho-Z)

Acc.Voltage: $25.0 \mathrm{kV}$ Take Off Angle: $35.6 \mathrm{deg}$

Element Net Bement Wt.\% Atom \% Atom \%

Line Counts Wh.\% Error

TiL $0.94+1 / 2$.

$\begin{array}{llllll}\text { AuL } & 3299 & 9 \overline{0} .06 & +\overline{4} .69 & \overline{79.37} & +\overline{3} . \overline{3} .97\end{array}$

Total

$\overline{100.00}$

Figure 3.34 (e)

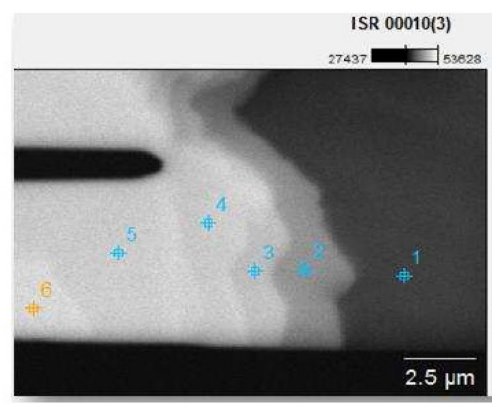

Fin Aug 19 12:17:06 2011

Filter Fit Chi squared value: 85.160 Emors: $+/-1$ Sigm Correction Method: Proza (Phi-Fho-z)

Acc.Vottage: $25.0 \mathrm{kV}$ Take Off Angle: $35.6 \mathrm{deg}$

Element Net Element Wt.\% Atom \% Atom \%

$\begin{array}{lccccc}\text { Line } & \text { Counts } & \text { Wh. } \% & \text { Error } & & \text { Error } \\ \text { TiK } & 288 & 2.05 & +/-0.24 & 7.92 & +/-0.94\end{array}$

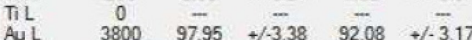

Au M

Total

2584

100.00

100.00

Figure 3.34 (f)

Figure 3.34: (a) through (f) shows the Au-Ti interface at 50,000 magnification and the points where the EDX data were collected 


\subsection{Au-Nb sputtered alumina, interface}

Figure 3.35 and 3.36 showed the $\mathrm{Au}-\mathrm{Nb}$ sputtered alumina interface. Formation of intermetallic layers at the $\mathrm{Au} / \mathrm{Nb} /$ Alumina could be possible in figure 3.35 (b) although a more concrete technique like TEM is required to ensure if there are intermetallic layers present at this interface.

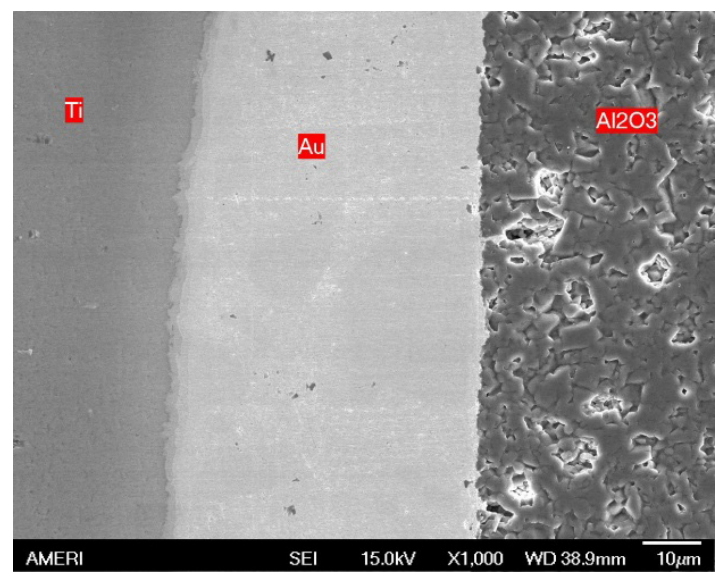

Figure 3.35: Overall interface at $1000 \mathrm{X}$

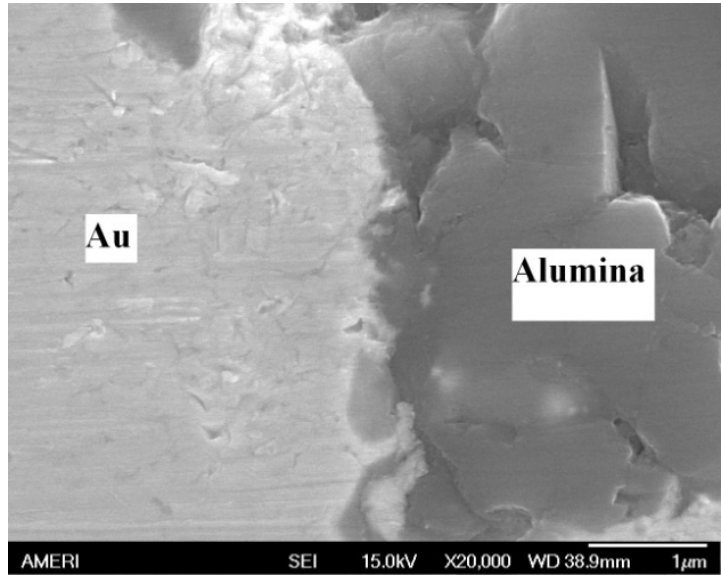

Figure 3.36: Au-Nb sputtered alumina Interface at $20000 \mathrm{X}$

\subsection{New Design of Ti ferrule for brazing}

Due to the change in the design of the Ti ferrule based on the overall package and processing required by the packaging team of the Boston Retina project, the design of Ta electrode was changed. The new design of Ti ferrule stood off from the heater and hence an obvious thermal difference between the ferrule and the heater built up. This changed forced the use of gradual heating for that design which resulted in more than 5 minutes of interaction of molten gold with Ti before gold wicked up through capillary action. After brazing the assembly was not found intact and the ceramic disk came off. Figure 3.37(a) and (b) shows the new design of Ti ferrule which could not be successfully brazed to the ceramic disk using the current Ta resistive heater method. 

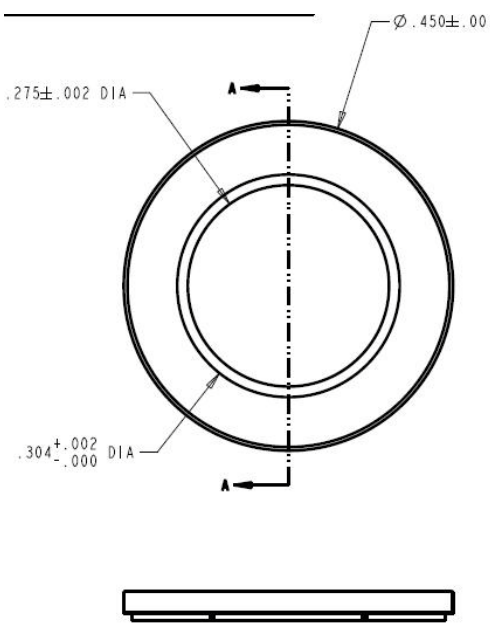

(a)

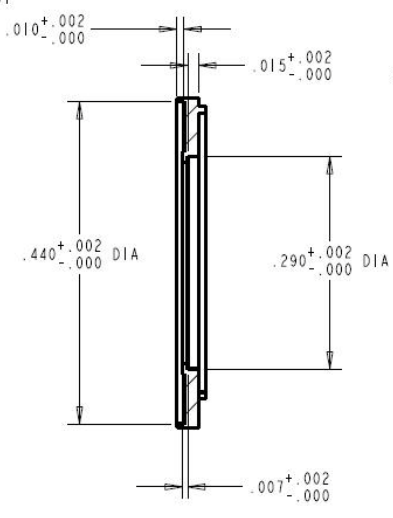

SECTION A-A

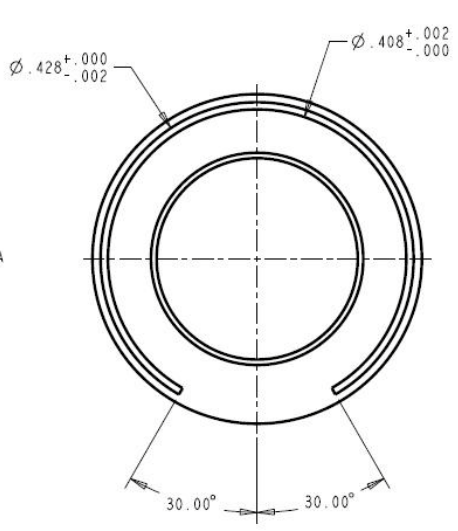

(c)

Figure 3.37: Ti ferrule of new design, (a)- Bottom view, (b)- Side view (c)- Top view

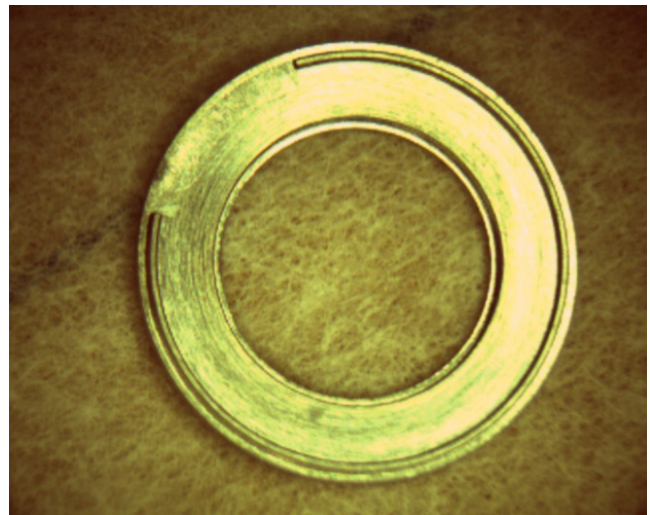

Figure 3.37(d): Ti ferrule of new design top view

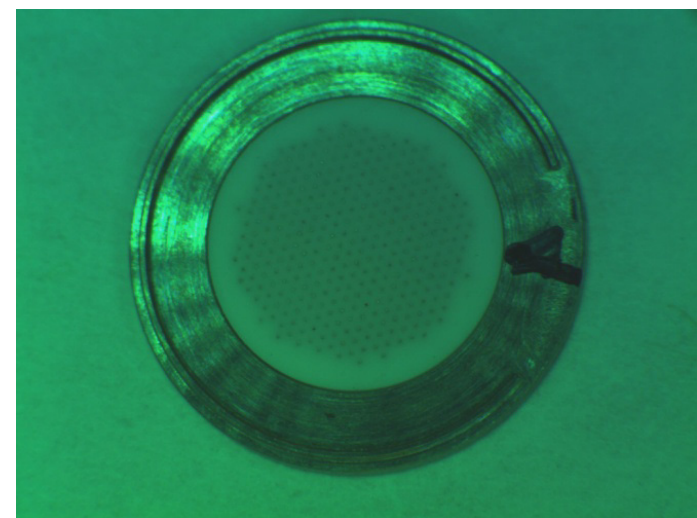

Figure 3.37(e): Ti ferrule of new design with the feedthrough disk

\subsection{EDX analysis of the wetting studies samples for molten gold on Ti substrate}

\section{at $1075 \pm 10{ }^{\circ} \mathrm{C}$ for 287 seconds}

Sample on which gold was kept molten for 287 seconds is subjected to EDX analysis and TEM analysis. When the Au-Ti interface obtained during brazing and during wetting studies were studied under SEM and EDX it was observed that some or all of these 
Intermetallic compounds shown in the binary phase diagram formed at the interface.

Figure 3.38 shows a back scattered compositional image of the Au-Ti interface formed during wetting studies for molten gold on titanium held for 287 seconds.

FIU-AMERI-EDS Test 091708(10)

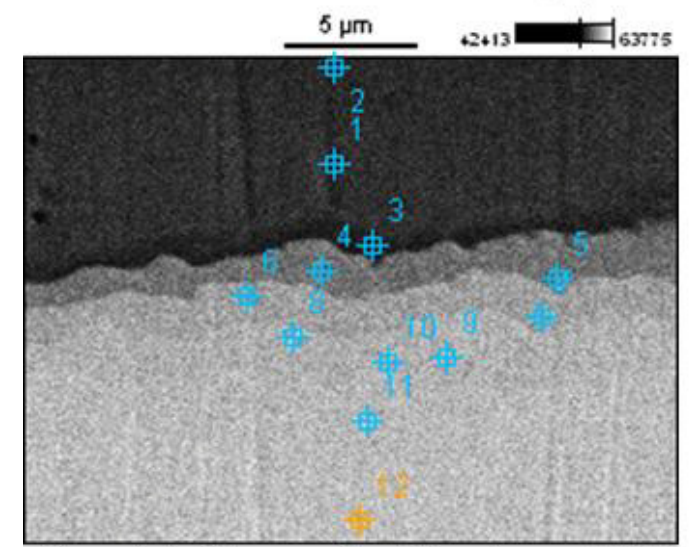

Figure 3.38: SEM image at 5000x where EDX point scan is performed

Table 3.7: EDX analysis at the different points shown in figure 1 showing atomic percentages of $\mathrm{Au}$ and $\mathrm{Ti}$ at different point

\begin{tabular}{lcc} 
& Ti-K & Au-M \\
\hline FIU-AMERI-EDS Test 091708(10)_pt1 & 93.73 & 6.27 \\
FIU-AMERI-EDS Test 091708(10)_pt2 & 95.37 & 4.63 \\
FIU-AMERI-EDS Test 091708(10)_pt3 & 91.32 & 8.68 \\
FIU-AMERI-EDS Test 091708(10)_pt4 & 74.35 & 25.65 \\
FIU-AMERI-EDS Test 091708(10)_pt5 & 72.19 & 27.81 \\
FIU-AMERI-EDS Test 091708(10)_pt6 & 55.92 & 44.08 \\
FIU-AMERI-EDS Test 091708(10)_pt7 & 48.76 & 51.24 \\
FIU-AMERI-EDS Test 091708(10)_pt8 & 44.25 & 55.75 \\
FIU-AMERI-EDS Test 091708(10)_pt9 & 32.64 & 67.36 \\
FIU-AMERI-EDS Test 091708(10)_pt10 & 37.09 & 62.91 \\
FIU-AMERI-EDS Test 091708(10)_pt11 & 18.78 & 81.22 \\
FIU-AMERI-EDS Test 091708(10)_pt12 & 8.97 & 91.03 \\
\hline
\end{tabular}

As per the above analysis it is possible that points 4, 79 and 11 represents the Intermetallic compounds $\mathrm{Ti}_{3} \mathrm{Au}, \mathrm{TiAu}, \mathrm{TiAu}_{2}$ and $\mathrm{TuAu}_{4}$ this possibility could only be confirmed by performing TEM at the cross section. Figure 3.39 shows a line scan EDX 
FIU-AMERI-EDS Test 091708(13)

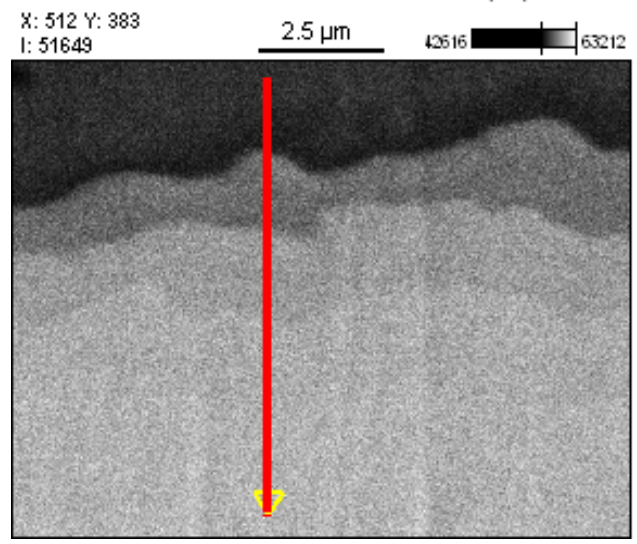

Figure 3.39: Line scan EDX analysis at the interface of approximately 8 $\mu \mathrm{m}$ length

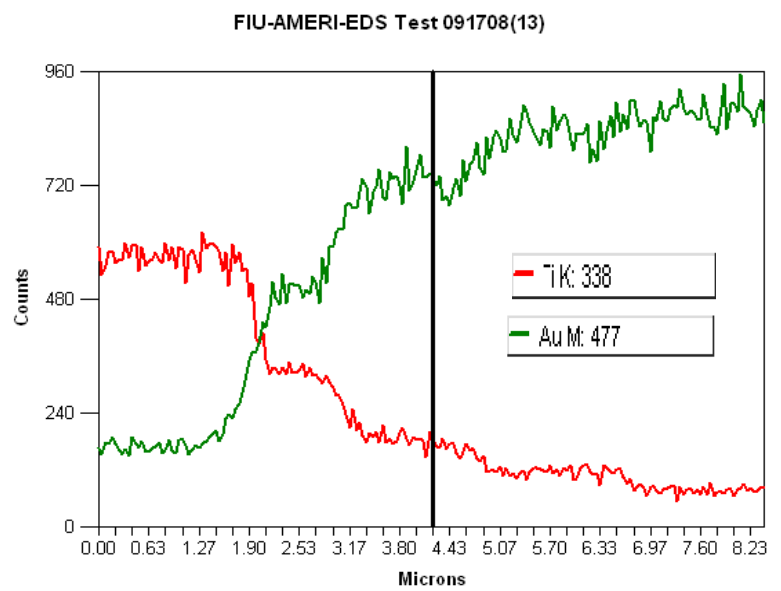

Figure 3.40: Count rate variation along the length of the EDX line scan

composition profile at the Au-Ti interface. The pattern shown in the change in the count rate in figure 3.40 also suggests the possibility of formation of all the different Intermetallic compounds between $\mathrm{Au}$ and $\mathrm{Ti}$.

The Ti-300 sec (4D) samples where gold was kept molten over Ti substrate for 5 minutes were observed to fracture at the interface of gold and $\mathrm{Ti}$ and solidified gold drop separated from the sample. An image of the separated solidified gold drop and its impression over the Ti substrate are shown in the figure 3.41 (a) and (b) respectively.

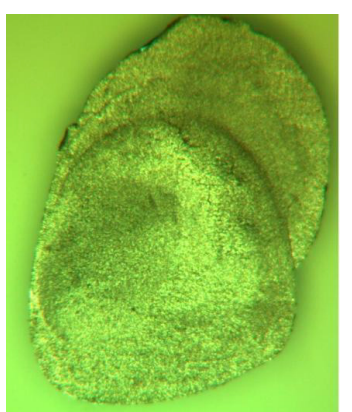

Figure 3.41(a): Fractured gold drop

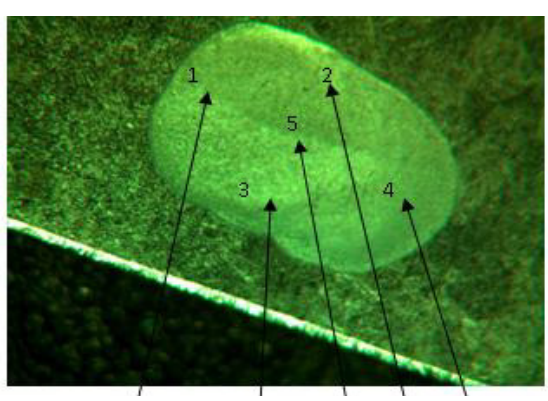

Figure 3.41(b): Drop's Impression on Ti substrate and the points where EDX was performed 
Figure 3.42 shows the EDX spectra obtained at the 5 points shown on figure $3.41(\mathrm{~b})$ which consistently shows the atomic ratio of $\mathrm{Ti}$ to $\mathrm{Au}$ as $1: 2$, suggesting the presence of $\mathrm{TiAu}_{2}$ compound at the interface causing crack propagation and failure at the interface. All the five points showed the presence of only $\mathrm{TiAu}_{2}$ compound with the atomic percentages in the range of $\pm 5 \%$.

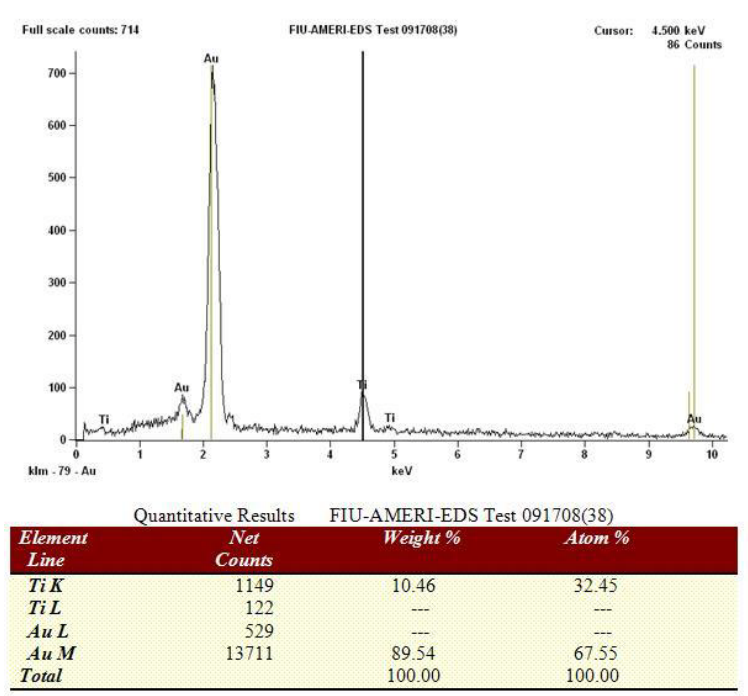

Figure 3.42: EDX at point 5 in figure 3.41 (b)

\subsection{Modulus Mapping at the Au-Ti interface}

The 2D Modulus Mapping has been carried out on the wetting studies samples Ti-300 sec- $1^{\text {st }}$ and Ti-300 sec- $2^{\text {nd }}$ and Ti-300 sec- $3^{\text {rd }}$ samples using Hysitron TriboIndenter $®$ (Hystrion Inc., Minneapolis, MN) with the nano-DMA (Dynamic Mechanical Analyzer) transducer. The experimental parameters are as follows:

1. Tip used $-100 \mathrm{~nm}$ Berkovich, Static Load $-2 \mu \mathrm{N}$, Dynamic Load $-1 \mu \mathrm{N}$, 
2. Frequency $-200 \mathrm{~Hz}$, Maps were obtained at three places in each sample - at Interface, - Gold at Distance, - Titanium at Distance. All maps were obtained for $30 \times 30 \mu \mathrm{m}$ area

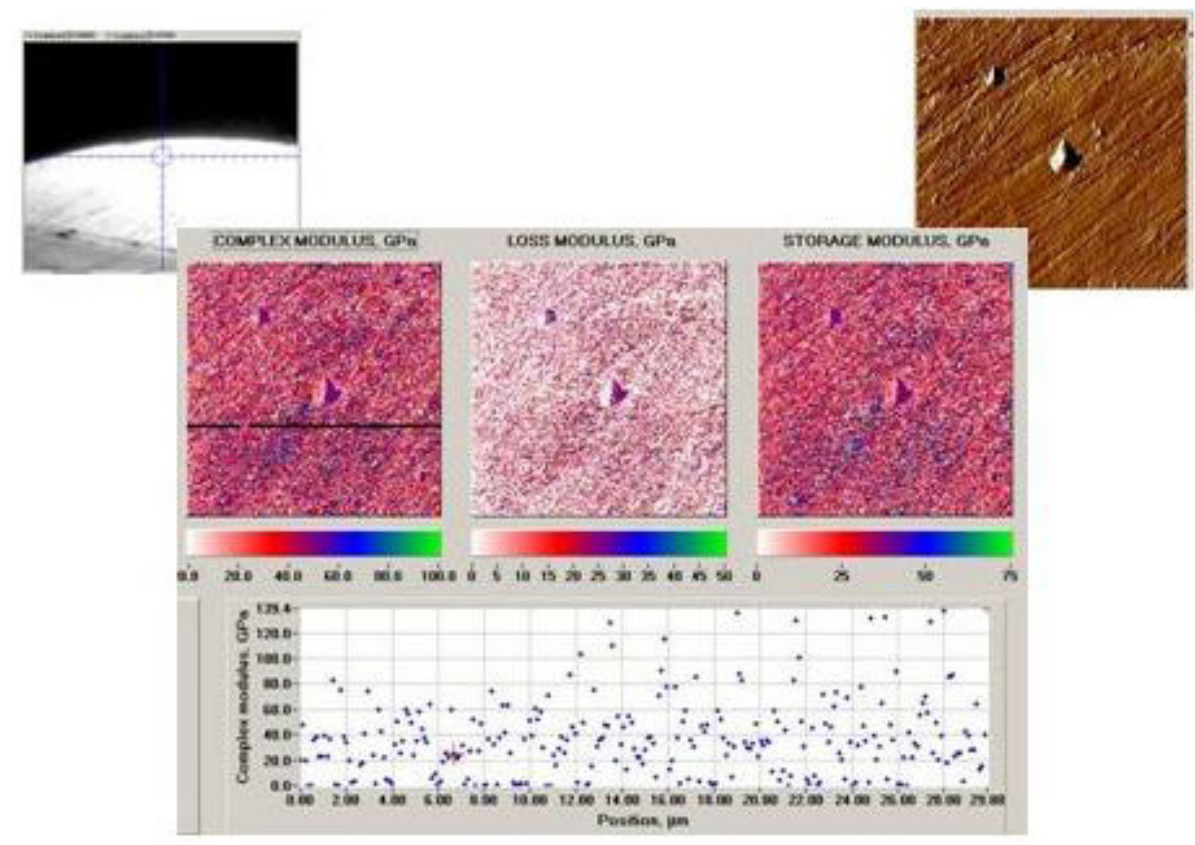

Figure 3.43: Modulus Maps on Sample Ti-300 sec- $3^{\text {rd }}$ on Gold away from the interface Images of samples Ti-300 sec- $1^{\text {st }}(4 \mathrm{D}-1)$ and Ti-300 sec- $3^{\text {rd }}(4 \mathrm{D}-3)$ are shown in figure 3.43 and 3.44 respectively. These samples showed fracture at the Au-Ti interface and epoxy has been penetrated in between gold and Ti during sample mounting. Figure 3.43 through 3.45 shows the screen shot of the data obtained for modulus mapping on gold away from the interface, Ti away from interface and modulus map at the interface in sample Ti-300 sec- $3^{\text {rd }}(4 \mathrm{D}-3)$, and the comparison in figure 3.46. 
There could be several reasons for the large variation in modulus including sample polishing.

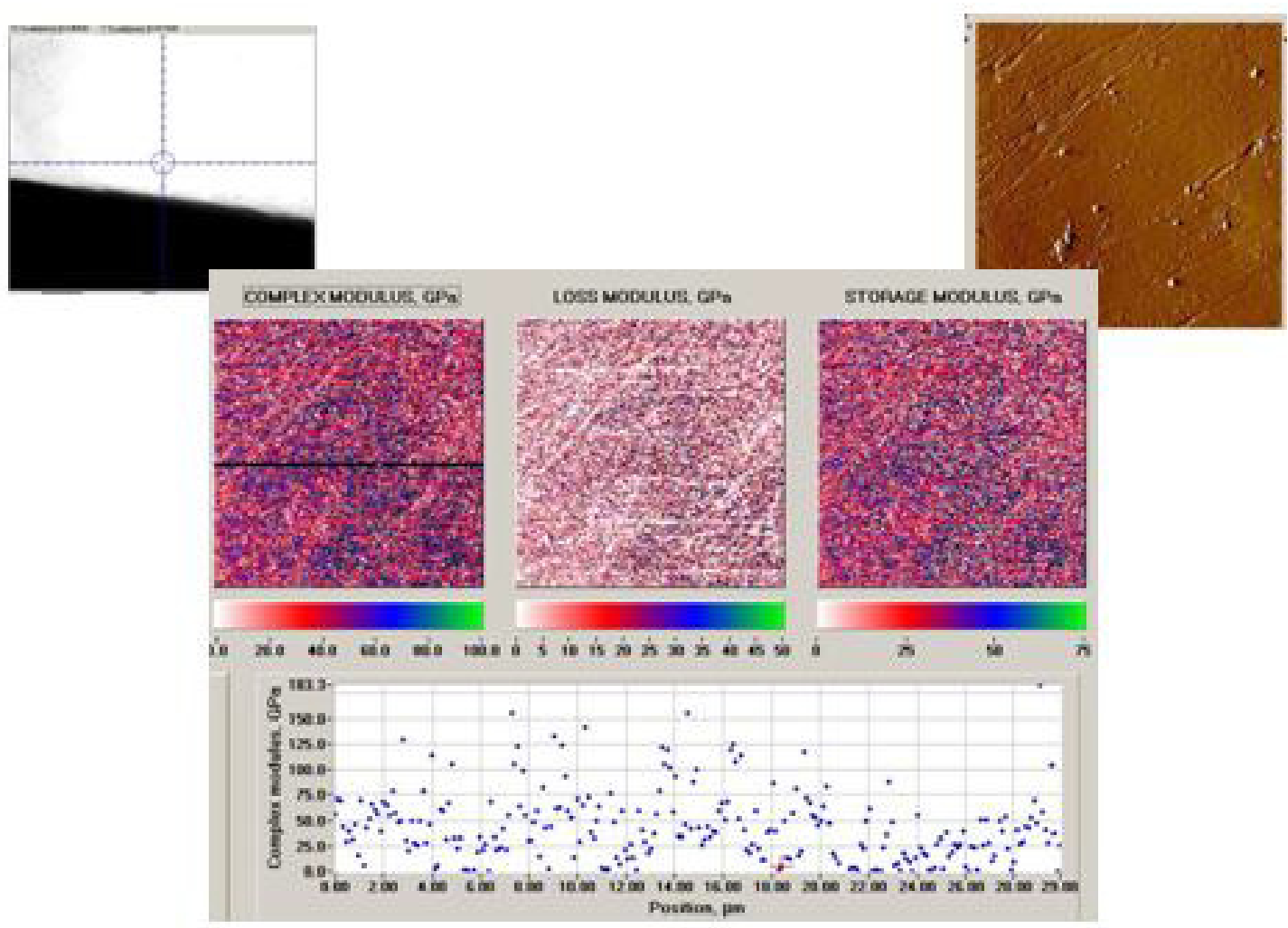

Figure 3.44: Modulus Maps on Sample Ti-300 sec- $3^{\text {rd }}$ (4D3) on Titanium away from the interface

The color bar clearly indicate the difference in the modulus values at different point because of the formation of reaction products between gold and Ti at the interface. These reaction products have different modulus from either Ti or Au. Figure 3.46 shows a comparative picture of modulus map for the three different locations namely Au away from the interface, Ti away from the interface and the interface. 


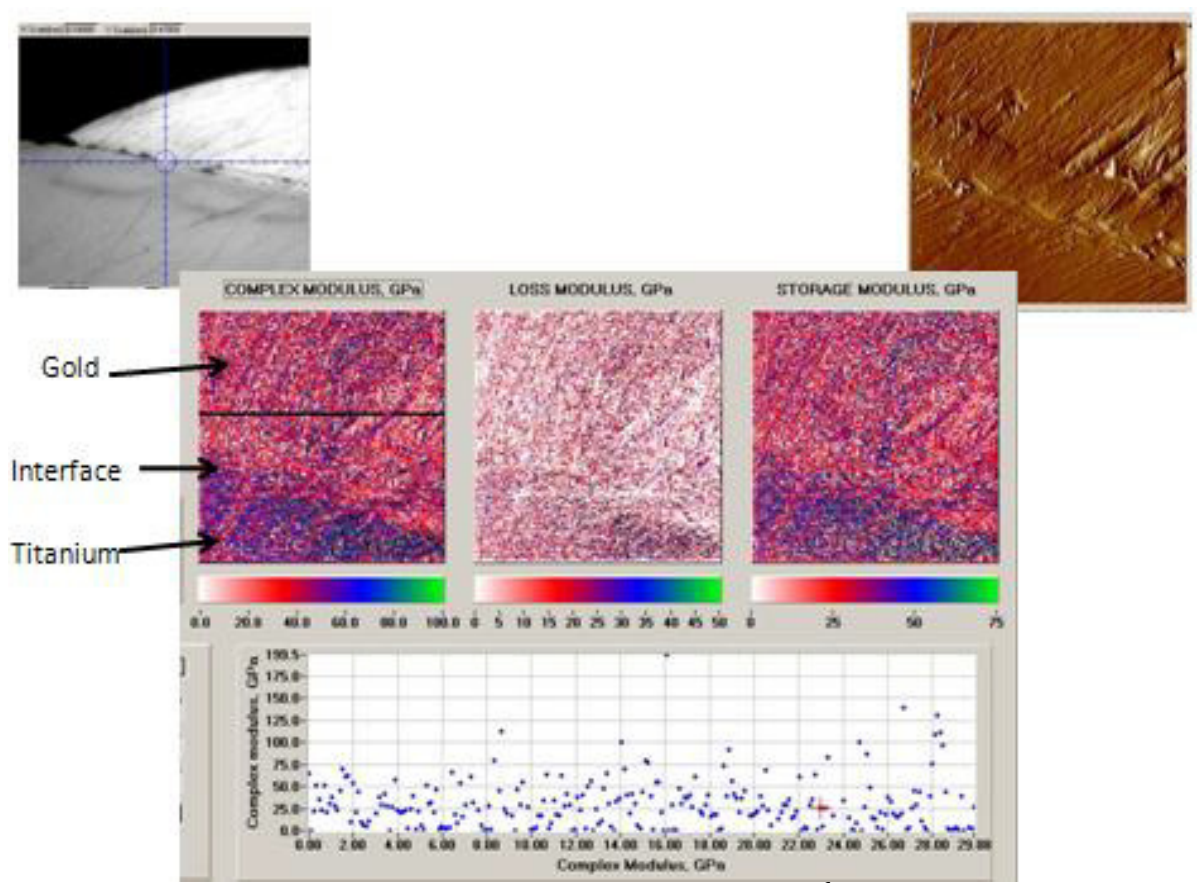

Figure 3.45: Modulus Maps on Sample Ti-300 sec- $3^{\text {rd }}(4 \mathrm{D} 3)$ at the Interface

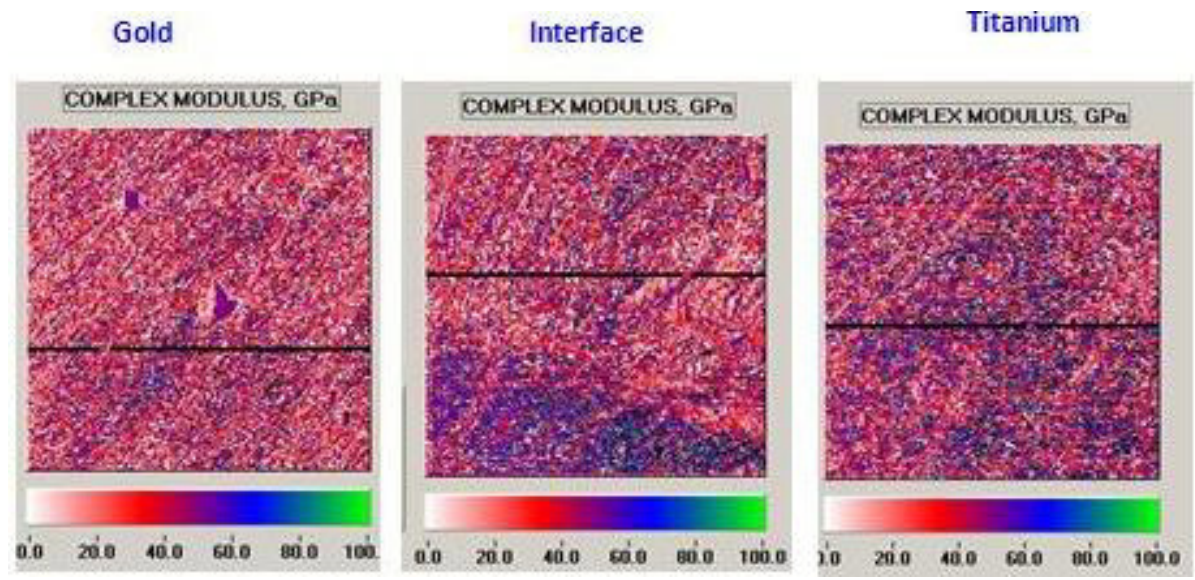

Figure 3.46: Modulus Maps on Sample 4D3: Comparison

The results obtained for the sample Ti-300 sec- $3^{\text {rd }}$ (4D3) are as follows- Au near interface (Average) $=36.28 \mathrm{GPa}$; with the average value of standard deviation for 5 points is 38.9Gpa.

$\mathrm{Au}$ distant from interface (Average) $=36.88 \mathrm{GPa}$; with the average value of standard deviation for 10 points is $37.88 \mathrm{Gpa}$. 
Ti distant from Interface (Average) $=48.19 \mathrm{GPa}$; with the average value of standard deviation for 10 points is $40.82 \mathrm{GPa}$.

Ti near interface (Average) $=57.6 \mathrm{GPa}$, with the average value of standard deviation for 5 points is $40.87 \mathrm{GPa}$.

\subsection{Quasistatic Nanoindentation}

In order to completely characterize the $\mathrm{Au}-\mathrm{Ti}$ interface, a nanoindentation experiment was performed at the Au-Ti interface for samples Ti-300 sec- ${ }^{\text {st }}(4 \mathrm{D} 1)$, and Ti-300 sec- $3^{\text {rd }}$ (4D3). The experimental parameters were set as followed:

- $\quad$ Tip used - $100 \mathrm{~nm}$ Berkovich, Peak Load - $2500 \mu \mathrm{N}$, Loading unloading Constant Rate $-250 \mu \mathrm{N} / \mathrm{s}$, Dwell $-3 \mathrm{~s}$

- Indents were made at four places in each sample (1) Gold near Interface, (2) Titanium near interface, (3) Gold at Distance, (4) Titanium at Distance.

The variation in the loading and unloading curves at the gold surface and at the Ti surface close to the interface is caused by the formation of intermetallic compounds between $\mathrm{Ti}$ and gold. Results of indentation experiments are shown in table 3.8 below.

Table 3.8: Modulus and hardness values measured by nanoindentor

\begin{tabular}{|c|c|c|c|c|c|c|c|c|}
\hline $\begin{array}{c}\text { Sample } \\
\text { name }\end{array}$ & \multicolumn{2}{|c|}{ Gold } & \multicolumn{2}{c|}{$\begin{array}{c}\text { Gold Near } \\
\text { Interface }\end{array}$} & \multicolumn{2}{c|}{ Titanium } & \multicolumn{2}{c|}{$\begin{array}{c}\text { Titanium near } \\
\text { interface }\end{array}$} \\
\hline & $\begin{array}{c}\mathrm{E} \\
(\mathrm{GPa})\end{array}$ & $\begin{array}{c}\mathrm{H} \\
(\mathrm{GPa})\end{array}$ & $\begin{array}{c}\mathrm{E} \\
(\mathrm{GPa})\end{array}$ & $\begin{array}{c}\mathrm{H} \\
(\mathrm{GPa})\end{array}$ & $\begin{array}{c}\mathrm{E} \\
(\mathrm{GPa})\end{array}$ & $\begin{array}{c}\mathrm{H} \\
(\mathrm{GPa})\end{array}$ & $\begin{array}{c}\mathrm{E} \\
(\mathrm{GPa})\end{array}$ & $\begin{array}{c}\mathrm{H} \\
(\mathrm{GPa})\end{array}$ \\
\hline $\mathrm{Ti}^{-300}$ & $95 \pm 5$ & $2.2 \pm$ & $114 \pm 8$ & $\begin{array}{c}3.2 \pm \\
0.3\end{array}$ & $127 \pm 3$ & $4.5 \pm$ & $121 \pm$ & $4.2 \pm$ \\
sec-1 $^{\text {st }}$ & $95 \pm$ & 0.08 & & & 0.01 & 6 & 0.6 \\
\hline $\mathrm{Ti}^{-300}$ & $149 \pm$ & $4.9 \pm$ & $147 \pm$ & $4.5 \pm$ & $138 \pm$ & $4.5 \pm$ & $148 \pm$ & $3.8 \pm$ \\
sec-3 $^{\text {rd }}$ & 2 & 0.08 & 26 & 1.4 & 0.2 & 0.2 & 3 & 0.2 \\
\hline
\end{tabular}


1. Sample Ti-300 sec- $1^{\text {st }}$ (4D1) shows a clear indication of reaction product (intermetallic compounds) formation at interface - increase in $\mathrm{E}$ and $\mathrm{H}$ of Gold at interface and decrease for $\mathrm{Ti}$

2. Sample Ti-300 sec- $3^{\text {rd }}$ (4D3) does not show increase in $\mathrm{E}$ and $\mathrm{H}$ of gold at interface - but a wide variation in $\mathrm{E}$ and $\mathrm{H}$ indicates intermetallic compounds formation.

\subsection{Leak Testing of Brazed Assembly}

The brazed assemblies discussed in section 3.5 were subjected to helium leak testing to determine their leak rate. A Varian vacuum technology, Model 979 series Helium Mass spectrometer leak detector shown in figure 3.47 (a) and the fixture used to test the brazed assembly to determine its leak rate is shown in figure 3.47 (b). The fixture was manufactured at the machine shop at FIU. O-rings of proper size were bought from outside vendor. The brazed assembly is placed on the o-ring shown in figure 3.47 facing down. The vacuum is pulled and once a vacuum level of $1 \mathrm{X}^{-4} \mathrm{~Pa}$ is reached helium gas is sprayed over the brazed assembly. The leak rate measured by the mass spectrometer is of the of the order of $1.6 \times 10^{-8} \mathrm{~atm}-\mathrm{cc} / \mathrm{second}$.

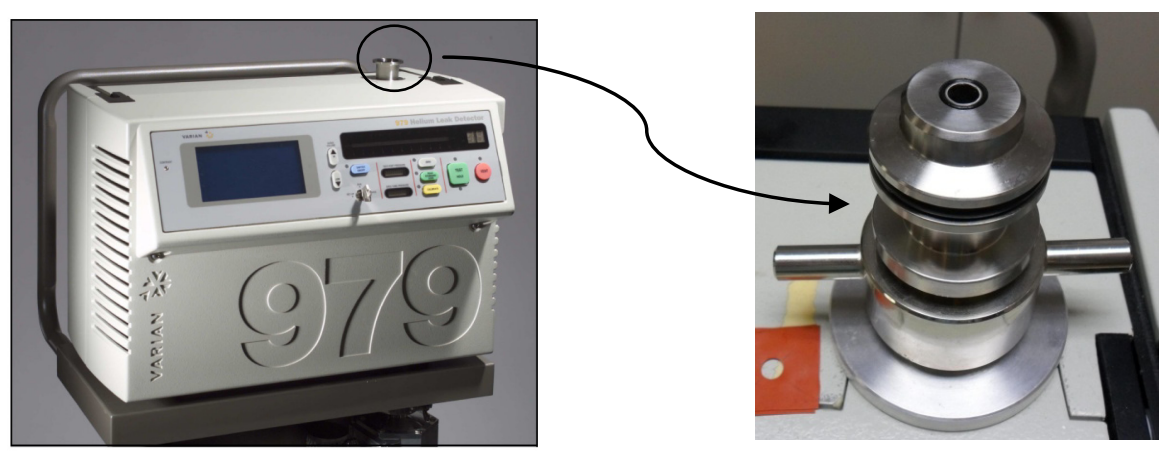

Figure 3.47(a): Varian 979 Helium leak detector

Figure 3.47(b): Fixture mounted on the test port of Varian 979 Helium leak detector 


\subsection{Mechanical testing of Au-Ti brazed joint}

To determine the strength of the brazed joint of $\mathrm{Ti}$ and $\mathrm{Au}$ a test similar to nail head pull testing was performed [88]. Raw materials used for fabrication of samples are shown in figure 3.48. Ti electrode in a shape of a flat dog bone which were also used for wetting studies are used as a substrate over which Ti rod of $3 \mathrm{~mm}$ in diameter is brazed by electrical resitance heating using pure gold as braze filler metal.

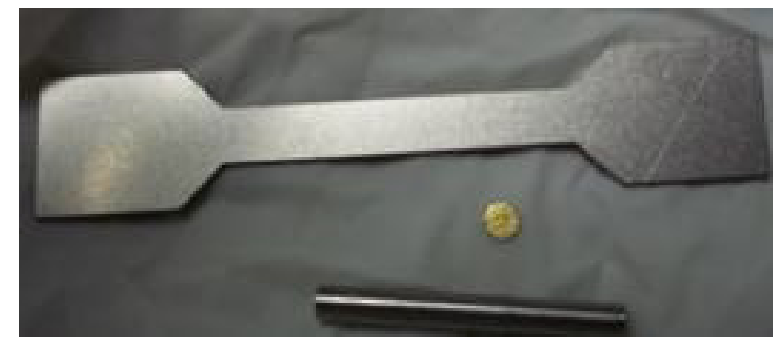

Figure 3.48: Raw materials used for making brazed joints

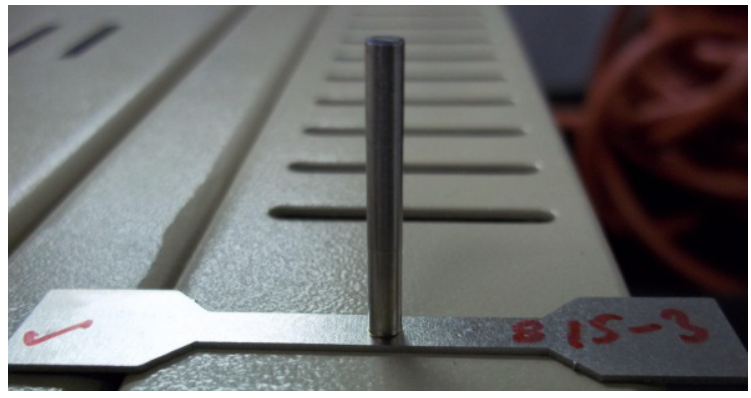

Figure 3.50: Brazed sample

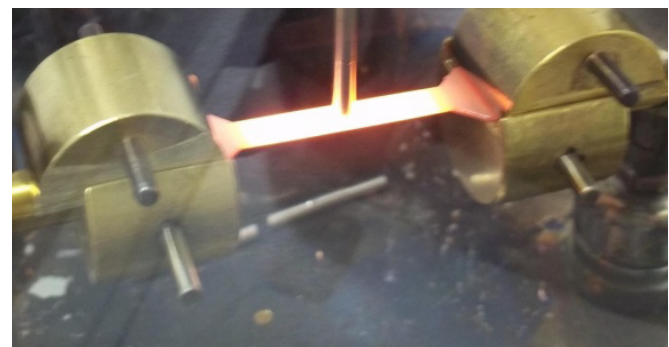

Figure 3.49: Heated electrode showing the central hot zone

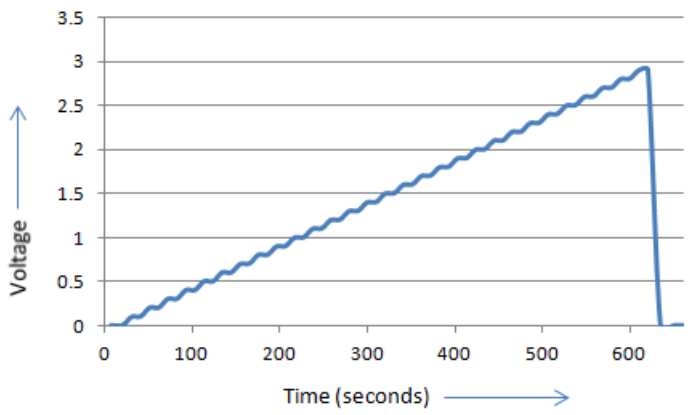

Figure 3.51: Lab View data for voltage Vs time

The sample shown in figure 3.50 was be tested in the MTS mechanical testing machine of model 858 test sytem with a load call of $1000 \mathrm{~N}$. The fixture used to hold the sample as shown in figure 3.52. This fixture prevent deformation of the Ti during testing and also minimizes moments during testing and test essentially the brazed joint sterngth only. 


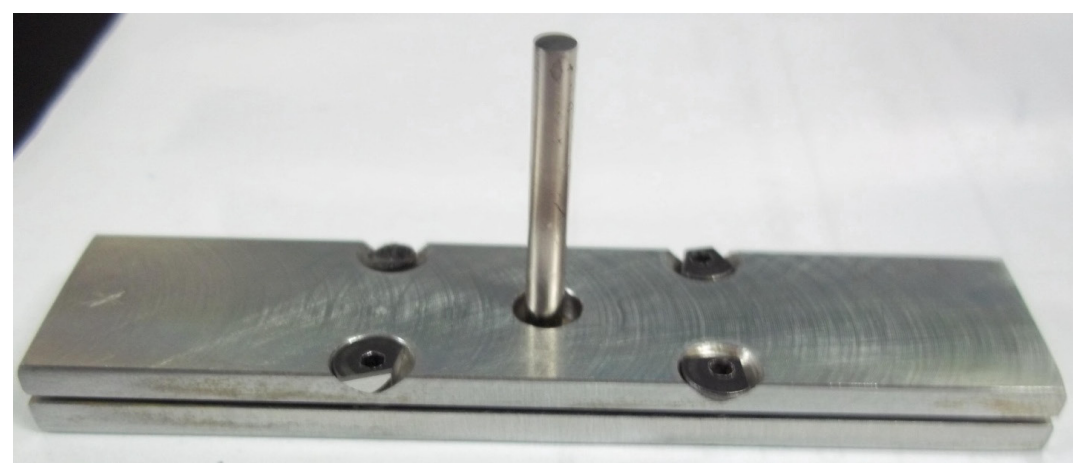

Figure 3.52: Holding fixture for holding the brazed sample

Rate of pull for the first lot of samples is $0.01 \mathrm{~mm} / \mathrm{second}$. Strain rate is kept as 2.5 $\mathrm{mm} / \mathrm{min}$. Fixture shown in figure 3.52 slides into the groove of the bottom holder of machine and the top grip was holding the Ti rod $10 \mathrm{~mm}$ away from the joint to avoid the moments of forces and to keep the stress uniaxial. Sample numbers S8, S13 and S9 have molten gold and $\mathrm{Ti}$ in contact for time period of 30 seconds while sample $\mathrm{S} 15, \mathrm{~S} 18$ and S7 have molten gold in contact with Ti for 40 seconds.

Table 3.9: Fracture Strength obtained for different samples

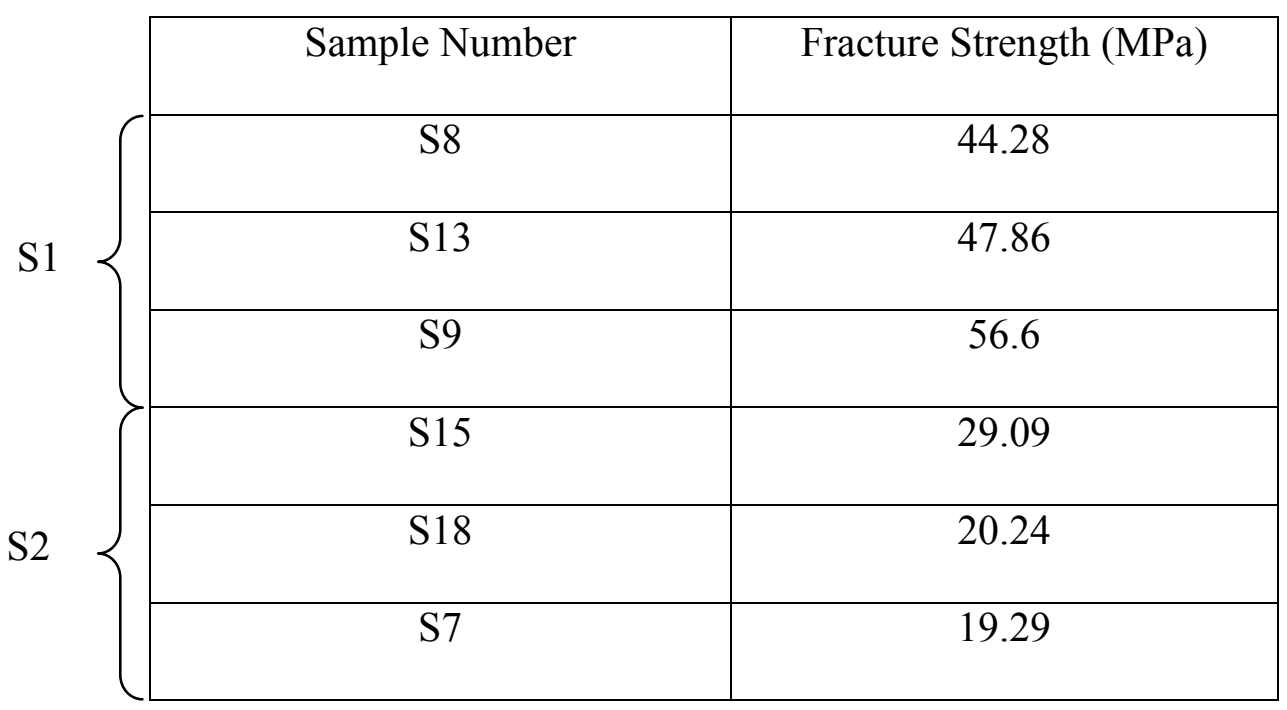




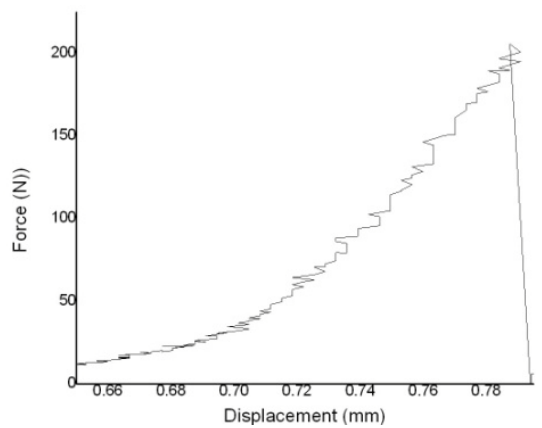

Figure 3.53: Force Vs displacement data obtained from testing for one of the sample

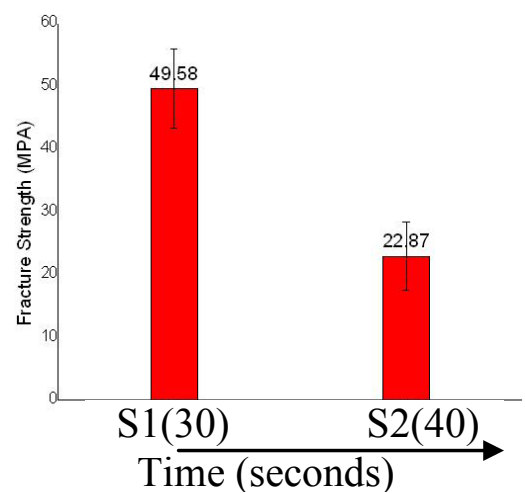

Figure 3.54: Fracture Strength values obtained for different samples

$\mathrm{S} 1$ in figure 3.54 corresponds to the average values of S8, S13 and S9. The average value for these three samples is $49.58 \mathrm{MPa}$ with a standard deviation of $6.34 \mathrm{MPa}$ while $\mathrm{S} 2$ in figure 3.54 corresponds to the average values of S15, S18 and S7. The average values for these sample is $22.9 \mathrm{MPa}$ with a standard deviation of $5.4 \mathrm{MPa}$.

\subsubsection{Analysis of Fractured Interface}

Optical image of fractured $\mathrm{Ti}$ substrate and the Ti rod is shown in figure 3.55 below. EDX point analysis on the Ti substrate and on Ti rod after fracture is shown in the figure 3.56 and 3.57 respectively. Atomic ratio suggests that $\mathrm{Ti}$ substrate has $\mathrm{TiAu}_{4}$ substrate while Ti rod surface has $\mathrm{TiAu}_{2}$ phase.

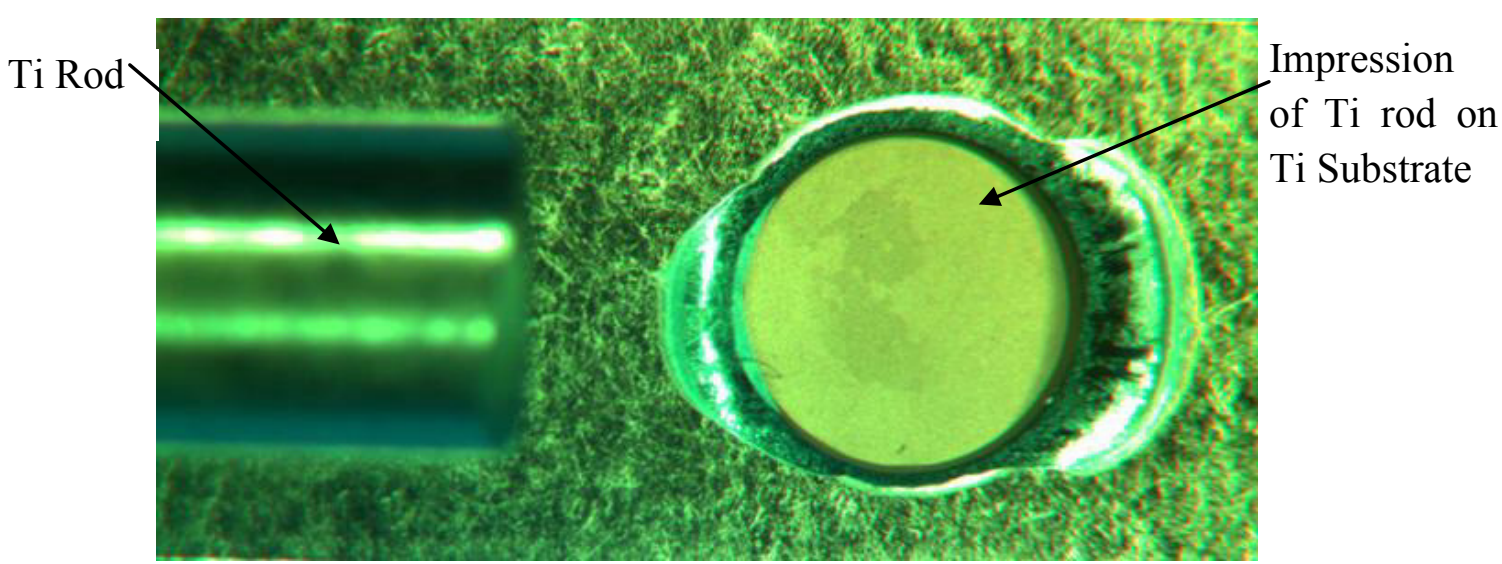

Figure 3.55: Fractured Ti substrate and Ti rod 
FIU-AMERI-EDS Test 091708(59)

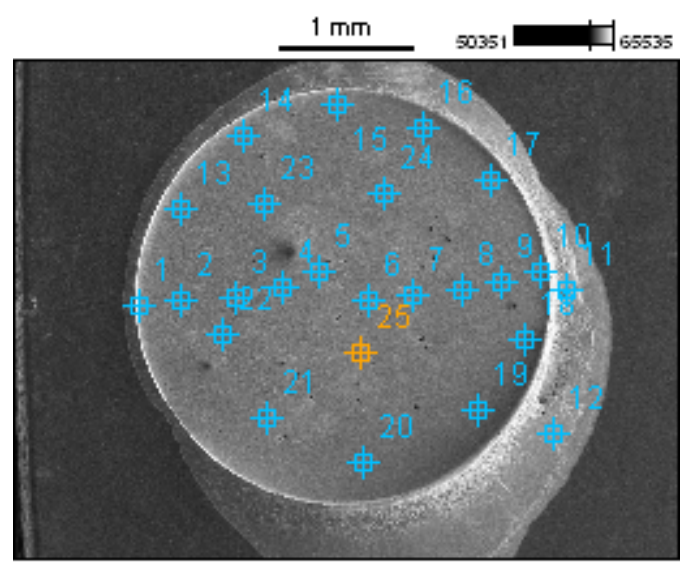

Figure 3.56: Ti impression on the substrate and points of EDX data

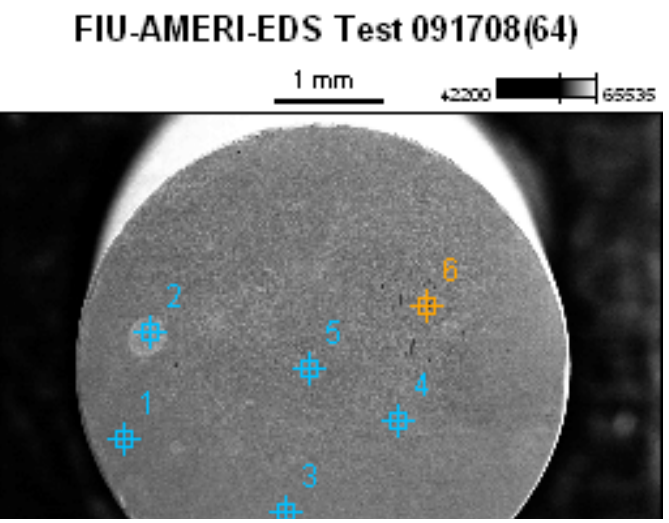

Figure 3.57: Ti rod and the points of EDX data collection
Table 3.10: EDX data for figure 3.56 in atomic percentages of $\mathrm{Ti}$ and $\mathrm{Au}$

\begin{tabular}{|c|c|c|}
\hline & $T i-K$ & $A u-M$ \\
\hline FIU-AMERI-EDS pt1 & 18.96 & 81.04 \\
\hline$F I U-A M E R I-E D S p t 2$ & 20.39 & 79.61 \\
\hline FIU-AMERI-EDS pt3 & 20.81 & 79.19 \\
\hline FIU-AMERI-EDS pt4 & 20.26 & 79 \\
\hline FIU-AMERI-EDS pt5 & 20.02 & 98 \\
\hline FIU-AMERI-EDS pt6 & 21.33 & \\
\hline FIU-AMERI-EDS pt 7 & 18.86 & .14 \\
\hline FIU-AMERI-EDS pt8 & 22.13 & 77.87 \\
\hline FIU-AMERI-EDS pt9 & 19.86 & \\
\hline FIU-AMERI-EDS pt10 & 22.04 & \\
\hline FIU-AMERI-EDS pt11 & 6.91 & .09 \\
\hline FIU-AMERI-EDS pt12 & 9.43 & \\
\hline FIU-AMERI-EDS pt13 & 19.87 & 80.13 \\
\hline FIU-AMERI-EDS pt14 & 20.29 & 79.71 \\
\hline FIU-AMERI-EDS pt15 & 20.30 & \\
\hline FIU-AMERI-EDS pt16 & 20.22 & 79.78 \\
\hline FIU-AMERI-EDS pt17 & 21.18 & 3.82 \\
\hline FIU-AMERI-EDS pt18 & 18.00 & 82. \\
\hline FIU-AMERI-EDS pt19 & 23.16 & 76.84 \\
\hline FIU-AMERI-EDS pt20 & 18.18 & \\
\hline FIU-AMERI-EDS pt 21 & 18.48 & \\
\hline FIU-AMERI-EDS pt 22 & 20.63 & 79.37 \\
\hline FIU-AMERI-EDS pt 23 & 20.11 & \\
\hline FIU-AMERI-EDS pt 24 & 19.76 & 80.2 \\
\hline FIU-AMERI-EDS pt 25 & 20.85 & 79.15 \\
\hline
\end{tabular}

Table 3.11: EDX data for figure 3.57 in atomic percentages of $\mathrm{Ti}$ and $\mathrm{Au}$

\begin{tabular}{lcc} 
& $T i-\boldsymbol{K}$ & $A u-M$ \\
\hline FIU-AMERI-EDS pt1 & 35.12 & 64.88 \\
FIU-AMERI-EDS pt2 & 33.79 & 66.21 \\
FIU-AMERI-EDS pt3 & 34.75 & 65.25 \\
FIU-AMERI-EDS pt4 & 33.79 & 66.21 \\
FIU-AMERI-EDS pt5 & 32.09 & 67.91 \\
FIU-AMERI-EDS pt6 & 99.31 & 0.69 \\
\hline
\end{tabular}

Figure 3.58 and 3.59 below shows SEM images of cross sectioned brazed assembly.

Figure 3.59 shows formation of at least 2 interlayers between $\mathrm{Au}$ and Ti. 


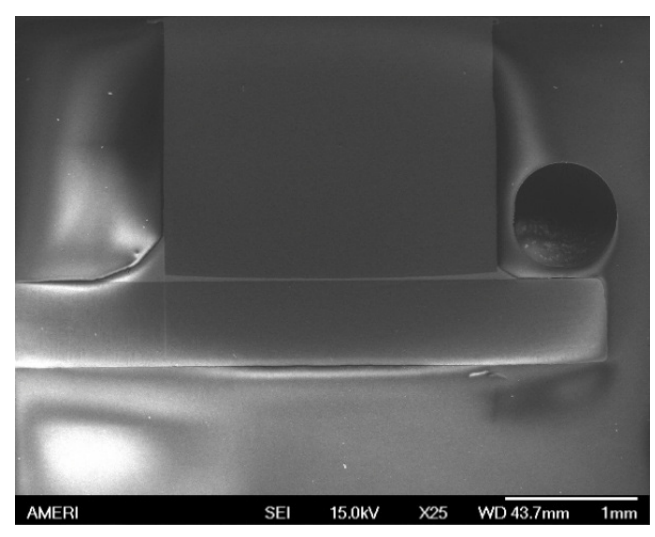

Figure 3.58: Cross sectioned brazed sample

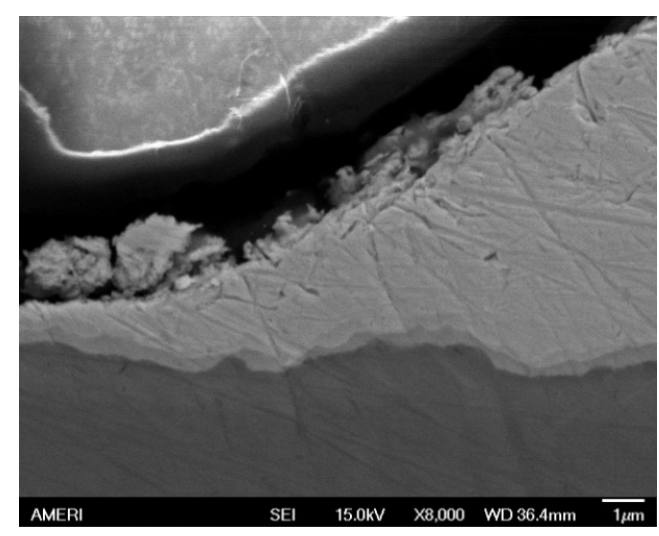

Figure 3.59: Au-Ti interface at $8000 \mathrm{X}$

\subsubsection{Fracture Strength of brazed samples}

Brazed sample of Ti to Ti were made using 99.99\% pure gold as braze material and were tested for pull strength. Fracture strength obtained varied from 56.6 $\mathrm{MPa}$ to $19.29 \mathrm{MPa}$ for a lot of 6 samples with the standard deviation of $15.54 \mathrm{MPa}$. Fracture surface of sample were analyzed using SEM and EDX. Fracture surface of sample showed the presence of $\mathrm{TiAu}_{2}$ and $\mathrm{TiAu}_{4}$ compounds on the surface of $\mathrm{Ti}$ rod and on Ti substrate respectively suggesting the fracture to occur in between these two intermetallic compounds. Cross section analysis of brazed sample showed an interlayer of approximately 1 micron thickness clearly showing at least 2 intermediate layers in the SEM image. 


\section{DISCUSSIONS AND CONCLUSIONS}

\subsection{Three point bend testing of HTCC alumina ceramic}

Three point bend samples prepared via HTCC standard process were tested as per ASTM C 1161 with a non articulating fixture. The obtained values of flexural strength of a lot a of 10 samples was found to have a tight distribution of flexural strength values with a standard deviation of $30.27 \mathrm{MPa}$. Sample chamfering was critical step to perform the testing correctly. Flexural strength value of $96 \%$ alumina ceramic as reported by Coorstek company is $358 \mathrm{MPa}$ while in the present work the mean value of flexural strength obtained is $337.3 \mathrm{MPa}$. The glass system which is present in the samples tested here is $50 \%$ kaolinite and $50 \%$ talc causes the slight variation from the reported value of Coorstek company $(358 \mathrm{MPa})$ as the glass system used by them is slightly different.

\subsection{Wetting Studies}

Wetting studies of gold with all the elements $\mathrm{Ti}, \mathrm{Ta}, \mathrm{W}$ and $\mathrm{Nb}$ as substrates were observed to be reactive wetting and dissolution of substrate was observed. Among the wetting behavior of gold to $\mathrm{W}$, Ta and $\mathrm{Nb}$, gold exhibit best wetting tendency towards Nb. Gold also showed excellent wetting towards Ti metal.

In the Au-Ti system the sample in which gold was kept molten over the Ti substrate and quenched showed fracture at the interface of Ti and Au. The facture surface was analyzed by EDX technique and $\mathrm{TiAu}_{2}$ compound was detected at the fractured surface over $\mathrm{Ti}$ substrate.

Spreading was observed to be rapid in $\mathrm{Au}-\mathrm{Ti}$ and $\mathrm{Au}-\mathrm{Nb}$ system while spreading was pretty slow in the $\mathrm{Au}-\mathrm{W}$ system. Au-W system initially shows an obtuse contact angle which eventually reaches close to 90 degrees in a time span of 90 seconds. Samples of 
$\mathrm{Au}-\mathrm{Ti}$ wetting studies were further analyzed by EDX and TEM for possible formation of intermetallic compounds. These samples were also analyzed by modulus mapping and nanoindentation experiments.

The low wetting angle and close match of thermal expansion of $\mathrm{Nb}$ to alumina is indicative that $\mathrm{Nb}$ thin film metallization would be best for metallizing the alumina ceramic for brazing purpose.

\subsection{SEM and EDX analysis}

SEM and EDX analysis at the Au-Ti interface showed the formation of possible intermetallic compounds between Au and Ti. SEM analysis in the backscattered compositional image mode showed layers having different contrast in the microstructure. Line scan EDX profile at the Au-Ti interface showed presence of all 4 possible intermetallic compounds as per Au-Ti binary phase diagram. EDX analysis at the interfaces of $\mathrm{Au}-\mathrm{W}$ and $\mathrm{Au}-\mathrm{Nb}$ system also showed dissolutive wetting in these systems.

\subsection{Modulus mapping at the Au-Ti interface}

Modulus mapping results showed that there is formation of reaction products between gold and $\mathrm{Ti}$ as there is considerable difference in the elastic modulus obtained at the interface and the values away from the interface.

\subsection{Nanoindentation at the Au-Ti interface}

Nanoindentation experiment was used to characterize the interface of Au-Ti. Hardness value was measured at gold away from interface, Ti away from interface and at both these elements close to the interface. There is variation between the slopes of the loading and unloading curves at the different points at interface representing the difference in the 
mechanical properties of interface at different points because of formation of reaction products (IMCs of Au-Ti) which were also confirmed by EDX analysis.

\subsection{Scratch testing at the Alumina/Nb interface}

Scratch testing at the polished Alumina/ $\mathrm{Nb}$ interface yielded the adhesion strength values of sputtered thin film of $\mathrm{Nb}$ to alumina ceramic. It can be concluded that a very adherent sputtered $\mathrm{Nb}$ films over polished alumina surface can be obtained. A large variation in the adhesion strength is observed which could be due to two reasons namely either because of the non uniformity in the surface roughness or because of the non uniformity in the thickness of the sputtered thin film. Scratch testing samples prepared with sputtered thin film of other metals did not yielded any reportable data.

\subsection{Vacuum Brazing}

Resistance brazing of alumina ceramic to titanium metal using pure gold as filler metal was successfully achieved. Strong and hermetic brazed joints were obtained. Alumina was metallized to increase the wetting towards gold by sputtering a thin film of $\mathrm{Nb}$ metal of $500 \mathrm{~nm}$ thickness. The brazed assembly was tested for hermeticity and a leak rate of the order of $1.6 \times 10^{-8}$ atm-cc of $\mathrm{He} / \mathrm{sec}$ is measured on Helium leak detector. Cross sectioning the brazed assembly and doing microscopic analysis and EDX analysis reveal that there are intermediate phase present at the interface of Au and Ti. EDX analysis gave their elemental composition as $\mathrm{Ti}_{3} \mathrm{Au}$ and $\mathrm{TiAu}$.

\subsection{Leak Testing of brazed assembly}

Helium leak testing on Varian 979 Helium leak detector was performed and the brazed assembly was hermetic of the order of $1.6 \times 10^{-8} \mathrm{~atm}-\mathrm{cc}$ of $\mathrm{He} / \mathrm{sec}$. 
The brazed assemblies which were made for longer periods of time were not hermetic and few of them even failed after cooling.

\subsection{Mechanical testing of Au-Ti brazed joint}

The average value of fracture strength for the three samples in which the interaction time of molten gold with $\mathrm{Ti}$ was 30 seconds is $49.58 \mathrm{MPa}$ with a standard deviation of 6.34 $\mathrm{MPa}$ while for the three sample when the interaction time was kept as 40 yields an average values of fracture strength as $22.9 \mathrm{MPa}$ with a standard deviation of 5.4 MPa. This is indicative of the growth of the brittle intermetallics as the interaction time of molten gold with Ti increases. Fracture surface analysis of the tested samples shown that the brazed sample fracture at the interface of the two intermetallic $\mathrm{TiAu}_{2}$ and $\mathrm{TiAu}_{4}$ which were detected by EDX on the two separate parts of the fractured sample. 


\section{SUGGESTIONS FOR FUTURE WORK}

\subsection{Tensile testing of brazed sample}

An effort was made in the present work to make the brazed joint to test for tensile strength. The testing standard tried to be followed was ASTM E8 [1]. Though the sample dimensions were different than E8. Figure 1 shows a picture of tensile sample made after brazing two $3 \mathrm{~mm}$ diameter Ti cylindrical rods of length 1 inch which were brazed to each other at one end using a $3 \mathrm{~mm}$ diameter and $0.1 \mathrm{~mm}$ thin gold foil. An effort was made in the direction to manufacture the test samples for tensile testing via brazing inside a micro furnace. Figure 3, 4 and 5 shows the fabrication of the micro furnace while figure 6 shows the micro furnace in operation collecting data.

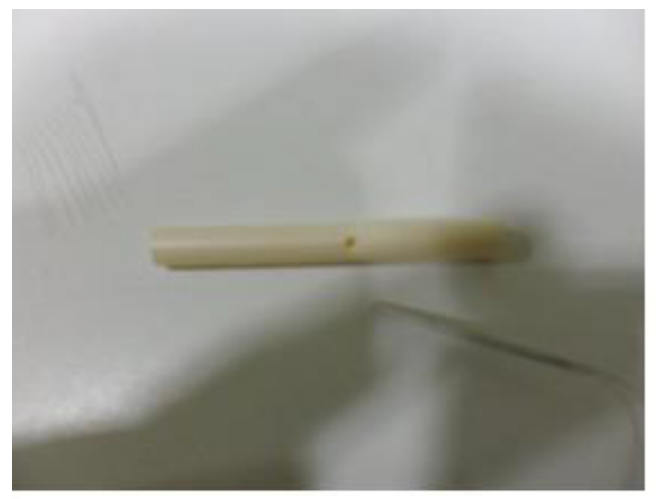

Figure 5.1: Alumina tube with hole drilled to insert thermocouple

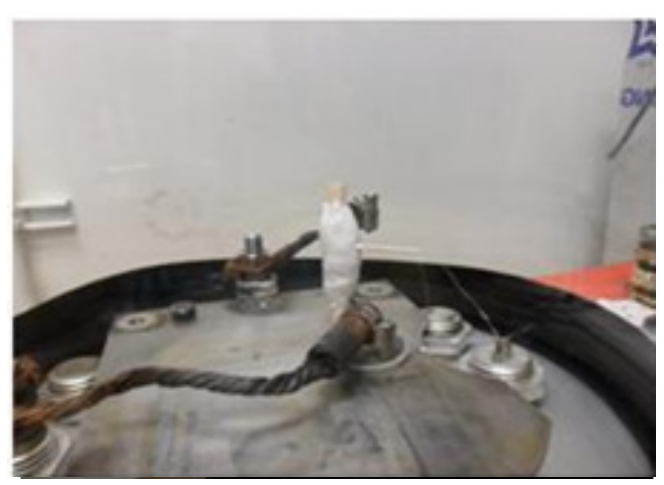

Figure 5.3: Micro furnace in operation and data collection

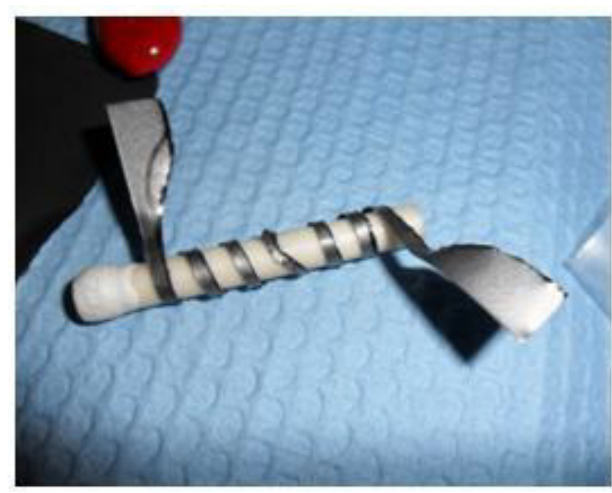

Figure 5.2: Ta sheet wrapped alumina tube

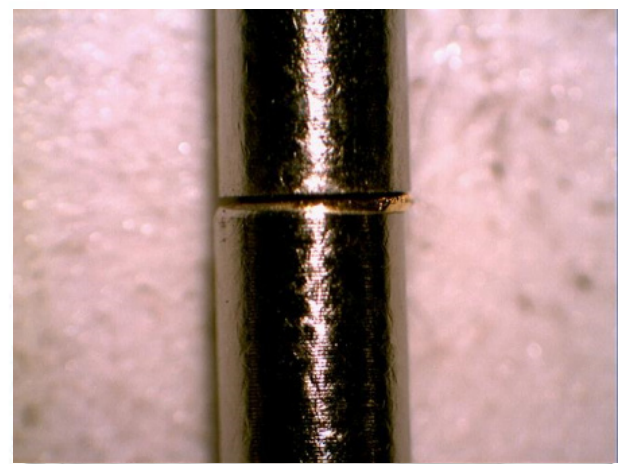

Figure 5.4: Brazed sample 
A hole was made in the alumina tube through a diamond tool and a thermocouple was glued to the alumina tube. The glue was cured at $250{ }^{\circ} \mathrm{C}$ for 4 hours. Figures 5.5 (a) through 5.5 (d) shows the data collected through the micro furnace. This effort was not also pursued to fabricate the tensile strength specimen as the there is considerable difference between the firing cycle of the Tantalum heating electrode and the micro furnace and hence the tensile strength obtained out of the samples made by this micro furnace would not be true representative of the brazed assembly. It is recommended in this work to manufacture a micro furnace that would produce a similar heating curve as that obtained for the Ta electrode used for making the brazed assembly.

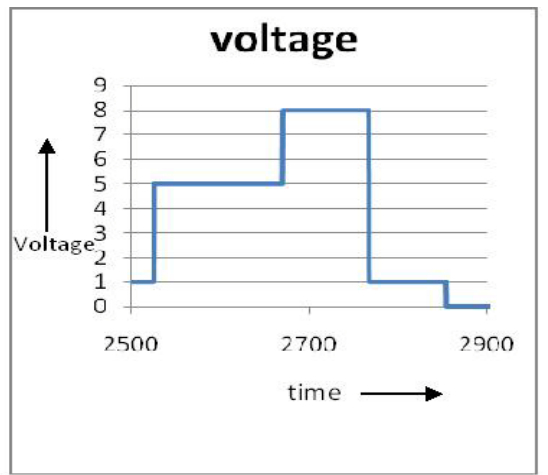

Figure 5.5 (a): Voltage Vs. time curve

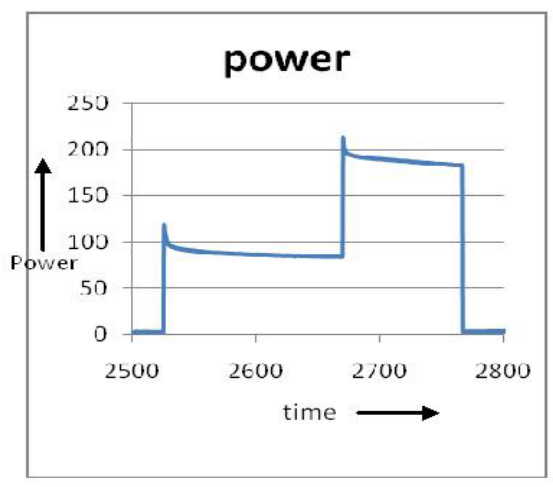

Figure 5.5(c): power Vs. time

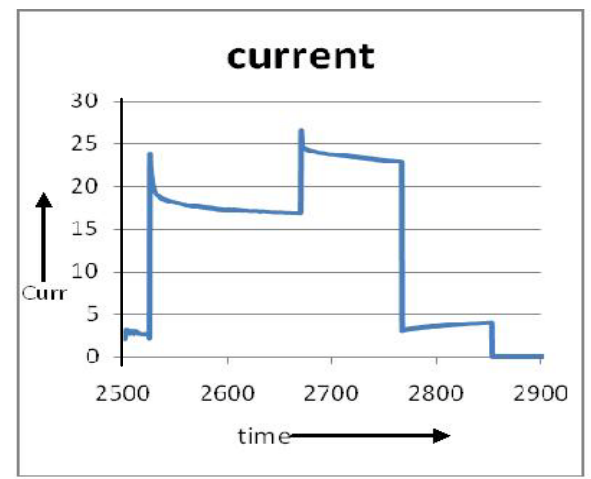

Figure 5.5(b): Current Vs. Time curve

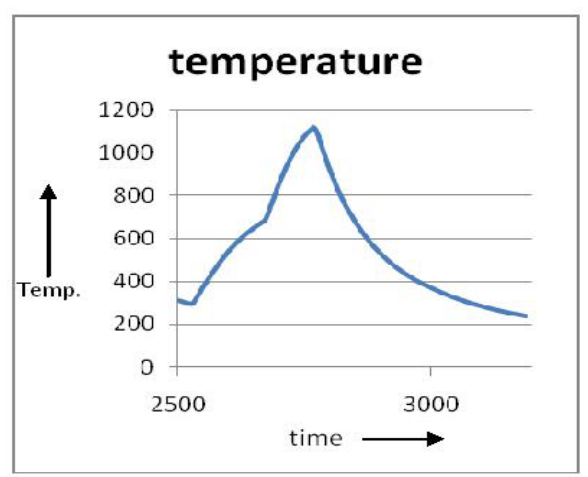

Figure 5.5 (d): Temperature Vs. time 


\subsection{Three/four point flexural strength testing of the samples with the vias}

In the present work the brazed assembly has 331 vias in it. Under the working environment this kind of ceramic disc would undergo enormous thermal stresses which might lead to crack initiation and propagation leading to failure of the device. An effort was made in the direction to test the flexural strength of HTCC alumina ceramic containing vias at the center in them. A picture of sample containing an array of vias of 2 by 3 is shown in the figure 5.6 .

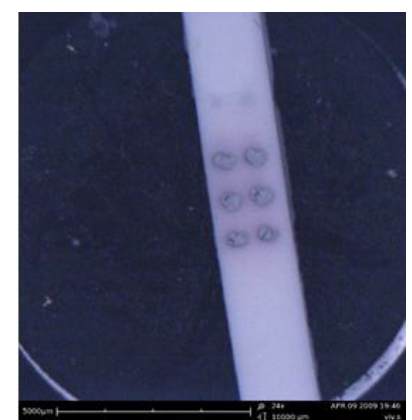

Figure 5.6: Three point bend samples containing vias

\subsection{Ti grain growth and determining the incubation period for the alpha to beta}

\section{transformation}

It was one of the initial aims of this study to do a grain growth kinetics study on titanium. Some efforts were made in that direction and some data were collected which were not sufficient enough to reach to a conclusion.

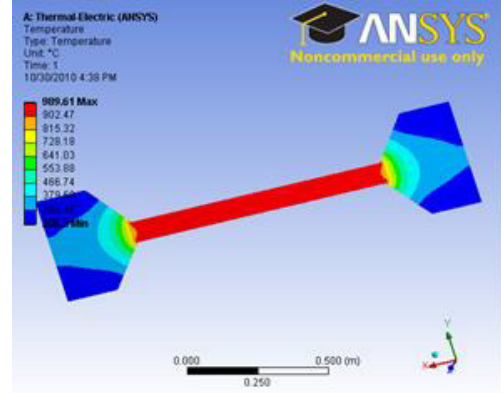

Figure 5.7: Ansys simulation of grain growth sample

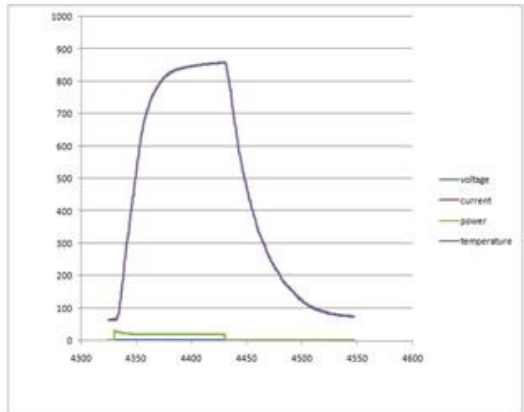

Figure 5.8: Temperature Vs. Time profile obtained the Ti heating element 
5.7 shows ansys simulations results on the design of samples that were used to study the alpha to beta phase transformation study. Figure 5.8 shows the heating cycle that was given to one of the sample in which the sample was heated and kept at a temperature for 100 seconds. The temperature was measured by an alumina coated thermocouple that was touching the surface of the sample. After the experiment the sample was cut and a portion of sample that was at the centre was taken for further analysis like XRD and optical microscopy. This experiment could give the values of incubation period for alpha to beta transformation in C.P titanium and the Ti grain growth with the time. 


\section{LIST OF REFERENCES}

[1] J.L. Murray, "The Au-Ti (Gold-Titanium) system", National bureau of standard, Bulletin of Alloy phase diagram Vol. 4., No.3 1983.

[2] F. J. Gil, J. A. Planell, "Grain growth kinetic of the near alpha titanium alloys", Journal Of Materials Science Letters 19, 2000, 2023 - 2024.

[3] F. X. Gil, D. Rodriguez and J. A. Planell, "Grain growth kinetics of pure titanium”, Scripta Metallururgica et Materialia Vol. 33.N.z 8, pp. 1361-1366, 1995.

[4] J. A. Howe, Intern. Mater. Rev. 38, 5 (1993) 257.

[5] J. T. Klomp, G. De With, Mater. \& Manuf. Proc. 8, 2 (1993) 129.

[6] K. Suganuma, Mater. Res. Soc. Symp. Proc. 314 (1993) 51.

[7] J. T. Klomp, G. De With, Mater. \& Manuf. Proc. 8, 2 (1993) 129.

[8] T. H. Chuang, M. S. Yeh, Y. H. Chai, Metallurgical and Materials Transactions A. 31A (2000) 1591.

[9] D. Huh, D. H. Kim, J. Mater. Res. 12, 4 (1997) 1048-1055.

[10] Brazing Fundamentals, (C) 2003 ASM International. All Rights Reserved. Brazing (\#06955G).

[11] Girish Kumar, K. Narayan Prabhu, "Review of non-reactive and reactive wetting of liquids on surfaces", Advances in Colloid and Interface Science 133 (2007) 6189.

[12] G. Elssner and G. Petzow, "Metal/Ceramic joining", ISIJ International, Vol. 30 (1990), No. 12, pp. 1011-1032.

[13] T.W. Barbee Jr. and D.L. Keith. Synthesis of Metastable Materials by SputterDeposition Techniques. in Proceedings of the Fall Meeting of the Metallurgical Society AIME. 1980. Pittsburgh, PA.

[14] J.J. Bautista and S.M. Petty, "Superconducting Nb thin film slow-wave structures", TDA progress report 42-75, July-september 1975.

[15] http://www.sct-ceramics.com/ceramic-feedthrough-71-En.php 
[16] L. C. Fontana, "Estudo da deposição de filmes de Ti e TiN e desenvolvimento do sistema modificado triodomagnetron- sputtering", D. Eng. Thesis, Mechanical Engineering/UFSC (1997) in Portuguese.

[17] B. Chapman, Glow Discharge Processes - Sputtering and plasma etching, WileyInterscience Publ., USA (1980).

[18] L. C. Fontana, J. L. R. Muzart, Surf. Coat. Tech. 107.

[19] H. Mizuhara, Vacuum Brazing Ceramics to Metals, Adv. Mater. Process., Vol 131 (No. 2), Feb 1987, p 53-55.

[20] A.J. Moorhead and A. Keating, Direct Brazing of Ceramic for Advanced HeavyDuty Diesels, Weld. J., Oct 1986, p 117.

[21] R.E. Loehman, Interfacial Reactions in Ceramic-Metal Systems, Ceram. Bull., Vol 68 (No. 4), 1989, p 891.

[22] M.G. Nicholas and R.J. Lee, Joining Dissimilar Materials, Met. Mater., Vol 5 (No. 6), 1989, p 348.

[23] J.T. Klomp, in Ceramic Microstructures 86: Role of Interfaces, J.A. Pask and A.G. Evans, Ed., Plenum Press, 1988, p 307.

[24] P. R. Chidambaram, G. R. Edwards, D. L Olson, Metallurgical Transactions B 23 (1992) 215.

[25] S. Timoshenko, Analysis of bi-metal thermostats, J. Opt. Soc. Am. 11 (1925) 233255.

[26] O. Iancu, Berechnung von thermischen Eigenspannungsfeldern in Keramik:MetallVerbunden, Ph.D. Thesis, University of Karlsruhe, Karlsruhe, Germany, 1989.

[27] K. Suganuma, ISIJ Int. 30, 12 (1990) 1046.

[28] A. E. Martinelli, "Diffusion bonding of silicon carbide and silicon nitride to molybdenum". PhD Thesis, McGill University, Montreal, Canada (1996).

[29] A. Levy, Thermal residual stresses in ceramic-to-metal brazed joints, J. Am. Ceram. Soc. 74 (9) (1991) 2141- 2147.

[30] Abhijit Kar, et. al., "Effect of interfacial thickness and residual stress on the mechanical property of the alumina-stainless steel braze joint interface", Materials Science and Engineering A 498 (2008) 283-288. 
[31] M. Galli, J. Botsis, andJ. Janczak-Rusch, "Relief of the Residual Stresses in Ceramic-Metal Joints by a Layered Braze Structure", Advanced Engineering Materials 2006, 8, No. 3.

[32] Bealka, D. J, Pedro Henrique, Morgan Advanced Ceramics, Inc., US patent 6586675 .

[33] M. Rohde, I. Su"dmeyer, A. Urbanek, M. Torge, "Joining of alumina and steel by a laser supported brazing process, Ceramics International 35 (2009) 333-337.

[34] Peytour C, Berthet P, Barbier F. et al. (1990) Interface microstructure and mechanical behavior of brazed Ti6Al4V/zirconia joints, J. Mater. Sci. Lett, 9:1129-31.

[35] Santella ML, Pak JJ (1993) Brazing titanium-vapor-coated zirconia. Welding Res Supplement, 165-172.

[36] Agathopoulos S, Moretto P, Peteves SD et al. (1997) Brazing of zirconia to Ti and Ti6Al4V In 1996 Amer Ceram. Soc. Meeting, Indianapolis, USA 1996, Ceram Joining, Ceram Trans. Indianapolis 77:75-82.

[37] Lasater BJ (2001) Methods for hermetically sealing ceramic to metallic surfaces and assemblies incorporating such seal, US Patent: 6,221,513 B1.

[38] Jiang G, Mishler D, Davis R et al. (2005) Zirconia to Ti-6Al-4 V braze joint for implantable biomedical device. J of Biomed Mater Res: Part B - Applied Biomatls 72B:316-321.

[39] Correia RN, Emiliano JV, Moretto P (1998) Microstructure of diffusional zirconiatitanium and zirconia-Ti6Al4V alloy joints. J Matl Sci 33:215-221.

[40] Agathopoulos S, Correia RN, Joanni E et al., "Interactions at zirconia-Au-Ti interfaces at high temperatures”, Key Eng Matls, 206-213, 2002, pp 487-490.

[41] Messler RW(2004) Joining of materials and structures-from pragmatic process to enabling technology, Elsevier Butterworth Heinemann, Burlington, MA

[42] Messler RW (1993) Joining of advanced materials, Elsevier Butterworth Heinemann Science, Burlington, MA.

[43] Agathopoulos S, Moretto P, Peteves SD et al. (1997) Brazing of zirconia to Ti and Ti6Al4V. In 1996 Amer Ceram. Soc. Meeting, Indianapolis, USA 1996, Ceram Joining, Ceram Trans. Indianapolis 77:75-82 
[44] Correia RN, Emiliano JV, Moretto P (1998) Microstructure of diffusional zirconiatitanium and zirconia-Ti6Al4V alloy joints. J Matl Sci 33:215-221

[45] Agathopoulos S, Pina S, Correia RN (2002) A review of recent investigations on zirconia joining for biomedical applications. Ceram Trans 138:35-147.

[46] Loeb GE, Richmond FJR (2001) BIONTM implants for therapeutic and functional electrical stimulation. In: Chapin JK, Moxon KA (ed) Neural prostheses for restoration of sensory and motor function. CRC Press, Boca Raton, FL.

[47] Adamson AW, Gast AP. Physical chemistry of surfaces. 6th Ed. New York: WileyInterscience; 1997. p. 347-79.

[48] Long J, Hyder MN, Huang RYM, Chen P. Adv Colloid Interface Sci. 2005;118:173-6.

[49] Masumi Ushio and Yoshihiro Somiyoshi, "The wetting of alumina substrate by liquid gold", Bull. Chemical Society Japan, 61, 809, 814, 1988.

[50] Yost FG, O’Toole EJ. Acta Mater 1998;46:5143.

[51] Ambrose JC, Nicholas MG, Stoneham AM. Acta Metall Mater 1993; 8:2482.

[52] Barbangelo A, Sangiorgi R. Mater Sci Eng A 1992;156:217.

[53] Sharps PR, Tomsia AP, Pask JA. Acta Metall 1981;29:855.

[54] Liang Yin, Bruce T. Murray, Timothy J. Singler, "Dissolutive wetting in the Bi-Sn system”, Acta Materialia 54 (2006) 3561-3574.

[55] Liang Yin a, Stephan J. Meschter b, Timothy J. Singler, "Wetting in the Au-Sn System", Acta Materialia 52 (2004) 2873-2888.

[56] Paul Pietrokowsky, "A study of conformal phases in metal alloy system", $\mathrm{PhD}$ thesis, California Institute of Technology, 1959.

[57] H. Okamoto and T.B.Massalski, "The Au-Nb (Gold-Niobium) system”, CarnegieMellon university, Bulletin of Alloy phase diagram Vol. 6., No.2 1985.

[58] Masahiro Kitada, "Reactions in $\mathrm{Au} / \mathrm{Nb}$ bilayer thin films", Thin Solid Films Volume 250, Issues 1-2, 1 October 1994, Pages 111-114. 
[59] M. S. Wire and G. W. Webb, "Superconductivity and the b.c.c. to A-15 transformation in Nb-Aur alloys", Journal of Physics and Chemistry of Solids Volume 42, Issue 3, 1981, Pages 233-238.

[60] H. Okamoto and T.B.Massalski, "The Au-W (Gold-Tungsten) system", CarnegieMellon university, Bulletin of Alloy phase diagram Vol. 6., No.2 1985.

[61] J. W. Tester, Roy C. Feber, and C. C. Herrick, "Calorimetric Study of Liquid Gold", Journal of chemical and engineering data, Vol. 13, no. 3, July 1968.

[62] T. Kocha, M. Evaristob, A. Pauschitz, Manish Royc, A. Cavaleirob, Thin Solid Films 518 (2009) 185-193.

[63] S.P. Wena,b, R.L. Zonga, F. Zenga, S. Guoa, F. Pana, Applied Surface Science 255 (2009) 4558-4562.

[64] E.W. Niu, L. Li, et. al., Appl. Surf. Sci. 254(2008) 3909.

[65] Srinivasa R. Bakshi, Debrupa Lahiri, Riken R. Patel and Arvind Agarwal, "Nanoscratch Behavior of Carbon Nanotube Reinforced Aluminum Coatings" Manuscript submitted to Acta Materialia in Mar 2009.

[66] G. Wei, T.W. Scharf et. al, "Nanotribology studies of $\mathrm{Cr}, \mathrm{Cr}_{2} \mathrm{~N}$ and $\mathrm{CrN}$ thin films using constant and ramped load nanoscratch techniques", Surface and Coatings Technology $146-147$ (2001) 357-362.

[67] Shou-Yi Chang, Hung-Chun Tsai et. al., "Analyses of interface adhesion between porous $\mathrm{SiOCH}$ low-k film and $\mathrm{SiCN}$ layers by nanoindentation and nanoscratch tests", Thin Solid Films 516 (2008) 5334-5338.

[68] http://www.hysitron.com/LinkClick.aspx?fileticket=TFyL7LIea7Y\%3d\&tabid=115.

[69] P. Majumdar, S.B. Singh, M. Chakraborty, "Elastic modulus of biomedical titanium alloys by nano-indentation and ultrasonic techniques-A comparative study", Materials Science and Engineering A 489 (2008) 419-425.

[70] Titanium: A technical guide By Matthew J. Donachie.

[71] http://www.boulder.nist.gov/div853/lead_free/part1.html.

[72] Masafumi Kikuchi, Masatoshi Takahashi, Osamu Okuno, "Elastic moduli of cast Ti-Au, Ti-Ag, and Ti-Cu alloys", Dental Materials (2006) 22, 641-646.

[73] W.C. Oliver, G.M. Pharr, J. Mater. Res. 7 (1992) 1564. 
[74] H. Pelletier, J. Krier, A. Cornet, P. Mille, Thin Solid Films (2000) 147.

[75] O.R. Shojaei, A. Karimi, "Comparison of mechanical properties of TiN thin films using nanoindentation and bulge test" Thin Solid Films, Volume 332, Issues 1-2, 2 November 1998, Pages 202-208.

[76] C. Poilane, P. Delobelle, L. Bornier, P. Mounaix, X. Melique, D. Lippens, "Determination of the mechanical properties of thin polyimide films deposited on a GaAs substrate by bulging and nanoindentation tests", Materials Science and Engineering: A, Volume 262, Issues 1-2, 1 April 1999, Pages 101-106.

[77] A Karimi, O.R Shojaei, T Kruml, J.L Martin "Characterisation of TiN thin films using the bulge test and the nanoindentation technique" Thin Solid Films, Volumes 308-309, 31 October 1997, Pages 334-339.

[78] P. Delobelle, E. Fribourg-Blanc, D. Rèmiens, "Mechanical properties determined by nanoindentation tests of $\left[\mathrm{Pb}(\mathrm{Zr}, \mathrm{Ti}) \mathrm{O}_{3}\right]$ and $\left[\mathrm{Pb}\left(\mathrm{Mg}_{1 / 3} \mathrm{Nb}_{2 / 3}\right)_{1-\mathrm{x}} \mathrm{Ti}_{\mathrm{x}} \mathrm{O}_{3}\right]$ sputtered thin films", Thin Solid Films, Volume 515, Issue 4, 5 December 2006, Pages 1385-1393.

[79] Sheng-Rui Jian, Guo-Ju Chen, Ting-Chun Lin, "Berkovich Nanoindentation on AlN Thin Films", Nanoscale Res Lett (2010) 5:935-940.

[80] Marianne Dietiker, Ralph D. Nyilas, Christian Solenthaler, Ralph Spolenak, "Nanoindentation of single-crystalline gold thin films: Correlating hardness and the onset of plasticity", Acta Materialia 56 (2008) 3887-3899.

[81] C. M. D'souza "Observations of surface radial cracks on ceramic bend test fracture surfaces" Journal of Materials Science Letters 20, 2001, 213- 214.

[82] F. I. Baratta, W. T. Matthews and G. D. Quinn (1987) Errors associated with flexure testing of brittle materials. Report no. MTL TR 87-35, U.S. Army Materials Technology Laboratory.

[83] G. D. Quinn and R. Morel1 (1991) Design data for engineering ceramics: a review of the flexure test J. Am. Ceram. Soc. 74, 2037-2066.

[84] R. G. Hoagland, C. W. Marschall and W. H. Duckworth (1976) Reduction of errors in ceramic bend tests. J. Am. Ceram. Soc. 59, 189-192.

[85] G. A. Schneider ( 1989) "Thermal shock behavior of advanced ceramics" Dissertation, Universitat Stuttgart.

[86] "Commentary on U.S. army standard Test method for flexural strength of high performance ceramics at ambient temperature", George d. Quinn, August 1985, 
Army materials and mechanics research center Watertown, Massachusetts 021720001 .

[87] H. Okamoto and T. B. Massalski, Bull. Alloy Phase Diagrams 6, 319, (1985).

[88] WCTE 2006 - 9th World Conference on Timber Engineering - Portland, OR, USA August 6-10, 2006, "Nail Withdrawal and Pull-Through Strength of StructuralUse Panels", Benjamin Herzog, Borjen Yeh. 


\title{
Development of 3-D channels in LTCC for Capillary Cooling Structures for Thermal Management
}

\author{
W. Kirzy Jones, Feng Zheng Mohammed Siddiqui, Rambod Reyagna, Yong X. Tao \\ Florida International University \\ 10555 West Flagler Strect \\ Miami, FL 33036 \\ 305-393-0506; 305-348-2649(F), ionesăfiu cilu
}

\begin{abstract}
3 dimensional (3-D) capillary cooling network is being designed in a LTCC based electroa multiplier to handle power levels approaching $6.8 \mathrm{~kW} / \mathrm{cm}^{2}$. Methods for prodacing vertical and X-Y channels of various diameters and configarations are discussed. Channels with dimcnsions as small as $35-50 \mu \mathrm{m}$ have been realized in all dimensioes. The use of capillary cooling reduced both the requirements for pamping power and pumping pressure while reaching theoretical values of $10^{5} \mathrm{~W} / \mathrm{cm}^{3}$
\end{abstract}

Key Words: Micro channels, LTCC, capillary cooling

\section{Introduction}

To maximize thermal management of microelectronic devioes, new methods of heat sinks and cooling structures must be developed. As an example, switching speed of microclectronics directly correlases to the cooling capacity of such device with a cooling capacity in the order of $10^{5}$ W/cm' required to reach an order of up to $3.8 \times 10^{20}$ bits per second per $\mathrm{cm}^{2}$ for next generition computing devices [1]. This requirement is beyond the capability of current liquid cooled microchannel heat sinks. The use of a micro nerwork piping arrangement provides a vitra-high performance micro heat sink with the following features :(1) 3-D network piping goometry with very high surface/volume ratio(2) Capable of reaching $10^{\prime}$ W/cm asing encapsulated nano-sine phase change materials, which would result in an order of magnitude bigher cooling capacity than current microchannel heat sink. [X]

This work is based on a high power RF electron source using gated carton nanotube eminters and a ceramic eloctron multiplier for emission enhancement.[2] Previoas work on a bigh power ceramic based electron multiplier, as shown in Figure 1, indicates that this type of capillary micro network cooling stucture coald be well suited and integrated into the structure of the vertical maltiplier channels.

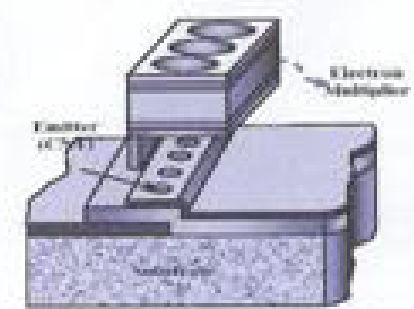

Figure 1- Electron Multiplier System consisting of CNT enitters and a high power electron multiplier

This type of heat sink lends itself to the cooling of a ceramic electron multiplier since the multiplier channels nun only vertically and the cooling structure can be integraled between the multiplier channets. Additionally, the capillary diameter can be modified to account for the increase in thermal load down the channel based on the increased electroe multiplication.

Figure 2 shows the conceptual design of the network piping system for one $1 \mathrm{~mm} 3$ unit. It consists of a network of tubes that are designed based on the Murny's Law, which states that, for a system of tubes containing a Newtonian fluid in laminar flow, the minimum volume for a given pressure drop occurs when the mdil of the tubes at a branch point satisfy the relationship.

$$
r_{0}^{3}=r_{1}^{3}+r_{2}^{3}+r_{3}^{3}+\ldots+r_{n}^{3}
$$

where $r_{0}$ is the radius of the incoming tube, and $r_{1}, r_{3}$ etc, are the mdil of the outgoing tubes. This piping 


\title{
Resistance Brazing of Alumina Ceramic to Titanium Using Pure Gold
}

\author{
Mohammad Siddiqui, Dr. W. Kinzy Jones \\ Florida International University, Miami \\ 10555 West Flagler Street, Miami, FL, USA \\ 305-336-7716,305-348-1932, msidd005@ fiu.edu
}

\begin{abstract}
Pure gold brazing of $96 \%$ alumina ceramic with CP titanium using electrical resistance heating has been analyzed. Wetting studies of gold with different refractory metals and titanium were performed. HTCC alumina ceramic was metalized with a $500 \mathrm{~nm} \mathrm{Nb}$ layer yielding hermetic joints having leak rate of the order of $1.6 \mathrm{X} 10^{-8} \mathrm{~atm}-\mathrm{cc} / \mathrm{sec}$. Adhesion strength was tested using nanoscratch testing using a nanoindentor on $100 \mathrm{~nm} \mathrm{Nb}$ on polished alumina.
\end{abstract}

Keywords: Brazing, resistance heating, wetting, adhesion nano scratch testing

\section{Introduction:}

One of the many promising applications of metal/ceramic joining is in biomedical implantable devices. Brazing of alumina ceramic to titanium metal using pure gold as the filler metal is evaluated in this paper. The binary phase diagram of gold and titanium [1] indicates 4 intermetallic compounds, $\mathrm{Ti}_{3} \mathrm{Au}, \mathrm{TiAu}, \mathrm{TiAu}_{2}$, and $\mathrm{TiAu}_{4}$. Brazing should therefore be time limited to minimize the intermetallic formation, since two of the intermetallics have limited solid solubility and are therefore probably brittle.. The formation of intermetallic phases has been shown by previous researchers during brazing of $\mathrm{Ti}$ with gold [2]. Presence of large amount of these brittle phases in the brazed joint interface is very deteriorating for the performance of brazed assembly. The second reason for rapid brazing is the fact that gold melts at $1064^{\circ} \mathrm{C}$ while $\mathrm{Ti}$ undergoes allotropic transformation from $\alpha$ $(\mathrm{HCP})$ to $\beta(\mathrm{BCC})$ at $883^{\circ} \mathrm{C}$. The grain growth in beta phase titanium is more than an order of magnitude faster than in the alpha phase. If titanium is maintained at temperatures above the allotropic transformation temperature for sufficient time, then grain grows occurs, softening the metal. Brazing using faster heating ramp rates, such as resistance heating, should allow processing to less than 30 seconds and minimizes grain growth.

\section{Experimental}

$96 \%$ alumina ceramic was prepared by standard high temperature cofired ceramic (HTCC) processing. Five (5) mil green tape was purchased from Maryland Ceramic and Steatite Co (Street, MD) Isostatic lamination of stacked green tape was done using a Model IL-4004 (PTC) isostatic lamination press at $3000 \mathrm{psi}$ and at $70{ }^{\circ} \mathrm{C}$. The disc was cut to initial green dimension using laser cutting. Since the alumina exhibited a $20 \% \mathrm{x}-\mathrm{y}$ shrinkage, the fired diameter was 313 mils after firing. The disc was centerless ground at Ferro Ceramic Inc. (Boston, MA) to 288 mils using a 800 grit diamond wheel. A picture of the ground disk is shown in figure 1 . The disks were masked with kapton and $500 \mathrm{~nm}$ thin film of $\mathrm{Nb}$ was sputtered on the ground edge to metallize the ceramic in order to improve the wettability of ceramic towards the braze filler metal [3-5]. Approximately 5 mils in radial direction on each side of a diameter was left unprotected on one face, allowing a ridge of sputtered $\mathrm{Nb}$ along the lateral surface. After sputtering the masking is removed and the disk was cleaned.

The titanium ferrule had a machined ledge onto which a gold perform was placed. The alumina ceramic was placed into the titanium ferrule, and due the tight tolerance of the centerless grinding, a gap of 2 mils was obtained ( 1 mil radially on both sides along any diameter). The gold perform wicked up the gap between the ceramic disk and the Ti ferrule due to capillary action when melting occurs.

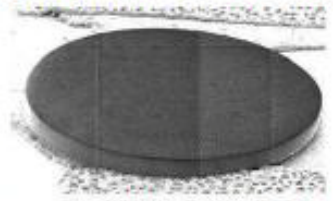

Figure 1 Centreless grounded disk 


\section{EDUCATION}

Florida international university, Miami, FL

Fall 2011

Ph.D., Materials Science and Engineering, GPA: 3.77

Dissertation Title: Vacuum brazing of alumina ceramic to titanium for biomedical implants using pure gold as the filler metal

Cleared FE Certification

April 2011

Indian Institute of Technology-KANPUR, INDIA

Master of Technology, Materials and Metallurgical Engineering, GPA: 8.00

August 2005

I.T-B.H.U, VARANASI, INDIA

Bachelor of Technology, Metallurgical Engineering, Overall GPA: 6.69

May 2003

WORK AND RESEARCH EXPERIENCE

Florida International University, Miami, FL

Fall 2007 - Fall 2011

Position: Research Assistant

- Hands on experience in the area of vacuum brazing of ceramic to metal and making leak tight joints of the order of $10^{-8} \mathrm{~atm}-\mathrm{cc} / \mathrm{second}$.

- Experience in manufacturing of Low Temperature Cofired Ceramics (LTCC), high temperature Cofired ceramic (HTCC), thick film fabrication and design.

- Experience in the area of LTCC micro channel fabrication, Screen printing, and fabrication of micro vias in HTCC/LTCC.

- Expertise in thermal analysis instruments DSC, TGA and flash diffusivity instruments. Hands on experience over a range of optical microscopes and scanning electron microscopes, FIB technique, Indexing TEM diffraction pattern. Hands on experience on $\mathrm{X}$ ray diffraction instruments.

- Experience in lithography tools for thick film mask making. Hands on experience of sputtering technique and profilometer.

Bharat Heavy Electricals Limited, Hardwar, INDIA

August 2005- August 2007

- Engineer in the foundry technology department of BHEL. Prepared 2D drawings and 3D models of different cast components. Prepared process sheet for different components for use in shop.

- Prepared heat treatment cycle of different components. Welding analysis of different Steel castings and NDT inspection of castings.

Teaching assistantships

- Teaching Assistant of "Heat transfer", "Mechanical Design-1", "Electronic Packaging", and "Materials Engineering", courses at FIU.

COMPUTER SKILLS

2D drawings and 3D models using AUTOCAD and Solid works, mechanical simulations 
using ANSYS, MS Office, Origin for data analysis.

\section{RESEARCH PUBLICATIONS}

1. Siddiqui, Mohammad, W. Kinzy Jones, "Resistance Brazing of Alumina Ceramic to Titanium Using Pure Gold" IMAPS 2011, proceedings of 44th International Symposium on Microelectronics, pp. 000845-000851, Long Beach, California, USA.

2. Jones W. K., Zheng Feng, Siddiqui Mohammad, et. Al., "Development of 3-D channels for capillary cooling structures for thermal management", Ceramic Interconnect and Ceramic Microsystems Technologies (CICMT 2008), Munich, Germany.

3. Siddiqui, M.S., Bhargava, Sanjeev, "Processing and characterization of iron copper alloy prepared by Mechanical alloying", Proceedings of MS\&T 2009.

4. Siddiqui Mohammad, Bhargava Sanjeev, "Cold compaction and sintering of iron copper mechanically Alloyed powder" Proceedings of ECTC 2008.

5. Mohammad Siddiqui, W. Kinzy Jones, Ali Karbasi, "Pull testing of Ti to Ti brazed joint with pure gold as the filler metal", Accepted Manuscript, $5^{\text {th }}$ International Brazing and Soldering Conference (IBSC 2012), Las Vegas, USA.

\section{POSTER PRESENTATIONS}

1. Poster presentation participation organized by Material Advantage at FIU in fall 2009.

2. Presented a research poster over the topic of "Development of $3 \mathrm{D}$ channels in LTCC for capillary cooling structures for thermal management" in the poster presentation contest organized by material advantage at FIU in 2008.

3. Presented a poster in the TMS annual meeting and conference in 2007.

\section{PRIZES, AWARDS AND HONOR SOCIETIES AFFILIATION}

- 2nd prize in the Materials Quest organized by MA @ FIU.

- 2nd prize by the "Electron Quiz" organized by the Electron chapter at FIU.

- $3^{\text {rd }}$ prize in the Brain Bowl Competition organized by AEMB society of Biomedical Engineering.

- Member of "Golden key honor Society" at FIU.

- Selected as one of the three students to represent FIU in "Materials Bowl" at TMS annual Meeting and conference 2010.

- All India GATE rank 55 ${ }^{\text {th }}$ in GATE exam 2003.

\section{PROFESSIONAL BODIES ASSOCIATION}

Name of the clubs at FIU

IMAPS

Materials Advantage

Materials Advantage
Position

President

Secretary

Vice President
Dates

Fall 2008-Fall 2009

Fall 2008-Summer 2009

Fall 2010-Summer 2011 